\title{
PNNL Fungal Biotechnology Core DOE-OBP Project
}

$\begin{array}{lll}\text { SE Baker } & \text { JR Collett } & \text { JK Magnuson } \\ \text { KS Bruno } & \text { DE Culley } & \text { EA Panisko } \\ \text { MG Butcher } & \text { Z Dai } & \end{array}$

November 2009

\section{Pacific Northwest}

NATIONAL LABORATORY

Proudly Operated by Battelle Since 1965 


\title{
DISCLAIMER
}

This report was prepared as an account of work sponsored by an agency of the United States Government. Neither the United States Government nor any agency thereof, nor Battelle Memorial Institute, nor any of their employees, makes any warranty, express or implied, or assumes any legal liability or responsibility for the accuracy, completeness, or usefulness of any information, apparatus, product, or process disclosed, or represents that its use would not infringe privately owned rights. Reference herein to any specific commercial product, process, or service by trade name, trademark, manufacturer, or otherwise does not necessarily constitute or imply its endorsement, recommendation, or favoring by the United States Government or any agency thereof, or Battelle Memorial Institute. The views and opinions of authors expressed herein do not necessarily state or reflect those of the United States Government or any agency thereof.

\author{
PACIFIC NORTHWEST NATIONAL LABORATORY \\ operated by \\ BATTELLE \\ for the \\ UNITED STATES DEPARTMENT OF ENERGY \\ under Contract DE-ACO5-76RL01830
}

Printed in the United States of America
Available to DOE and DOE contractors from the
Office of Scientific and Technical Information,
P.O. Box 62, Oak Ridge, TN 37831-0062;
ph: (865) 576-8401
fax: (865) 5765728
email: reports@adonis.osti.gov

\footnotetext{
Available to the public from the National Technical Information Service, U.S. Department of Commerce, 5285 Port Royal Rd., Springfield, VA 22161 ph: (800) 553-6847 fax: (703) 605-6900

email: orders@nits.fedworld.gov online ordering: http://www.ntis.gov/ordering.htm
} 


\section{PNNL Fungal Biotechnology Core DOE-OBP Project}

$\begin{array}{lll}\text { SE Baker } & \text { JR Collett } & \text { JK Magnuson } \\ \text { KS Bruno } & \text { DE Culley } & \text { EA Panisko } \\ \text { MG Butcher } & \text { Z Dai } & \end{array}$

November 2009

Prepared for

the U.S. Department of Energy

under Contract DE-AC05-76RL01830

Pacific Northwest National Laboratory

Richland, Washington 99352 


\section{Summary}

In 2009, we continued to address barriers to fungal fermentation in the primary areas of morphology control, genomics, proteomics, fungal hyperproductivity, biomass-to-products via fungal based consolidated bioprocesses, and filamentous fungal ethanol. "Alternative renewable fuels from fungi" was added as a new subtask. Plans were also made to launch a new advanced strain development subtask in FY2010. Project subtask highlights included:

- Morphology: Key accomplishments included analysis of genes involved in control of fungal bioprocess organism morphology and a morphology scoring system for quantitative measurement. This task was closed out and replaced beginning in FY10 with Advanced Strain Development.

- Genomics: Tools for generating defined marker genes and improved throughput gene deletions were developed. Gene expression constructs and strategies were also developed. Genetic analysis of genes identified through functional genomic studies as important for fungal bioprocesses was performed.

- Proteomics: Proteomic analysis of productive and non-productive fungal bioprocesses led to the identification of proteins and associated genes for follow-up analysis.

- Hyper-productivity and consolidated bioprocesses: Excellent progress was made towards understanding the biosynthesis of itaconic acid. Trichoderma reesei and Aspergillus terreus bioprocesses were baselined.

- Filamentous fungal ethanol: Flux modeling was used to understand Aspergillus oryzae pentose utilization and ethanol production. A number of deletion strains were made in A. oryzae.

- Alternative renewable fuels from fungi: We have explored possible fungal routes to nextgeneration renewable fuels-beyond ethanol.

- Advanced Strain Development: In FY 10, initiating the development of a core capability aimed at generating fungal strains with improved enzyme, biofuel, and organic acid secretion. 



\section{Acknowledgments}

We want to thank the U.S. Department of Energy Office of the Biomass Program for its continued financial support of this research project. We also want to thank the members of the industrial Partners Review Board (Novozymes, Inc., POET Energy, Inc., Verenium, Inc., Mycosynthetix, Inc., and Dyadic International) for providing their real-world perspectives to our project. 



\section{Acronyms and Abbreviations}

ATP adenosine tri-phosphate

BSEL Bioproducts, Sciences, and Engineering Laboratory

CAP citric acid production (medium)

COBRA Constraint-Based Reconstruction and Analysis

DO dissolved oxygen

DOE U.S. Department of Energy

DOE-SC U.S. Department of Energy Office of Science

DTU Technical University of Denmark

EST expressed sequence tag

FBA flux balance analysis

FOA 5-Fluoroorotic Acid

GFP green fluorescent protein

GUS glucuronidase

HPLC high-performance liquid chromatography

IMP Impedes $\underline{\text { Mitogenic signal Propagation }}$

JBEI Joint BioEnergy Institute

JGI Joint Genome Institute

LC liquid chromatography

LDRD Laboratory Directed Research and Development

MFS major facilitator superfamily

MS mass spectrometry

NMR nuclear magnetic resonance

PCR polymerase chain reaction

PKS polyketide synthase

PNNL Pacific Northwest National Laboratory

PPIB peptidyl-prolyl cis-trans isomerase B

PRB Partner Review Board

ROS reactive oxygen species

SBML System Biology Markup Language

SDM sulfate depleted medium

SSF simultaneous saccharification and fermentation

$\mathrm{SSH} \quad$ suppressive subtractive hybridization

WDG wet distillers grains 



\section{Contents}

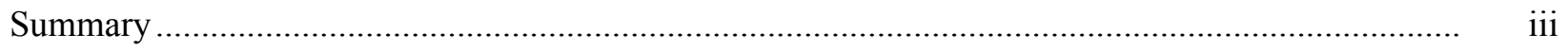

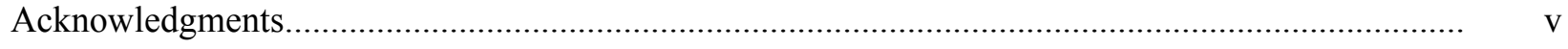

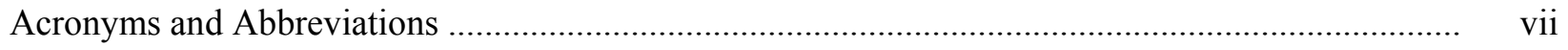

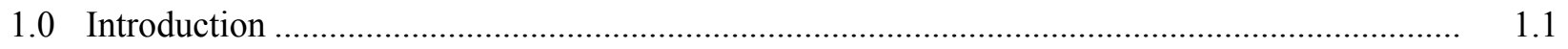

2.0 Major Subtask A.1: Morphology Control Technology .......................................................... 2.1

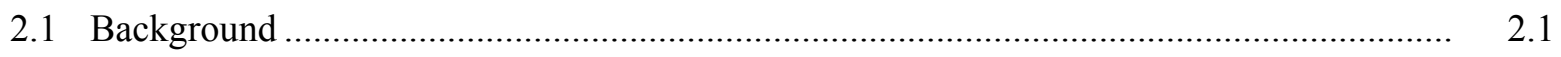

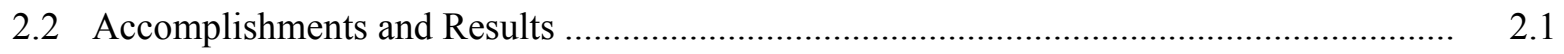

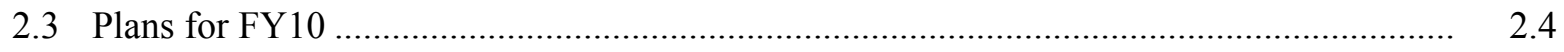

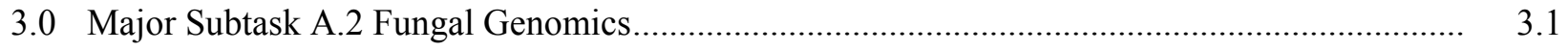

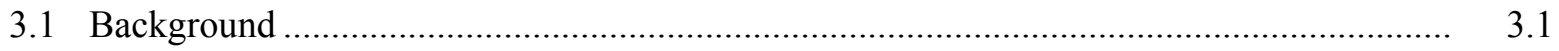

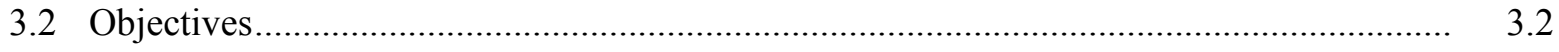

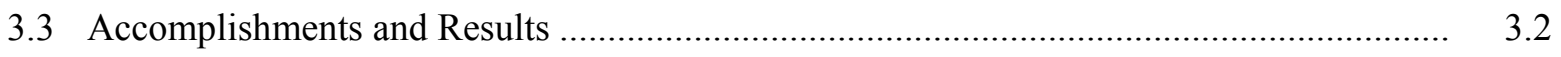

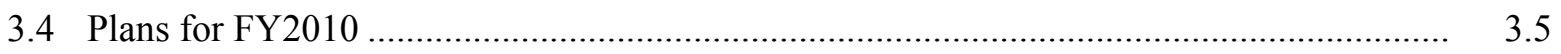

4.0 Major Subtask A.3 Fungal Proteomics ..........................................................................

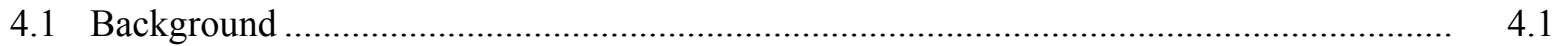

4.2 Accomplishments and Results ............................................................................. 4.1

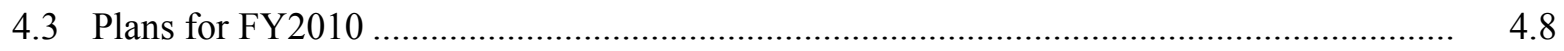

5.0 Major Subtask A.4a Fungal Hyperproductivity.............................................................. 5.1

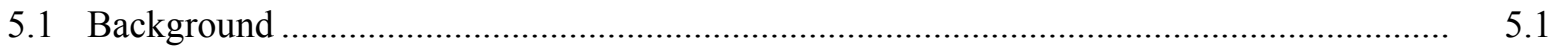

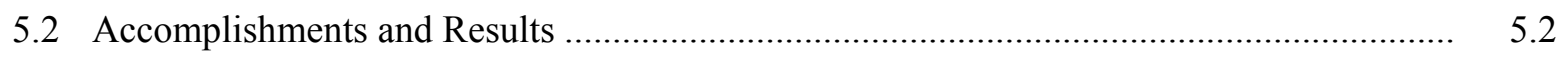

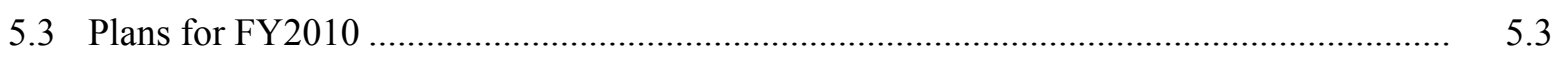

6.0 Major Subtask A.4b Consolidated Bioprocesses ............................................................ 6.1

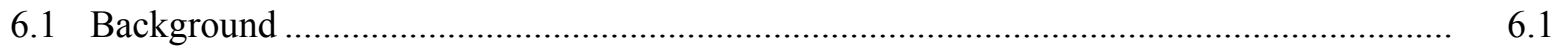

6.1 .1 Specific Objectives........................................................................................ 6.1

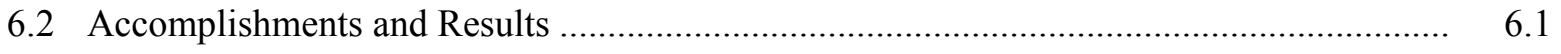

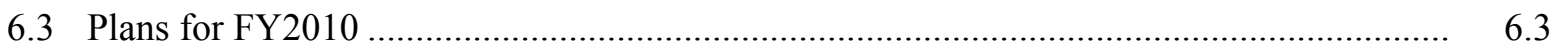

7.0 Major Subtask A.5 Alternative Fungal Ethanologen Characterization and Metabolic Model

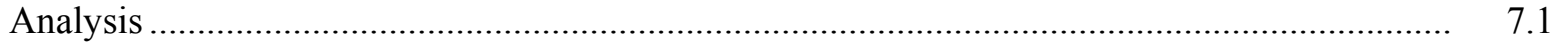

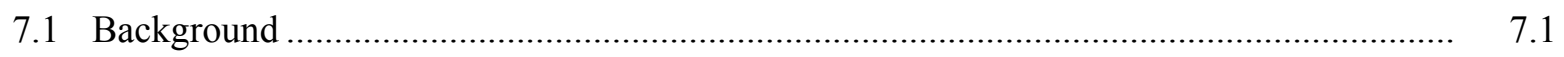

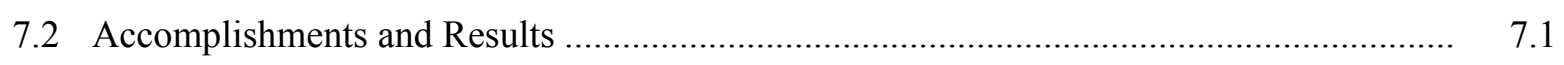

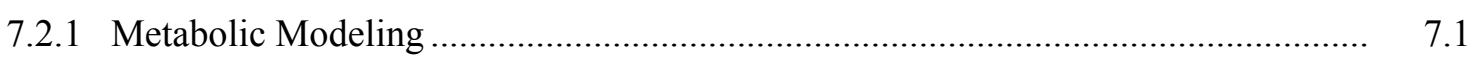

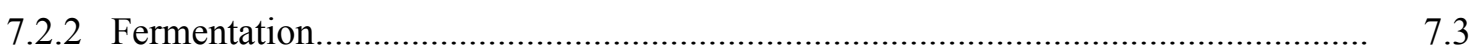

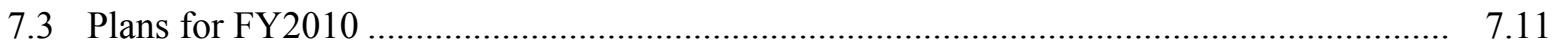


8.0 Major Subtask A.6 Alternative Renewable Fuels from Fungi.............................................. 8.1

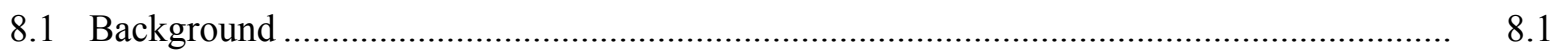

8.2 Accomplishments and Results ............................................................................ 8.1

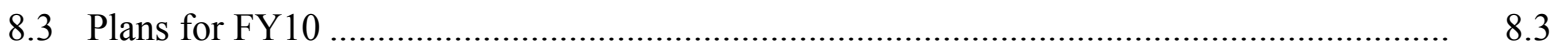

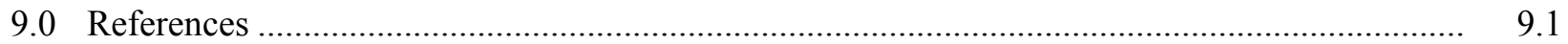

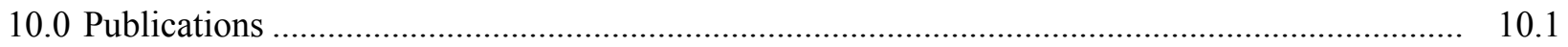

Appendix A: Complete Analysis Report …............................................................................ A.1

\section{Figures}

2.1. Scoring System for Fungal Morphology ..............................................................................

2.2. MapK1 Mutant Morphology Score ……............................................................................. 2.3

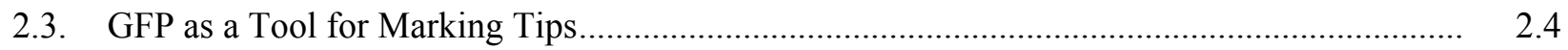

3.1. Mutation of ATP Sulfurylase in A. Niger ....................................................................... 3.4

3.2. Improved Homologous Recombination in the kusA Mutant ................................................. 3.5

3.3. The Percent Viability of Wildtype, $k u s A^{-}$, and $k u s A^{+}$Revertant Spores Exposed to

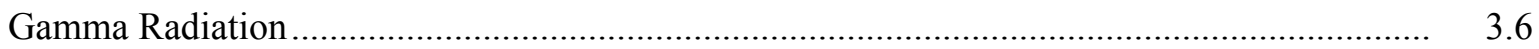

3.4. Phenotype Screen of Five Mutants (six colonies each) on CAP Media ................................. 3.7

4.1. Phytase Assays on Phytase from Wheat and Cell Lysates and Spent Media from A. niger Grown Under Filamentous (+ Mn) and Pelleted Conditions (no Mn) .................................... 4.4

4.2. Protein Sequence Alignment of JGI Gene Model 213198 and Human Cyclophilins................ 4.5

4.3. Anti-Cyclophilin Western Analysis to Identify Expression of JGI Gene Model 213198 from Cell Extracts of Filamentous (+ Mn) and Pelleted (-Mn) from A. niger Cultures..................... 4.6

5.1. 20-L Fermentation of Glucose to Itaconic Acid by Aspergillus terreus.................................. 5.2

5.2. Snapshot of the Aspergillus terreus Chromosome Region Containing the Lovastatin and Itaconic Acid Gene Clusters ...........................................................................................

6.1. Enzyme activities in Trichoderma reesei QM6a Grown on Cellulose...................................... 6.2

7.1. (Left chart) Ethanol Output Flux Changes Predicted from FBA of A. Oryzae Cellular Metabolism as a Function of Oxygen Uptake Flux

7.2. Ethanol Responsive Promoters from the E. coli Genes dnaK, grpE, katG, pgaA, and uspA Fused with Reporter Gene LacZ-Alpha in a pBS KS (+) Plasmid Background, Sequenced and Transformed into E. Coli

7.3. Exp 40, A. oryzae NRRL 697, alcR and creA Mutants Ethanol Production on $12 \%$ Glucose Minimal Medium Enriched with 0.5\% Yeast Extract (averages for nine replicates)

7.4. Exp 42, A. oryzae NRRL 697, alcR and creA Mutants Comparison for Ethanol Production on $12 \%$ Xylose Minimal Medium Enriched with $0.5 \%$ Yeast Extract (averages for nine replicates) 
7.5. Exp 51, Aspergillus oryzae NRRL 697 Model Strain Ethanol Production on 12\% Glucose Minimal Medium Enriched with 0.5\% Yeast Extract, 20-Liter Working Volume, and $2 \times 10^{7}$ Spores $/ \mathrm{mL}$

7.6. Exp 49, A. oryzae NRRL 697 Model Strain on Ethanol Production on 12\% Glucose Minimal Medium Enriched with 0.5\% Yeast Extract, 20-Liter Working Volume, and $2 \times 10^{7}$ Spores $/ \mathrm{mL}$

7.7. Exp 46, Xylitol Remaining from A. oryzae NRRL 697 Model Strain on 4\% Xylitol Minimal Medium Enriched with 0.5\% Yeast Extract, 250-mL flasks, $100 \mathrm{~mL}$ of working volume, and $2 \times 10^{7}$ spores $/ \mathrm{mL}$

7.8. Exp 44, A. oryzae NRRL 697 Model Strain Ethanol Production on 12\% Glucose Minimal Medium Enriched with $0.5 \%$ Yeast Extract, or $10 \%$ Source 1 Thin Stillage or 10\% Source 2 Thin Stillage, 250-mL flasks, $100 \mathrm{~mL}$ of working volume, and $2 \times 10^{7}$ spores $/ \mathrm{mL} \ldots \quad 7.10$

7.9. Exp 44, A. oryzae NRRL 697 Model Strain Ethanol Production on 12\% Xylose Minimal Medium Enriched with $0.5 \%$ Yeast Extract, or 10\% Source 1(S1) Thin Stillage or 10\% Source 2 (S2) Thin Stillage, 250-mL flasks, $100 \mathrm{~mL}$ of Working Volume, and $2 \times 10^{7}$ spores $/ \mathrm{mL}$

\section{Tables}

3.1. Fungal Expression Constructs ................................................................................... 3.2

3.2. Genetic Markers Available for Gene Manipulation in Relevant Strains ................................. 3.4

4.1. Proteins Higher in Abundance in the Filamentous vs. Pelleted Growth State ......................... 4.2

4.2. Proteins Higher in Abundance in the Pelleted vs. Filamentous Growth State ......................... 4.3

4.3. A Summary of Identifications from Affinity-Purified Ubiquitin ........................................... 4.7

8.1. Classes of Hydrocarbon and Hydrocarbon-Like Molecules Produced by Fungi ...................... 8.1 


\subsection{Introduction}

The research of the Pacific Northwest National Laboratory (PNNL) Fungal Biotechnology Team is focused on generating an in-depth understanding of the biological processes underlying efficient fungal bioprocesses whose end products are fuels, organic acids, and enzymes. The fundamental and practical knowledge and tools that we generate will improve the efficiency and ease of implementing fungal biotechnology in industry and lead to more rapid and effective development of new processes for the biorefinery industry.

Improved fungal biotechnology tools will be very important for establishing bioprocesses within integrated biorefineries. Fungi have the potential for a rapid, highly productive conversion of biomass resources to bio-based products and intermediates that bring economic benefit to the biorefinery industry. While fungal fermentations are currently used to produce a limited number of specialized products, the tools for broader and more rapid implementation of fungal-based production processes are needed for this industry. Moreover, many of the current fungal processes in use have been developed over many years without a clear understanding of the underlying biological mechanisms that allow the control and utilization of fungal organisms.

The overarching goal of this project is to generate innovative fungal-based biotechnology to enable a robust biorefinery industry. The project objectives are to:

- Reduce the cost of biofuels and bioproducts

o Directly utilize complex biomass

o Enable processes with high concentrations of end-products

(e.g., fuels, organic acids, and enzymes)

- Improve technology for engineering filamentous fungi

- Leverage industry needs and expertise to help guide the research program.

To achieve the objectives of creating tools that enable an economically viable biorefinery using fungal biotechnology, the research has been divided into six major technical subtasks.

- Morphology control

- Genomics

- Proteomics

- Hyper-productivity and consolidated bioprocesses

- Filamentous fungal ethanol

- Alternative renewable fuels from fungi.

The research conducted during FY2009 in these focus areas and research plans for FY2010 are presented in this report. 


\subsection{Major Subtask A.1: Morphology Control Technology}

\subsection{Background}

Proper morphology in filamentous fungi is known to be associated with highly productive bioprocesses for making small metabolites (fuels and chemicals) and enzymes. Therefore, genetically controlling morphology in filamentous fungi will ultimately lead to increased productivity and improved bioprocess efficiency. The genetics of morphology control in filamentous fungi is being examined using Aspergillus niger and citric acid production as our primary model system. Genes that are identified in A.niger will be examined for effectiveness in controlling morphology in our second model system, Aspergillus terreus and itaconic acid production. The ultimate goal is to control the morphology in any fungus that makes a fuel or product of interest. The research conducted under this subtask is focused on identifying genes that can be manipulated to induce a pelleted morphology and an accompanying model that provides a framework for understanding morphology control in filamentous fungi.

Our current morphology control model provides a system-level explanation. These systems include the $G$ protein system, the Ras signaling system, the ubiquitin system, and the reactive oxygen species (ROS) response system.

\subsection{Accomplishments and Results}

In FY09, we continued our research efforts on the three systems mentioned above. In the G protein system, three additional $\mathrm{G}$ protein-coupled genes were deleted. Thus far, we have deleted all $\mathrm{G}$ protein

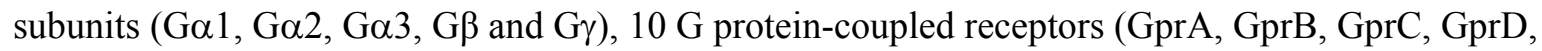
GprE, GprF, GprH, GprM, GprN, GprP). Among those deleted genes in the G protein system, we found that $\mathrm{G} \alpha 1, \mathrm{G} \beta$, and GprB have notable effects on fungal growth and development. In the Ras regulatory system, the Impedes Mitogenic signal Propagation (IMP), which inhibits the functional coupling between Raf and MEKkinases of the Raf-MEK-ERK scaffolding protein KSR1, was identified with the T-DNA insertion with the first exon of the IMP gene via Agrobacterium-mediated transformation. The interruption of the IMP gene has a dramatic effect on A. niger morphology and asexual sporulation. To further examine the function of the IMP gene, we created a gene-deletion construct and an affinity-tag fusion for transformation into A. niger. The mutants with IMP deletion or affinity-tagging were generated. The confirmation and isolation of those proteins associated with the IMP are underway.

The ubiquitin protein system exerts its functions by ubiquitinating the targeting proteins for degradation, protein compartmentation, or temporal regulation. Three approaches have been employed to further understand how the ubiquitin protein system is involved in A. niger morphology. First, those ubiquitinated proteins should be identified via affinity-tagging purification. The second one is to delete the selected genes to examine their contribution in fungal morphology. The final one is to conditionally express the ubiquitin or ubiquitinated proteins in fungi to determine their potential effects on fungal morphology and chemical or protein production. The ubiquitinated proteins were purified from $A$. niger biomass of either filamentous or pelleted growth by affinity purification. The ubiquitinated proteins were determined by liquid chromatography-mass spectrometry (LC-MS). Some of ubiquitinated proteins identified from either filamentous or pelleted growth were selected for gene deletion. Ten oligo 
nucleotides were designed and de novo synthesized, and gene-deletion construction, transformation, and characterization are ongoing. In addition, three ubiquitin-specific proteases and two SUMO-specific proteases were deleted, and their effects on fungal morphology are being examined.

To conditionally express a selected gene, two inducible promoters (nitrate reductase [niaD] promoter and Adenosine Triphosphate (ATP) sulfurylase [met3] promoter) were selected. Since the met3 promoter has not been well studied in filamentous fungi, the met3 promoter activity would be examined with the Beta-glucuronidase (GUS) reporter gene. The met3 promoter was isolated from Aspergillus nidulans and inserted upstream of the coding region of the GUS reporter gene. The transgene expression was transformed into A.niger. The met3 promoter activities under culture conditions with or without methionine are being examined. In addition, the cDNA of the polyubiquitin gene under the control of the niaD promoter was constructed and transferred into A.niger. The effects of polyubiquitin on fungal morphology are also being examined.

Additional suppressive subtractive hybridization (SSH) genes were selected for examining their effects on fungal morphology by gene deletion.

Morphology Score-A. niger citric acid production is analyzed by measuring the amount of citric acid made by a strain. Part of the analysis includes an examination of the morphology associated with production. To facilitate this analysis and aid in comparison between mutants, we have developed a scoring system for A. niger pellets. Our sytem is based upon the knowledge that strains that contain larger numbers of tip cells give higher production. To score a pellet, you simply draw a $10-\mu \mathrm{m}$ circle around the original spore. Place another $30-\mu \mathrm{m}$ circle around the first circle. The number of tips that appear between these two rings will be the score. The example given in Figure 2.1 shows that $A$. niger 11414 grown in normal media (Figure 2.1A) will have a score of 1 . Germlings grown in citric acid production media will have numbers ranging from 3 to 7 with an average much higher than 1 . To test this approach, we examined a mutant in the MAP kinase gene (Figure 2.2). The mutant makes much less citric acid and would score a 1 to 2 . Data from this mutant as well as growth in normal media are consitent with this scoring system. One potential problem will be with defining what constitutes a tip. We have created green fluorescent protein (GFP) fusions to proteins known to localize to tips in fungi (Meyer et al. 2008). This GFP fusion effectively labels tips in normal media (Figure 2.3A) as well as CAP media (Figure 2.3B). We will examine multiple mutants and compare the citric acid production level to the morphology score in future work. 


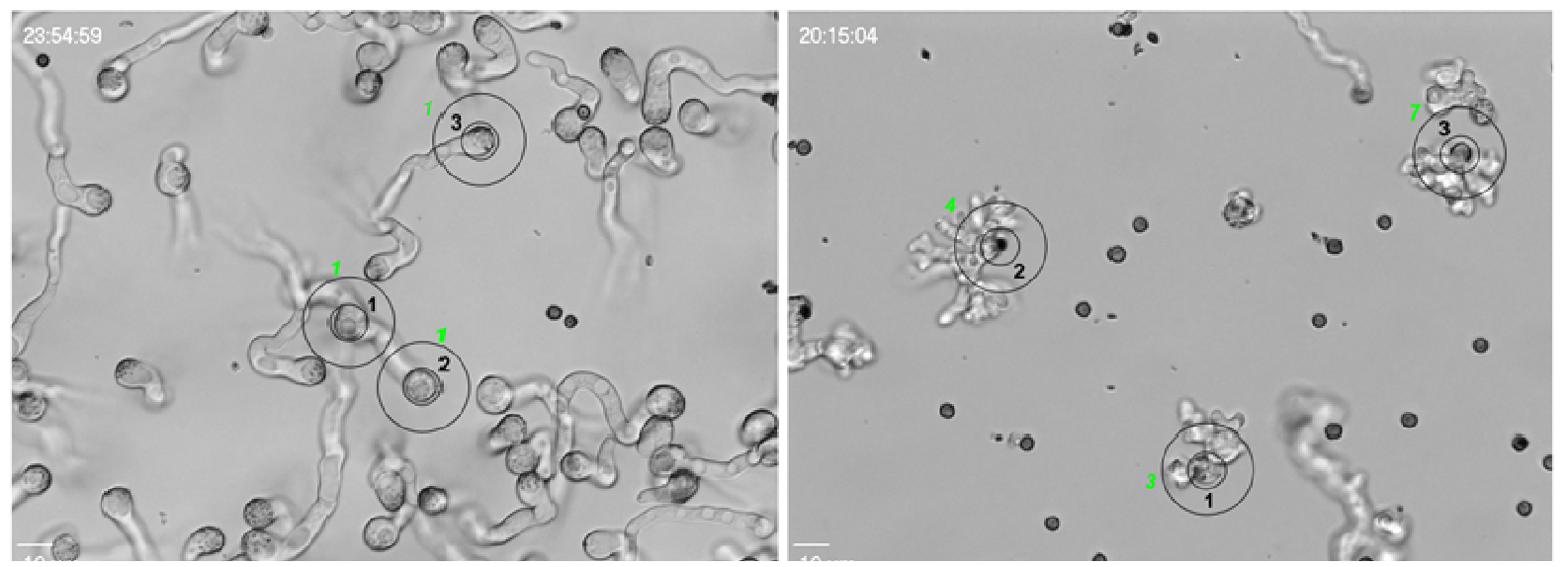

Figure 2.1. Scoring System for Fungal Morphology. The number of tips found between two concentric circles is proposed as a scoring mechanism that correlates morphology and production. In this example, germlings grown in complete media (left) are given a score of 1 . Germlings grown in citric acid production media score between 3 and 4 (right). This is also consistent with citric acid production since very little is produced in complete media.

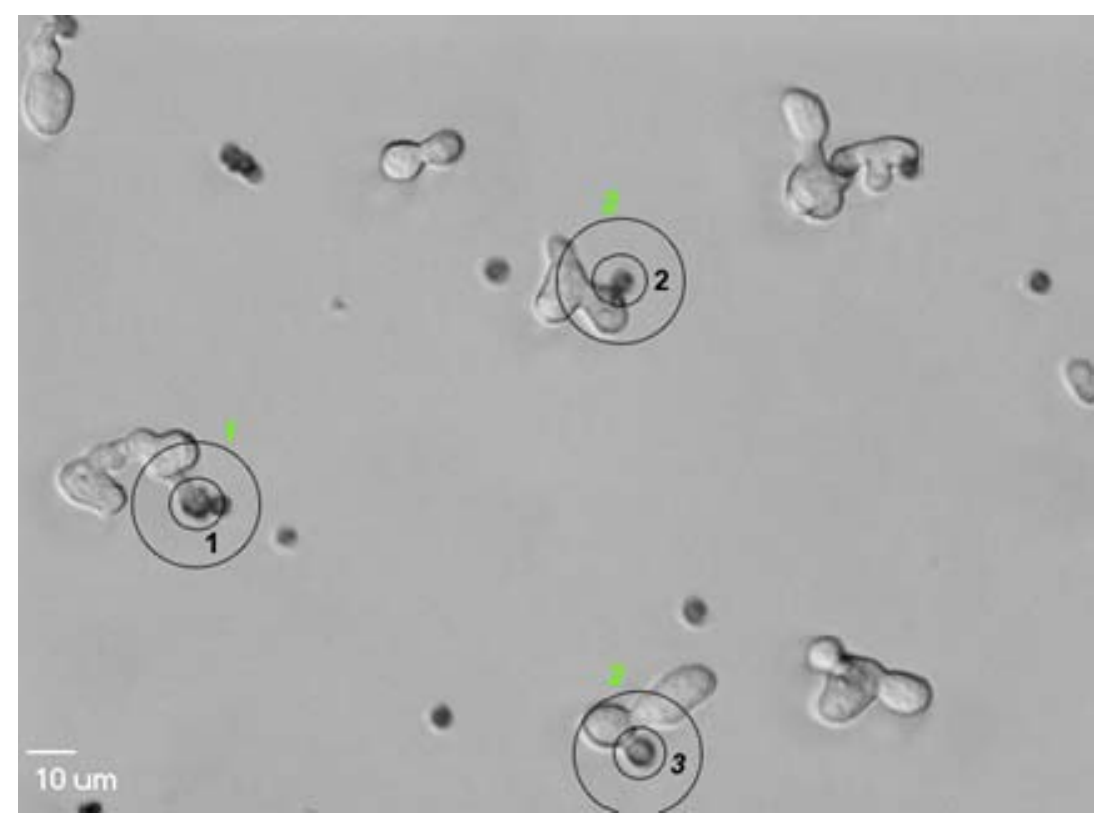

Figure 2.2. MapK1 Mutant Morphology Score. Deletion of the Mapk1 gene results in the inability to make multiple tips in citric acid production media. This leads to extremely low levels of citric acid as well as a low morphology score. 
SpaA-GFP

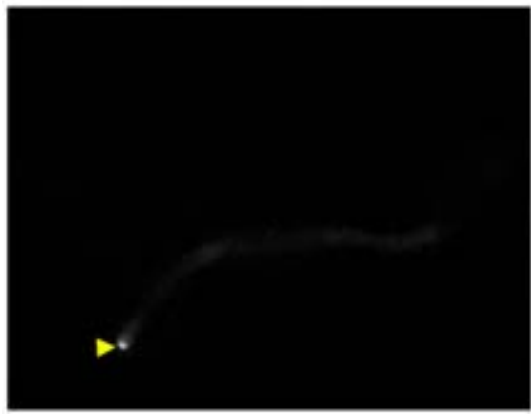

SpaA-GFP

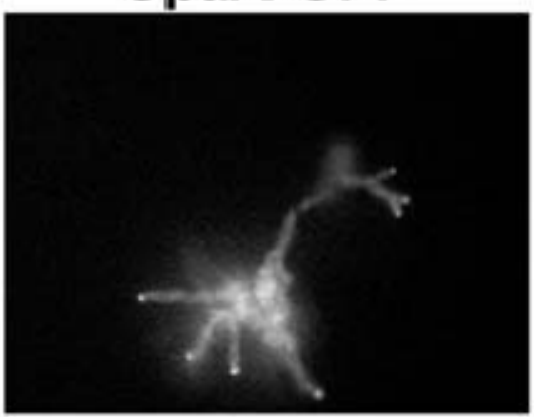

merge

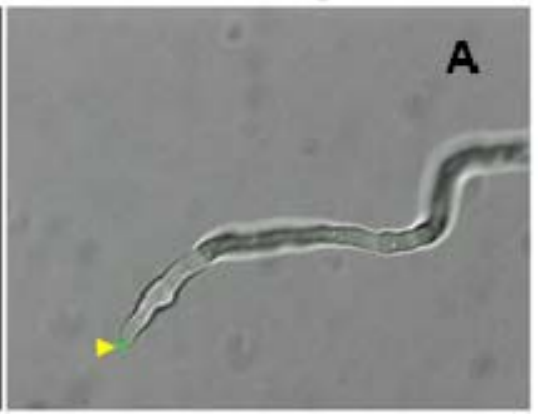

DIC

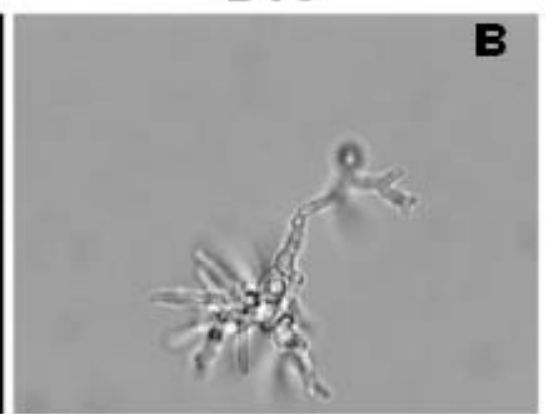

Figure 2.3. GFP as a Tool for Marking Tips. A gene fusion was made to the polarisome component SpaA. The fusion was integrated at the SpaA gene locus. This marker allows us to clearly define tips in different culture conditions, such as complete media (A) and CAP media (B).

\subsection{Plans for FY10}

This task is being eliminated and transitioned into a new task, Advanced Strain Development. 


\subsection{Major Subtask A.2 Fungal Genomics}

\subsection{Background}

For decades, industrial bioprocesses, such as those that will be employed in the biorefinery, have been developed by an empirical, random approach. In other words, multiple rounds of random mutagenesis and screening have been used to improve the microbial strains involved in a time-consuming process. The advent of whole genome sequencing and global, or "shotgun," proteomics makes targeted strainimprovement approaches an attractive alternative that may save time and money. We are using available genomics and proteomics (Subtask A.3) resources and developing additional tools to identify and/or confirm genes and regulatory elements that control fungal morphology and hyperproductivity of small metabolites (fuels and chemicals). The genome sequences of model fungi are obtained via collaboration with the U.S. Department of Energy (DOE) Joint Genome Institute (JGI). Ultimately, this subtask will provide the information and tools that are required to modify fungi predictably; in other words, metabolically engineer a fungus to produce a desired product (fuel, chemical, or enzyme) more efficiently.

We have an ongoing effort to extend our genetic analysis of Aspergillus niger. Candidate morphology and hyperproductivity genes are derived from analysis of the DOE JGI A. niger genome and the associated expressed sequence tag (EST) data. In FY07, we generated several mutants in high-level signaling pathway genes (MAP kinases), manganese homeostasis genes, and cell wall synthesis genes. In FY08, we performed genetic, functional genomics and phenotypic analyses of these and other $A$. niger genes that are potentially involved in controlling fungal morphology and organic acid production. We will continue to work with the JGI to improve fungal genome sequence resources, especially those for $A$. niger. In FY07, two close "relatives" of $A$. niger entered the sequencing queue, and their sequences are scheduled for completion in late FY08 or early FY09.

We have established a strong collaboration with the Technical University of Denmark (DTU). The DTU collaboration is important for access to additional state-of-the-art functional genomic tools. These tools include metabolic modeling software for various Aspergillus species and an A. niger Affymetrix microarray that DTU has developed. The microarray allows global monitoring of gene expression at the mRNA level (transcriptomics), which augments our global proteomic characterization of gene expression at the protein level. These two functional genome approaches provide complementary data on morphology control and hyperproductivity.

The development of efficient genetic tools is an essential part of the genomics subtask that supports the entire Fungal Biotechnology Task. Several methods for accelerated gene deletion have been applied in other organisms. These include split marker gene deletion and gene silencing using siRNA and reversible markers. We will apply these methods to our model production organisms. Another desirable capability would be a set of promoters that allow for the control of expression of target genes. In FY09, we will initiate a screen for promoters that are advantageous for production conditions. 


\subsection{Objectives}

- Enable a high-throughput pipeline for genetic analysis of A. niger citric acid production (both morphology and productivity characteristics).

- Use analysis of proteomic and transcriptomic data to generate candidate genes for further characterization.

- Adapt methods used in the study of $A$. niger morphology and citric acid production for the study and subsequent engineering of $A$. terreus.

\subsection{Accomplishments and Results}

Overexpression-Part of our approach to understanding and improving fungal fermentation includes manipulating specific genes. This is largely done by gene deletion followed by analyzing the resulting phenotype. Another important way to analyze gene function is by overexpressing the gene. Overexpression can be achieved by promoter replacement or multiple copy integration. Promoters used in this analysis can either be constitutive or inducible. In the study of fermentation, inducible promoters that are not affected by catabolite repression are important since many of our fermentations are performed with glucose. In the past year, we have tested overexpression of genes using several combinations of promoters (Table 3.1).

Table 3.1. Fungal Expression Constructs

\begin{tabular}{cccc}
\hline Promoter & Function & Reagent & Results \\
\hline NiaD & Inducible & Nitrate, repressed by Ammonium & Testing \\
Met3 & Inducible & Sulfate, repressed by Methionine & Testing \\
gpdA & Constitutive & None & High expression in AmA \\
\hline
\end{tabular}

Overexpression can be achieved with any of these promoters when integrated into a plasmid capable of being maintained through mitosis without integrating into the chromosome (Gems et al. 1991). This plasmid, referred to as AmA, contains a portion of the A. nidulans chromosome that allows it to be replicated and maintained during vegetative growth. We have used an AmA plasmid that contains the pyr4 gene from Neurospora crassa. This marker will allow us to delete genes using hygromycin and overexpressing genes in that genetic background.

Map Kinase-Routine growth of Aspergillus niger includes the formation of long branching hyphae that form a web of filaments forming a mycelium. During citric acid production, filament formation is suppressed, and bulbous chains of cells aggregate into small pellets that are devoid of any extensive filamentation. The subsequent addition of manganese to a production culture causes polar growth to resume and citric acid production to cease. Previous observations indicate that these pellets contain multiple tips emanating from individual cells. In an effort to understand signaling mechanisms that control pellet formation, we deleted several MAP Kinsae genes in a citric acid production strain of $A$. niger (ATCC11414). Gene deletion of an orthologue of Magnaporthe grisea PMK1 resulted in a strain with reduced citric acid production. This mutant displays an atypical pellet morphology with extensive apolar growth and an inability to form large pellets. Adding manganese restores filamentation; however, 
this MAP kinase mutant has fewer extending hyphae than the parental strain. This is an indication that the mutant is incapable of initiating multiple sites of polar growth under these conditions.

Reversible markers-Functional genome studies depend on an efficient targeted gene manipulation system. DNA-mediated transformation requires the use of markers that allow transformants that have stably integrated the DNA of interest to be selected. A number of selectable markers have been described for the transformation of filamentous fungi, including auxotrophic mutants that are transformed with the corresponding gene and antibiotic resistance markers such as hygromycin. These routine markers are not always available for use in production strains without well developed genetic tools such as auxotrophs. Also, some fungi, such as A. oryzae, are resistant to certain antibiotics. A marker system must be applicable to a wide range of organisms and can be implemented without altering the productivity of the strain through mutagenesis. In past years, we have created uracil auxotrophs by manipulating the pyrG gene in A. niger. PyrG ${ }^{-}$mutants of production strains of A. niger, A. oryzae, and Trichoderma reesei have been successfully produced using double-joint PCR-based homologous integration of a small deletion in the pyrG locus. This procedure has proven useful in making gene knockouts. This PCR approach can be adapted to any marker that has both forward and reverse selection. One such marker is the gene coding for ATP-sulfurylase. It is required for using sulfate as a source of sulfur. This enzyme also metabolizes selenate, which is analogous to sulfate and has similar chemistry. Selenate is toxic to strains that carry a functional ATP-sulfurylase gene. Therefore, mutants can be selected on media containing selenate. The resulting mutation is then no longer capable of growing on media in which sulfate is the sole source of sulfur (Figure 3.1). We have successfully created this mutation in A. niger 11414 by using the same approach used to create the pyrG auxotroph. We anticipate creating similar mutants in A. oryzae to increase the number of available markers in each system.

Aspergillus terreus, A. oryzae, A. carbonarius, T. reesei-An important part of the genomics task is to facilitate genetic manipulation in all strains of interest. We have successfully transformed and deleted genes in a variety of fungi. Table 3.2 contains a list of the status of this tool development.

Aspergillus niger High Throughput Gene Deletions and Analysis-In recent years, a large-scale genome wide gene deletion project has been performed on Neurospora crassa (Colot et al. 2006). This approach was, in part, facilitated by the discovery of genes required for non-homologous end joining of DNA (Ninomiya et al. 2004). Using the same approach, we have adapted these tools to the citric acidproducing strain of $A$. niger 11414. A reversible gene insertion was placed into the kusA locus using a split marker approach used previously in A. nidulans (Nielsen et al. 2008). This mutation disrupts kusA activity and greatly increases the rate of homologous integration (Figure 3.2). However, strains lacking a functional kusA gene are susceptible to mutation, particularly double-stranded breaks in DNA (Meyer et al. 2007). Direct repeats of the kusA gene flank the pyrG marker in this mutation. Revertants are selected by plating on media containing FOA. We tested the mutant as well as a revertant of the mutant selected on FOA and compared these to the parental 11414 strain by exposing them to varying levels of gamma radiation. The kusA mutant is much more sensitive to this treatment because it is incapable of rejoining non-matching DNA strands (Figure 3.3). The revertant was no longer as sensitive to the treatment, indicating the restoration of the kusA function in these strains. 

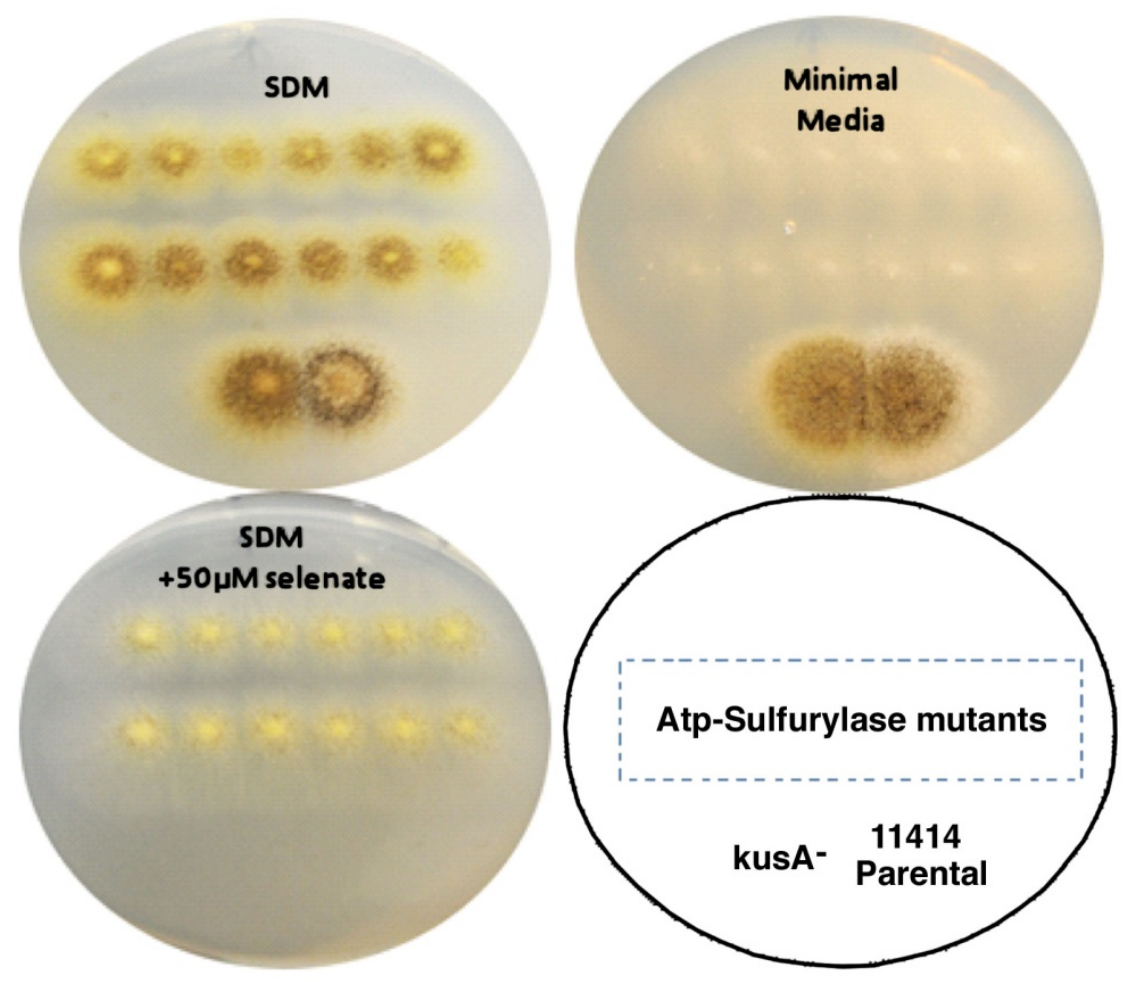

Figure 3.1. Mutation of ATP Sulfurylase in A. Niger. The ATP sulfurylase gene can be used as a reversible genetic marker. Cells lacking this gene are insensitive to $50 \mu \mathrm{M}$ selenate (bottom left) but require the addition of methioniine and cannot grow on minimal media containing only sulfate as a source of sulfur (top left) (sulfate depleted medium [SDM]).

Table 3.2. Genetic Markers Available for Gene Manipulation in Relevant Strains

\begin{tabular}{lccc}
\hline \multicolumn{1}{c}{ Species } & Transformation & Markers & Deletions \\
\hline A. terreus ATCC 32359 & Protoplast, KCl & Hygromycin, Bleomycin & 5 genes \\
A. oryzae NRRL697 & $\begin{array}{c}\text { Protoplast, } \\
\text { Ammonium Sulfate }\end{array}$ & pyrG & 4 genes \\
Trichoderma reesei QM6A & Protoplast, $\mathrm{MgSO}_{4}$ & pyrG, Hygromycin & 3 genes \\
A. carbonarius & Protoplasts, $\mathrm{MgSO}_{4}$ & Hygromycin & $\begin{array}{c}\text { Hyg integration, } 0 \\
\text { deletions }\end{array}$ \\
A. niger ATCC11414 & P Protoplast, & $\begin{array}{c}\text { Hygromycin, Bleomycin, } \\
\text { pyrG, Sc }\end{array}$ & 40+ genes deleted \\
\hline
\end{tabular}

Using the KusA mutant, we have initiated a high throughput deletion protocol to analyze citric acid production. A modified version of the Primer3 software for automatically picking primers for all genes within a genome was obtained from Dr. Hildur Colot at Dartmouth University. The software was adapted to process genomes and gene-feature annotation files downloaded from the Broad Institute's collection of Aspergillus genomes. Out of 11200 A. niger genes, the program was capable of automatically picking primers for 11030 genes. Primers for 32 of these genes were synthesized and successfully used to amplify the targeted genes. 
One advantage of using the kusA mutant is that it greatly reduces the effort needed for screening the deletions. The homologous transformation rate is close to $100 \%$. This allows us to reverse the usual order of this type of analysis. We can pick transformants and screen for phenotype first. Transformants that display changes in morphology or citric acid production can then be screened to verify proper integration and gene deletion. Figure 3.4 demonstrates a plate assay for growth in citric acid production media. Six transformants of the A. niger 11414 kusA ${ }^{-}$strains were picked for each gene. Spores were replica plated using a pin replicator. This analysis shows that the manganese transporter, smfA, forms much tighter colonies on this medium and is likely required for Mn uptake in these conditions. This type of plate screen will help accelerate genetic analysis of $A$. niger. We plan to delete large classes of genes, including all genes thought to play a role in MAP Kinase signaling as well as genes involved in reactive oxygen species generation and mitigation.

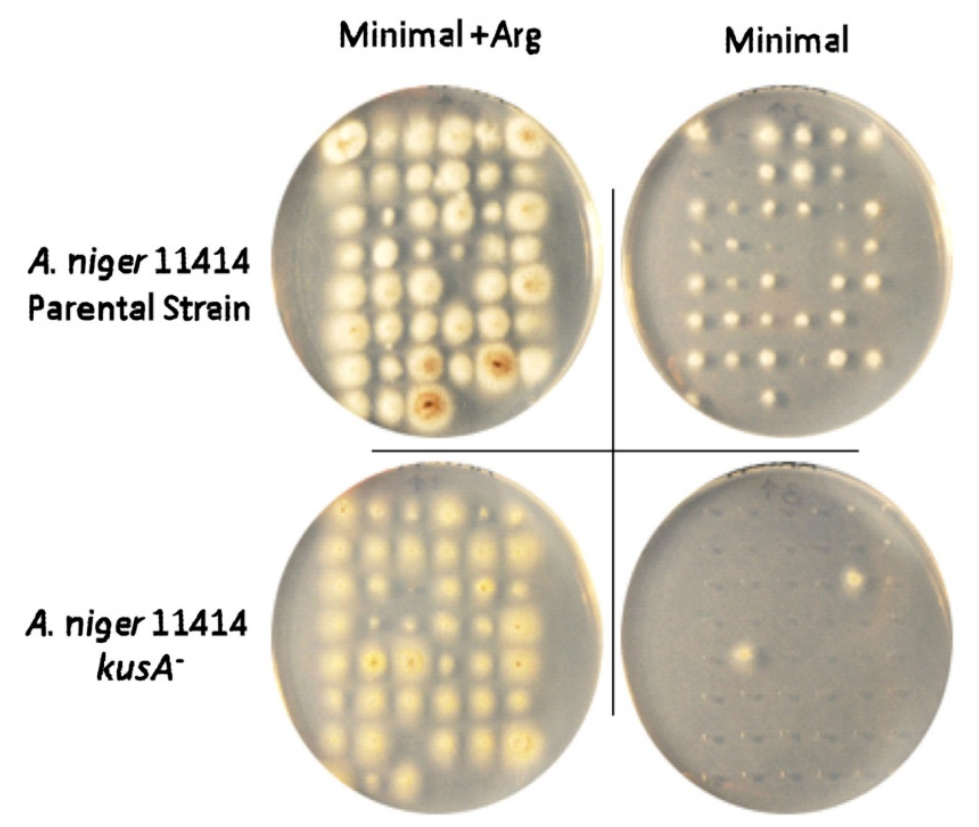

Figure 3.2. Improved Homologous Recombination in the kusA Mutant. Colonies grown from wildtype and $k u s A^{-}$spores collected from individual $\operatorname{ArgB}$ knockout transformants. Colonies in which homologous recombination occurred grew on media containing arginine, but did not grow on media lacking arginine. Using the $\operatorname{argB}$ gene as a test, we have seen an increase in homologous recombination from $20 \%$ in the parental strain to $95 \%$ in the $k u s A^{-}$strain.

Joint Genome Institute Project Leads-Jon Magnuson: Dunaliella salina genome, Columbia River periphytan population census and Scott Baker: Aspergillus niger, Trichoderma atroviride, Piromyces, Orpinomyces, Aspergillus aculeatus and Aspergillus carbonarius genomes, Aspergillus terreus ESTs.

\subsection{Plans for FY2010}

The DOE has made and continues to make a large investment in fungal genome sequencing at the Joint Genome Institute. The goal of the Fungal Genomics Task is to use genomic, proteomic, and transcriptomic experimental data to enable rapid and high-throughput methods for discovery and 
functional characterization of genes that are potentially involved in fungal morphology control and organic acid and enzyme hyperproductivity. Using Aspergillus niger, we will apply successful strategies from this model system to other fungi, including A. terreus. The activity in this task not only draws data from the other tasks; it also directly supports them by generating and analyzing various mutant strains for use in proteomic, morphology, and fermentation experiments. Planned accomplishments for the year include:

- Promoters ranked according to their characteristics

- Phenotype analysis of six signaling/transcription factor/reactive oxygen species (ROS) genes in A. niger and/or A. terreus

- Trichoderma reesei cellulase improved strains sequenced in collaboration with DOE Joint Genome Institute

- Construction of six signaling/transcription factor/ROS genes in A. niger and/or A. terreus

- Make KU mutants in A. terreus and A. oryzae.

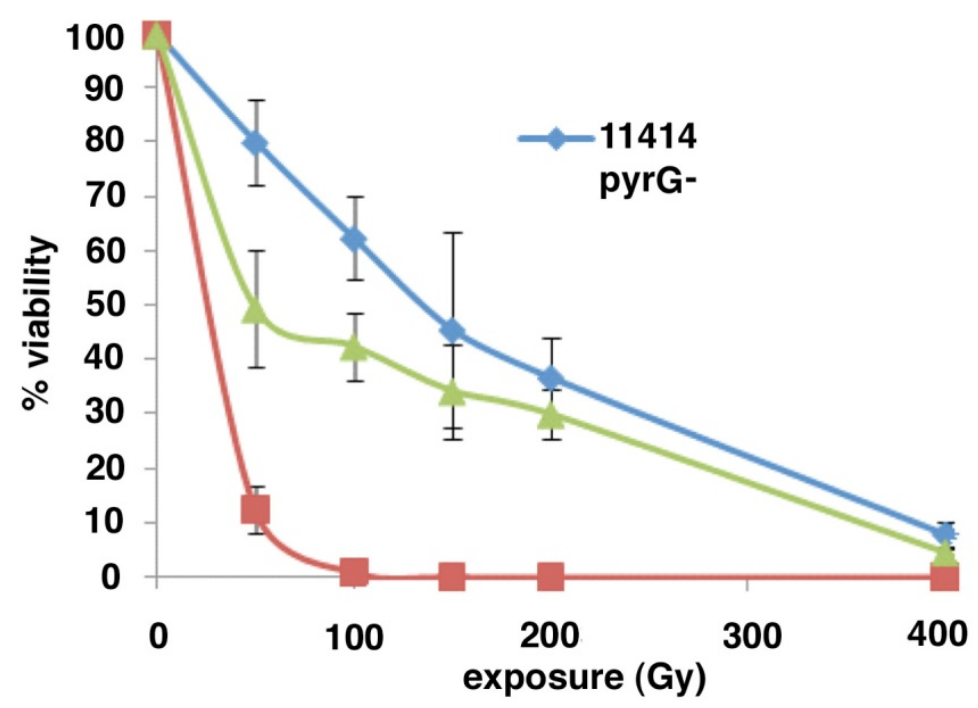

Figure 3.3. The Percent Viability of Wildtype, $k u s A^{-}$, and $k u s A^{+}$Revertant Spores Exposed to Gamma Radiation. The percent viability of the $k u s A^{+}$revertant is very similar to that of the wildtype and significantly higher than that of $k u s A^{-}$, demonstrating that the $k u s A^{+}$revertant has restored capability to repair DNA. 


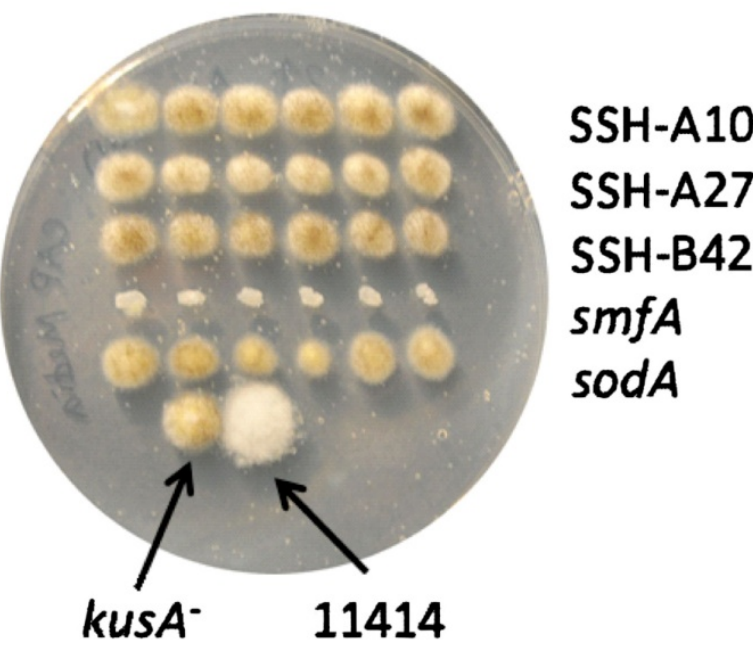

Figure 3.4. Phenotype Screen of Five Mutants (six colonies each) on CAP Media. The Smf mutant displays a unique phenotype in all six colonies, illustrating the high rate of homologous recombination in the $k u s A^{-}$strain. 


\subsection{Major Subtask A.3 Fungal Proteomics}

\subsection{Background}

Proteomics has been defined as the study of the "protein complement expressed by a genome" (Wilkins et al. 1996). With current technology, a single MS analysis in which peptides are eluted into the instrument directly after separation by LC can identify thousands of parent proteins. Several methodologies have been described for global relative protein quantitation between two separate samples using these techniques (Wilkins et al. 1996; Conrads et al. 2000; Gao et al. 2003; Gygi et al. 1999). We have applied this technology to the study of morphology control and hyperproductivity in filamentous fungi. We expect that the discovery of proteins whose abundances differ in the pelleted and filamentous growth states of $A$. niger will identify proteins involved in the control of cellular processes related to morphology determination.

Our goal is to have a rigorous global proteomics procedure developed and demonstrated that proceeds from experimental design all the way through data interpretation. Relative quantitation between the two growth conditions is performed using mixed-effects statistical modeling (described in detail in Daly et al. 2008). One peptide may be more easily detected and quantified by the mass spectrometer than another peptide of equal molarity due to the physical properties of the peptide (number of sites available for protonation, hydrophobicity, etc.). In other words, two peptides resulting from trypsin digestion of one protein may not be detected with equal sensitivity, which causes problems when combining abundance measurements from different peptides of the same parent protein. However, the relative response of the instrument to one peptide compared to another is independent of other factors in an experiment, such as dilution. This relationship allows for the relative peptide response to be estimated and subsequently corrected, which provides more precise estimates of protein abundances by pooling information across peptides.

\subsection{Accomplishments and Results}

Our proteome analysis of $A$. niger under filamentous and pelleted growth conditions included nine biological replicates. Each of the two samples for a biological replicate was split into three separate tubes for samples processing. All samples had two LC/MS injections, yielding a total of 108 data sets. Overall, 729 proteins were observed sufficiently to be modeled out of a total of 1735 proteins identified. As is often the case with "shotgun" proteome analysis, a significant number of proteins were observed only once during the analysis (500). Of the proteins modeled, 353 had p-values calculated to be less than 0.05 . Proteins modeled had relative abundances that ranged from 0.3 - to 4 .2-fold differences between the two growth states.

Of particular interest are those proteins that were indicated to be highly differentially expressed between the two conditions. The 19 proteins identified in the analysis that were calculated to have the highest relative abundance in filamentous cells are presented in Table 4.1. The range of relative abundances in the corrected Table 4.1 is 1.5 to 4.4 fold. Similarly, modeling indicated that 13 proteins identified to be approximately half as abundant in filamentous relative to pelleted cells had calculated p-values less than 0.05 (Table 4.2). The results present some intriguing protein targets for additional study. Ribosomal protein L34, which was identified as more abundant in pelleted cells, has been 
identified as an inhibitor of cyclin-dependent kinases (Moorthamer and Chaudhuri 1999). Would over expression of this gene affect cell cycle? Ornithine decarboxylase is the initial step in the polyamine pathway. Polyamines are implicated in cell growth in differentiation in several eukaryotes, which makes it another attractive target for genetic manipulation. We have spent most of our effort on identifying proteins with convincing identifications from blast analysis whose expression could be verified by enzyme or Western analysis. To that end, we focused on protein ID 47229 (phytase), 214686 (oxalate decxarboxylase), and 213198 (peptidyl-prolyl cis-trans isomerase B) (Table 4.1).

Table 4.1. Proteins Higher in Abundance in the Filamentous vs. Pelleted Growth State

\begin{tabular}{rlrcl}
\hline JGI ID & \multicolumn{1}{c}{ Blast ID } & Score & E-Value & \multicolumn{1}{c}{ Notes } \\
\hline 206270 & Srp68, Canis familiaris. & 377 & $4 \mathrm{e}-35$ & $\begin{array}{l}\text { Subunit of signal recognition particle, } \\
\text { targets secretory proteins to ER }\end{array}$ \\
\hline 47229 & PhyB, Aspergillus awamori & 2274 & 0 & 3-Phytase B \\
\hline 210783 & Pmp20, Aspergillus fumigatus & 639 & $2 \mathrm{e}-66$ & Peroxiredoxin pmp20 \\
\hline 37155 & Uncharacterized & 253 & $2 \mathrm{e}-21$ & From Acanthamoeba polyphaga mimivirus \\
\hline 214686 & OxdC, Bacillus subtilis & 1082 & $1 \mathrm{e}-117$ & Oxalate decarboxylase \\
\hline 207705 & Rpn9, Schizosaccharomyces pombe & 847 & $6 \mathrm{e}-90$ & 26S proteasome regulatory subunit \\
\hline 184329 & FaeA, Aspergillus awamori & 253 & $3 \mathrm{e}-21$ & Feruloyl esterase A \\
\hline 199424 & None & & & \\
\hline 191172 & Bgl2, S. pombe & 246 & $2 \mathrm{e}-20$ & Glucan 1,3-beta-glucosidase \\
\hline 213198 & PpiB, Aspergillus niger & 1024 & $1 \mathrm{e}-111$ & Peptidyl-prolyl cis-trans isomerase B \\
\hline 201930 & Rp124, Neurospora crassa & 379 & $3 \mathrm{e}-35$ & 60 S ribosomal protein L24 \\
\hline 54717 & None & & & \\
\hline 56985 & Tcb1, Saccharomyces cerevisiae & 1384 & $1 \mathrm{e}-151$ & Tricalbin-1 \\
\hline 41962 & Smd2, S. pombe & 342 & $3 \mathrm{e}-32$ & Small nuclear ribonucleoprotein Sm D2 \\
\hline 130857 & Sdh1, S. pombe & 2014 & 0 & Probable succinate dehydrogenase subunit \\
\hline 207660 & FksA, A. niger & 9361 & 0 & 1,3-beta glucan synthase subunit \\
\hline 48843 & SudA, Emericella nidulans & 5239 & 0 & Chromosome segregation protein sudA \\
\hline 209528 & Rnc1, S. pombe & 733 & $1 \mathrm{e}-76$ & RNA-binding protein rnc1 \\
\hline 210479 & Mcm7, S. pombe & 2218 & 0 & DNA replication licensing factor mcm7 \\
\hline & & & \\
\hline
\end{tabular}


Table 4.2. Proteins Higher in Abundance in the Pelleted vs. Filamentous Growth State

\begin{tabular}{rlccl}
\hline JGI ID & \multicolumn{1}{c}{ Blast ID } & Score & E-Value & \multicolumn{1}{c}{ Notes } \\
\hline 209511 & Rpl34, Saccharomyces cerevisiae & 410 & $4 \mathrm{e}-40$ & 60 S ribosomal protein L34b \\
\hline 54942 & Ak, S. cerevisiae & 958 & $1 \mathrm{e}-102$ & Aspartokinase \\
\hline 53577 & $\begin{array}{l}\text { Uncharacterized, } \\
\text { Schizosaccharomyces pombe }\end{array}$ & 610 & $2 \mathrm{e}-62$ & \\
\hline 128537 & Aspf7, S.pombe & 264 & $4 \mathrm{e}-23$ & Allergen \\
\hline 208611 & Uncharacterized, S. pombe & 2319 & 0 & Importin subunit beta 3 \\
\hline 212190 & Imb3, S. pombe & 1024 & $\mathrm{e}-110$ & $\begin{array}{l}\text { Glycosylphosphatidylinositol-anchored } \\
\text { protein involved in cell wall biosynthesis }\end{array}$ \\
\hline 190790 & Ecm33, Aspergillus fumigatus & 1265 & $\mathrm{e}-138$ & 1,3 -beta-glucanosyltransferase gel4 \\
\hline 212716 & Gel4, A. fumigatus & 505 & $4 \mathrm{e}-51$ & 60 S ribosomal protein L27a \\
\hline 212102 & Rp127, S. cerevisiae & 160 & $3 \mathrm{e}-10$ & $\begin{array}{l}\text { HTH APSES-type DNA-binding domain } \\
\text { containing protein }\end{array}$ \\
\hline 212069 & Uncharacterized, S. pombe & 598 & $2 \mathrm{e}-61$ & $\begin{array}{l}\text { Nascent polypeptide associated complex } \\
\text { subunit alpha }\end{array}$ \\
\hline 200566 & Egd2, Aspergillus niger & 689 & $8 \mathrm{e}-72$ & Uncharacterized oxidoreductase \\
\hline 46787 & Tma29, S. cerevisiae & 457 & $6 \mathrm{e}-45$ & Iron sulfur cluster assembly protein 2 \\
\hline 127054 & Isu2, S. cerevisiae & & \\
\hline
\end{tabular}

We initially attempted to assay phytase with an assay kit. The kit is a coupled reaction that releases a fluorescent reaction product for detecting phytase activity. A. niger was grown in CAP media with and without manganese. Cell extracts were prepared by freeze grinding fungal biomass and then subsequently solubilizing the material in phytase reaction buffer. Spent media samples were prepared for assay from the two conditions by filtering through a 2-micron membrane. Phytase from wheat was used as a positive control. As shown in Figure 4.1, activity was detected in both cell extracts with slightly higher activity in pelleted cells as compared to filamentous. However qualitatively when the spent media extracts are compared, there is significant phytase activity detected under filamentous conditions over the background given by CAP media. The combined intracellular and extracellular phytase activities support the data from the proteomics work which, indicated that phytase is more abundant in A. niger grown under filamentous conditions. Due to the interference by CAP media in the assay, we have begun phytase assays with the method described in Piddington et al. (1993) to obtain quantitative phytase activates. 


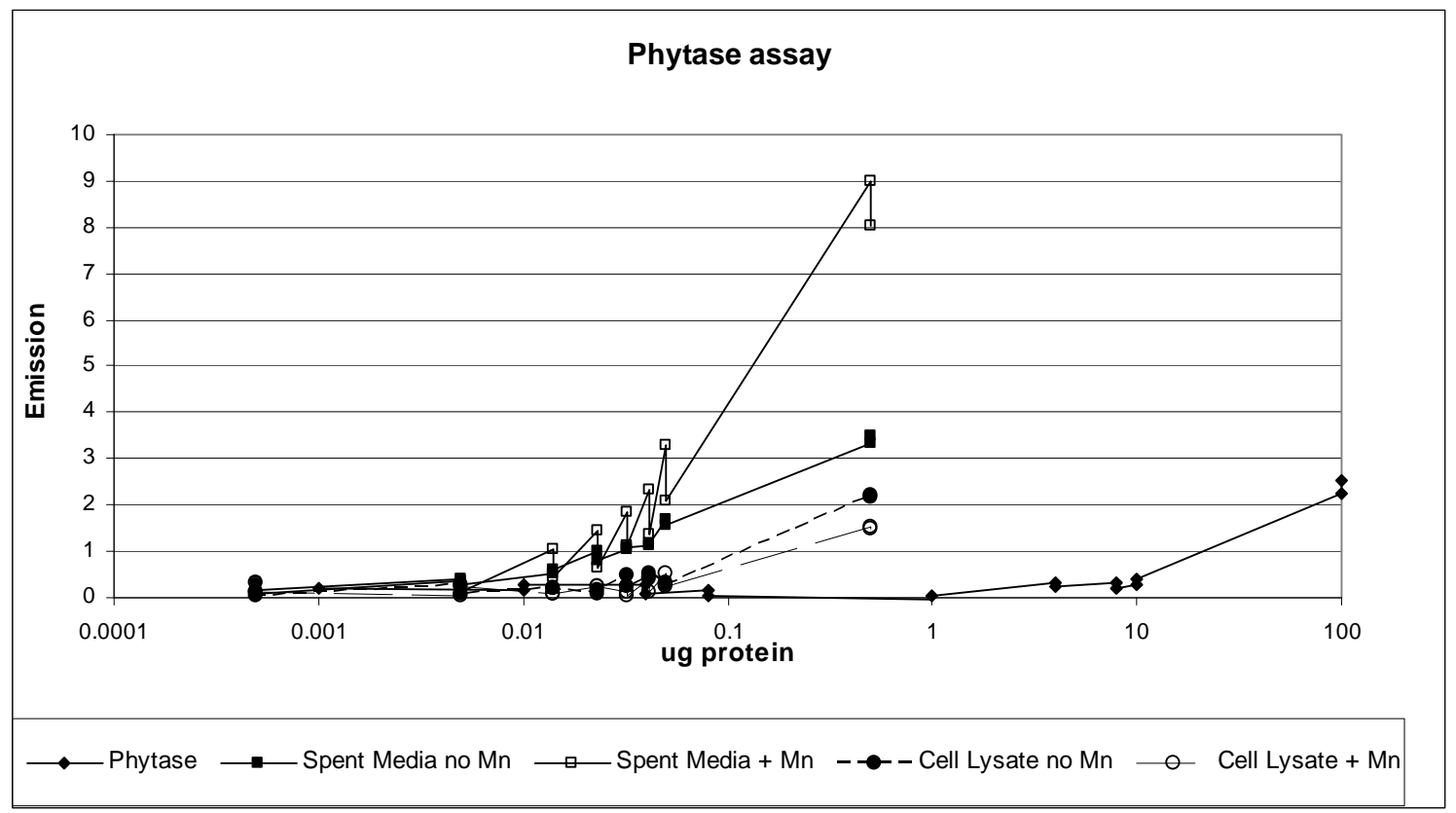

Figure 4.1. Phytase Assays on Phytase from Wheat and Cell Lysates and Spent Media from A. niger Grown Under Filamentous (+ Mn) and Pelleted Conditions (no Mn)

Oxalate decarboxylase activity of cellular lysates was performed as described in Bergmeyer et al. (1985, pp. 126-327). Again, A. niger was grown in CAP media both with and without manganese with extracts being prepared by freeze grinding fungal biomass. The cell extract was solubilized in $100 \mathrm{mM}$ phosphate buffer, pH 5. Extracts from filamentous cell lysates had an average oxalate decarboxylase activity of 3.1 units $/ \mathrm{ml}( \pm 0.2)$, while no activity could be detected in extracts of pelleted cells. This collaborates the proteomics data, which indicated that oxalate decarboxylase is higher expressed in $A$. niger under filamentous growth conditions.

JGI gene model 213198, identified as peptidyl-prolyl cis-trans isomerase B (PPIB) by blast analysis, has significant homology to cyclophilin B (Figure 4.2). An antibody to cyclophilin B was available commercially, and it was used to perform Western analysis on cell lysates from A. niger grown under filamentous and pelleted conditions (four biological replicates). Results are shown in Figure 4.3(A) and Figure 4.3(B). PPIB is predicted to have a molecular weight of $23 \mathrm{kD}$. As seen in Figure 4.3(A), there appears to be some cross reactivity between the anti-cyclophilin B antibody and some proteins around 30 $\mathrm{kD}$ and $40 \mathrm{kD}$. Focusing in on the region around $20 \mathrm{kD}$ (Figure 4.3(B)), we observe three protein bands (labeled A, B, and C) that might be PPIB or its degradation products. Both protein bands B and C and also the summed intensity of all three bands were determined by densitometry to be greater under filamentous conditions (with manganese) than pelleted. These results support the protoeomic data analysis. However, protein band A is not consistent with the proteomic data and in addition is not consistent across replicates. 


\begin{tabular}{|c|c|c|c|}
\hline P23284 & MLRLSERNMKVLLAAALIAGSVFFLLLPGPSAADEKKKGPKVTVKVYFDLRIGDEDVGRV & 60 & PPIB_HUMAN \\
\hline P62937 & 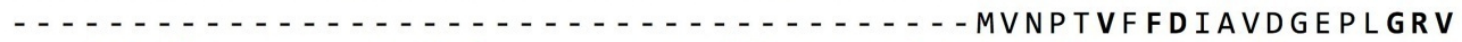 & 20 & PPIA_HUMAN \\
\hline$\underline{213198}$ & $\begin{array}{c}-- \text { MNFKNIFLSFFFVLAVG - - - - - LALVHAEDAQPRGPKITSKVFFDIEHGDKPLGRV } \\
. \\
* * * * \\
*\end{array}$ & 51 & \\
\hline P 23284 & 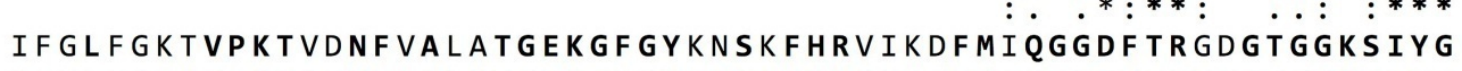 & 120 & PPIB_HUMAN \\
\hline P62937 & SFELFADKVPKTAENFRALSTGEKGFGYKGSCFHRI IPGFMCQGGDFTRHNGTGGKSIYG & 80 & PPIA_HUMAN \\
\hline$\underline{213198}$ & 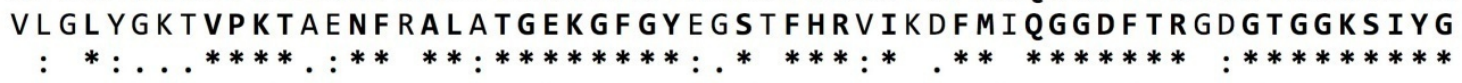 & 111 & \\
\hline P 23284 & ERFPDENFKLKHYGPGWVSMANAGKDTNGSQFFITTVKTAWLDGKHVVFGKVLEGMEVVR & 180 & PPIB_HUMAN \\
\hline P62937 & EKFEDENF I LKHTGPG I L MANAGPNTNGSQFF I CTAKTEWLDGKHVVFGKVKEGMNIVE & 140 & PPIA_HUMAN \\
\hline 213198 & 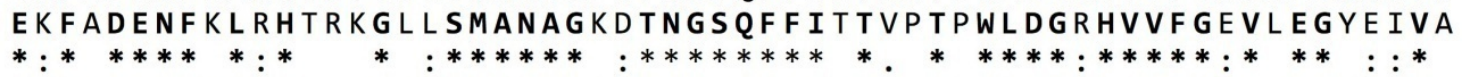 & 171 & \\
\hline P 23284 & KVESTKTDSRDKPLKDVIIADCGKIEVEKPFAIAKE - - - 217 PPIB_HUMAN & & \\
\hline P62937 & AMERFGSRN-GKTSKKITIADCGQLE- - - - - - - - - & & \\
\hline$\underline{213198}$ & Q I ENVPKGRSDRPVETVKIVKSGELESEDKAGEKGSSHEEL & & \\
\hline & $: * \quad \quad \quad .: \quad: \quad: *^{*} \ldots *:: *$ & & \\
\hline
\end{tabular}

Figure 4.2. Protein Sequence Alignment of JGI Gene Model 213198 and Human Cyclophilins 
(A)

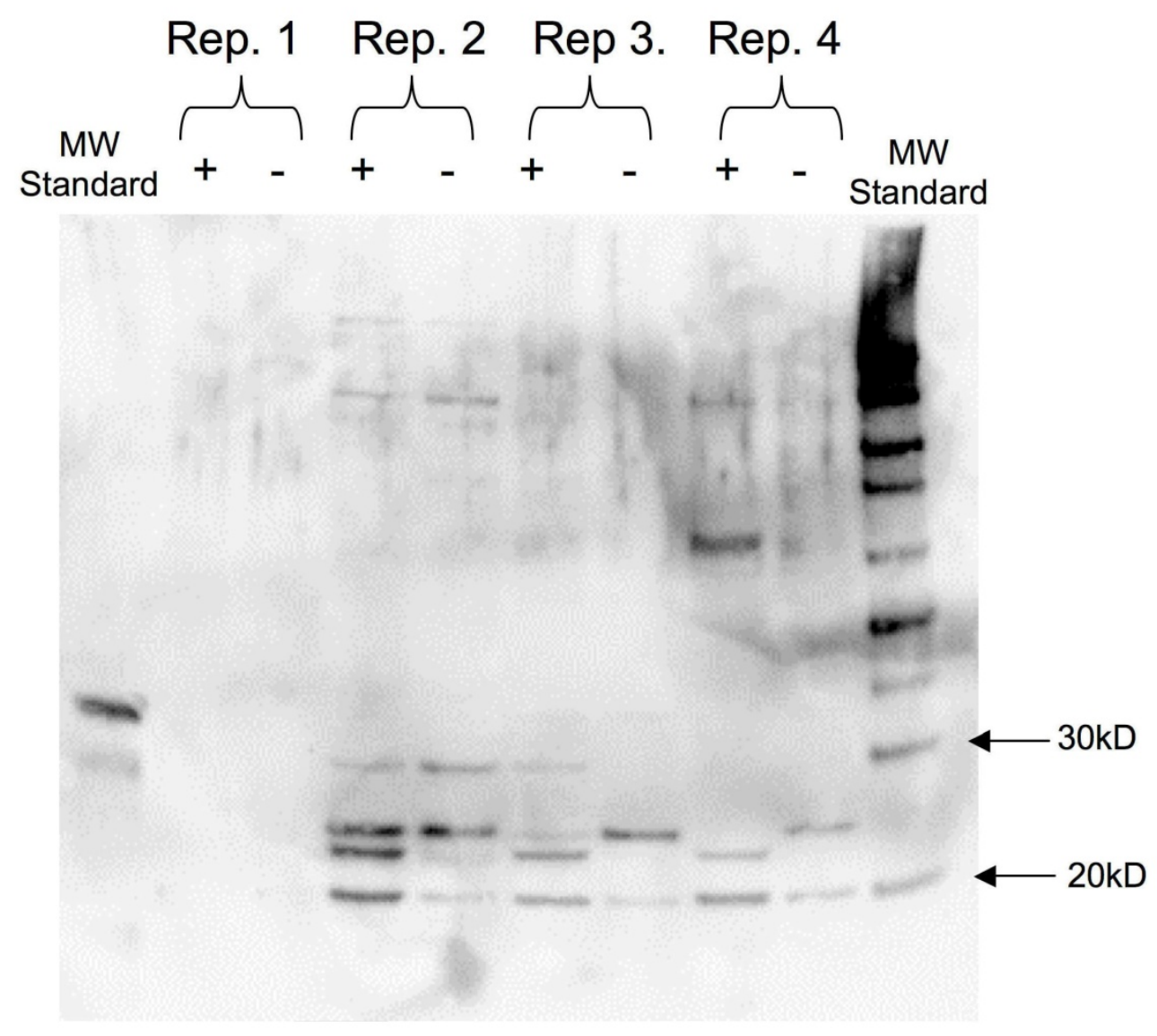

(B)

$\begin{array}{llll}\text { Rep. } 1 & \text { Rep. } 2 & \text { Rep. } 3 & \text { Rep. } 4\end{array}$

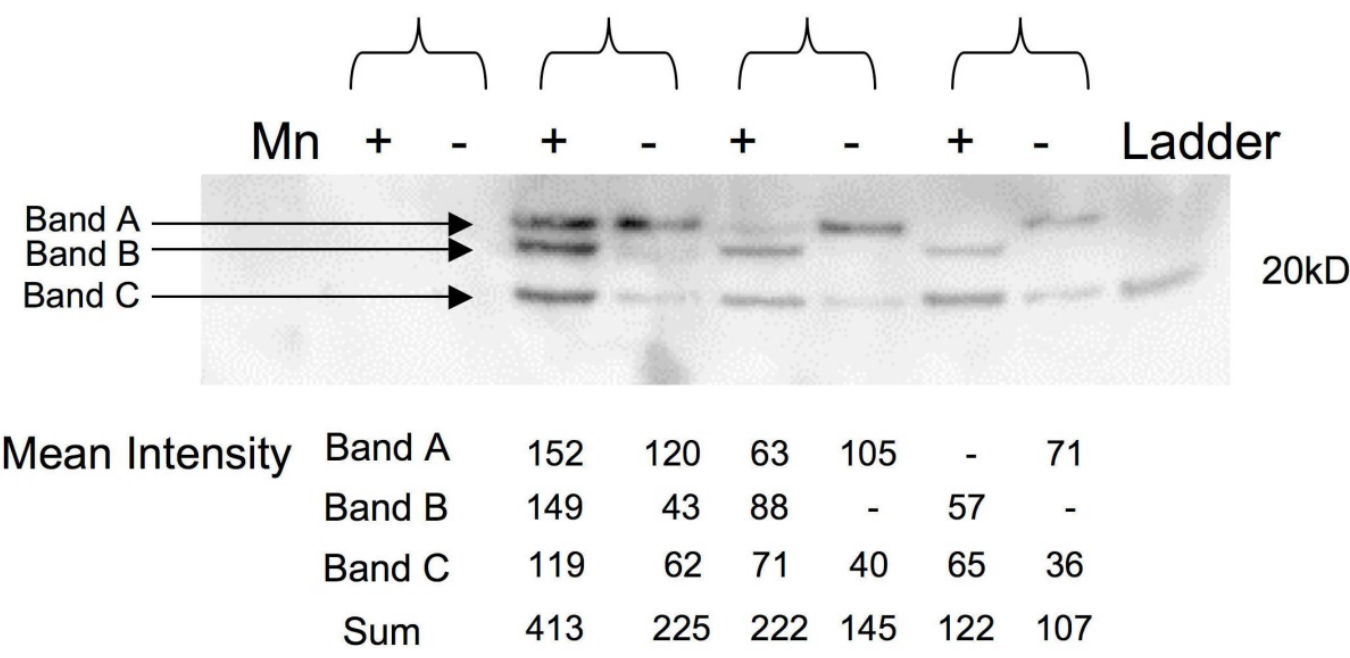

Figure 4.3. Anti-Cyclophilin Western Analysis to Identify Expression of JGI Gene Model 213198 from Cell Extracts of Filamentous (+ Mn) and Pelleted (-Mn) from A. niger Cultures 
We ran a gel in parallel with a Western analysis and excised a 5-mm band from each sample lane centered about the 20-kD line and performed in-gel tryptic digestion for LC/MS analysis. However, an $A$. niger gene deletion strain of PPIB for additional Western analysis may be required to definitively identify which band is PPIB.

Proteome analysis was also performed on affinity-purified samples produced under subtask A.1. A histidine-tagged version of the ubiquitin gene was transformed into A. niger, and proteins that were bound to ubiquitin were isolated from the cell lysate. Three replicates were performed for A. niger grown in CAP media with and without manganese added. Elution off the nickel column was done step-wise by $\mathrm{pH}$, resulting in three separate eluates per sample. Triplicate LC/MS injections were performed for a total of $54 \mathrm{LC} / \mathrm{MS}$ datasets. An overview of the analysis is presented in Table 4.3. A complete report is presented in Appendix A (attached as a word document). The analysis revealed that ubiquitin-associated proteins under the two conditions are fairly similar; the 15 proteins that were most often observed in the analysis are identical under either filamentous or pelleted growth conditions. Several 60S ribosomal proteins, an RNA helicase, actin, citrate synthase, and fructose bisphosphate aldolase were among the proteins identified most frequently. Only two proteins (each being observed three times) were identified as associated with ubiquitin and only when isolated from cells grown in CAP media. This was without added manganese (gene model numbers 124156 [transhydrogenase by blast] and 190014 [phosphate reductase involved in proline biosynthesis]). There were more than a dozen proteins (again with two or three observations) that were only observed as ubiquitin associated when isolated from cells grown in CAP media with manganese, including oxalate decarboxylase, formate dehydrogenase, and a protein required for nuclear migration within hyphae (nudE). A cell morphogenesis protein (gene model 38101) and several kinases identified in the analysis (gene model numbers 52248, 207707, 36874, 214022, and 35734) are attractive targets for additional investigations.

Table 4.3. A Summary of Identifications from Affinity-Purified Ubiquitin

\begin{tabular}{lcccc}
\hline Sample Description & $\begin{array}{c}\text { Number of } \\
\text { Datasets }\end{array}$ & $\begin{array}{c}\text { Total Number of } \\
\text { Peptides Observed }\end{array}$ & $\begin{array}{c}\text { Number of Unique } \\
\text { Peptides Observed }\end{array}$ & $\begin{array}{c}\text { Number of Unique } \\
\text { Proteins Observed }\end{array}$ \\
\hline No Mn, pH 4.5 & 9 & 389 & 81 & 42 \\
No Mn, pH 5.0 & 9 & 1547 & 225 & 119 \\
No Mn, pH 5.5 & 9 & 7483 & 1171 & 534 \\
Mn, pH 4.5 & 9 & 373 & 74 & 37 \\
Mn, pH 5.0 & 9 & 876 & 171 & 85 \\
Mn, pH 5.5 & 9 & 8874 & 1273 & 574 \\
\hline
\end{tabular}

Following are two related Laboratory Directed Research and Development (LDRD) projects:

- A multidisciplinary approach to engineer xylose and arabinose utilization for ethanol production by Saccharomyces cerevisiae.

- Identification of proteomic profiles and biomarkers in complex microbial systems absent of genomic sequence data. 


\subsection{Plans for FY2010}

We plan to:

- Provide a report on the global proteome analysis of the A. niger genetically modified strain to the parental A. niger strain for each strain

- Perform global proteomics on two genetically modified A. niger strains. 


\subsection{Major Subtask A.4a Fungal Hyperproductivity}

\subsection{Background}

The objectives of Subtask A.4a are to:

- Discover genes that are critical for various hyperproductive processes in fungi

- Develop tools and techniques with a model fungal producer of small metabolites and enzymes that can be widely applied to other hyperproductive fungal systems.

The objectives of this task are to support the overall goals of the project by providing targets for genetic engineering of fungi that will ultimately accelerate the development of novel enzyme or small molecule processes. They will also lead to improvements in current processes, including the utilization of different complex carbon feedstocks. This task is highly integrated with the others. It will rely in part on the tools and processes from Task A.2 to discover target proteins and their genes and manipulate the target organism, which will require the tools developed through Tasks A.1 and A.2. The study of the organism in authentic fermentation conditions with different nutrients, such as complex carbon sources, will use the tools from Task A.4b.

The model organism and process selected for study is A. terreus and its production of the small metabolite itaconic acid and biomass hydrolyzing enzymes. This fungus has a genome sequence available from the Broad Institute and has been the subject of a variety of past studies. The literature, however, is far less extensive than for $A$. niger. The morphology of the fungus in submerged fermentations is well behaved, though it does not exhibit the ideal pelleted morphology, so there is room for improvement. With the use of A. terreus for the "Hyperproductivity" and "Biomass to Products" tasks and A. oryzae for the "Fungal Ethanol" task, all of our tasks now use Aspergillus spp. as model organisms. This should facilitate the transfer of knowledge and genetic traits from one task and organism to another, e.g., morphology control genes from A. niger into A. terreus. The large number of functional genomics and modeling tools available for the Aspergilli also make these attractive model organisms.

The hyperproductivity of fuels, chemicals, and enzymes in fungi is a phenotype that is almost certainly associated with multiple genes. In addition to enzymes of the primary metabolic pathways leading to the production of small metabolites (fuels and chemicals) or amino acids for enzymes, other proteins likely to be important in hyperproductivity include substrate (sugar) and product transporters (Magnuson and Lasure 2004). Potentially these could be mitochondrial or plasma membrane or both types of transporters for key organic acids. Putative sugar and organic acid transporters in the A. terreus genome are being identified in silico using the genome sequence data. However, the functions of most transporters, even within a known protein family, cannot be verified based on sequence information alone. Also, we do not know all of the genes associated with increased or decreased organic acid production in fungi; therefore, discovery-based approaches will be needed to supplement rational biochemical and genomic pathway analyses.

In FY08, we prepared RNA samples from three different stages in the itaconic acid production process of $A$. terreus (before production begins, onset of production, and maximum production phase) and submitted them to JGI for cDNA preparation and EST sequencing. 


\subsection{Accomplishments and Results}

In FY09, we have made considerable progress in understanding the production of itaconic acid at the gene and transcript level and thus identifying potential genes for analysis with regard to their effect on this process. This progress was facilitated by the receipt of the A. terreus EST data from JGI. These data consisted of sequences for the cDNA derived from the mRNA for three different stages in itaconic acid production by $A$. terreus grown on a medium containing $10 \%$ glucose. The stages were as follows: 1) "pre," before itaconic acid production begins, 2) "onset," at the beginning of itaconic acid production (correlates with phosphate depletion), and 3) "production," early in the phase of maximum itaconic acid production rate (see Figure 5.1).

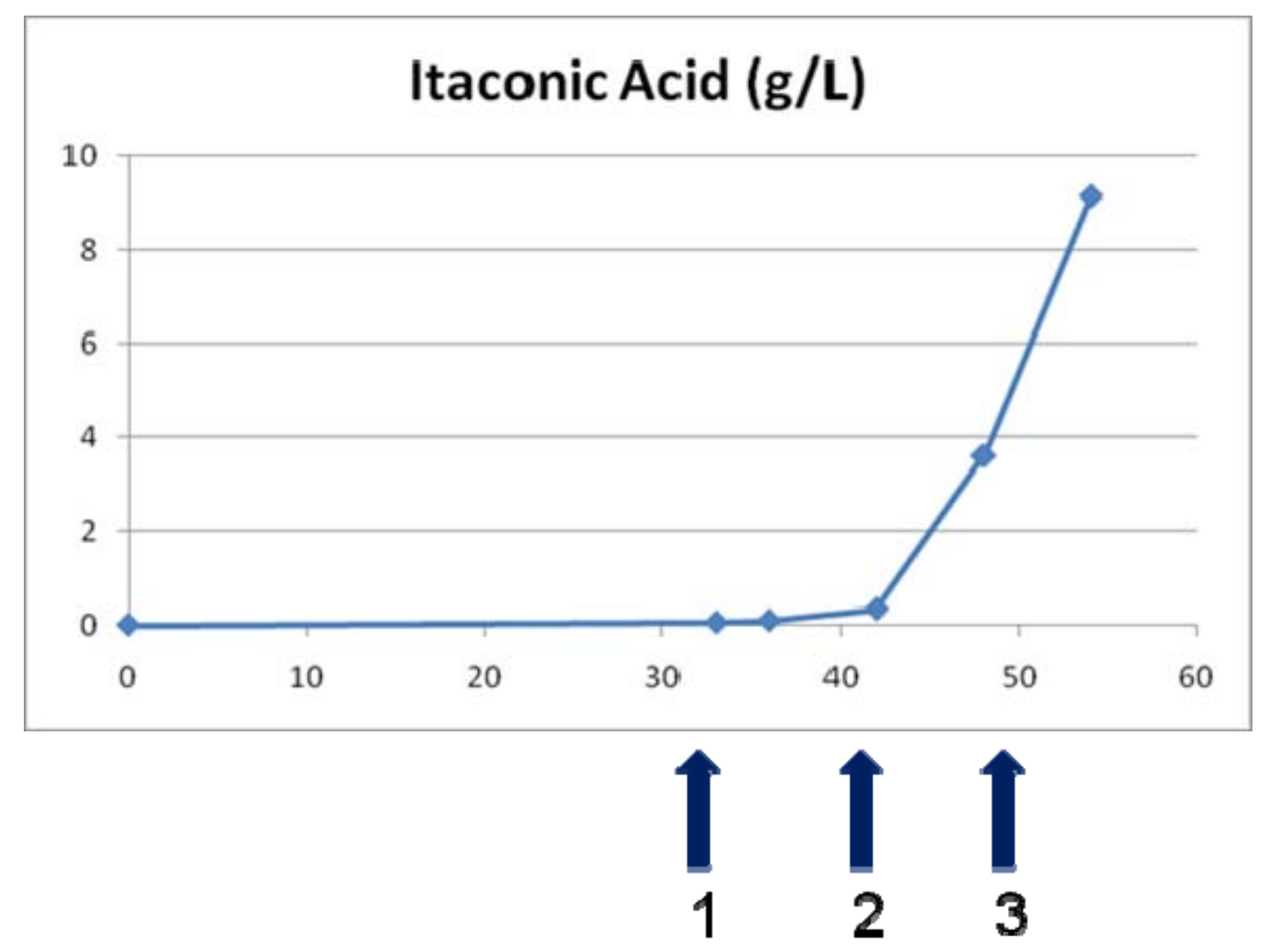

Figure 5.1. 20-L Fermentation of Glucose to Itaconic Acid by Aspergillus terreus. Samples were taken at the times indicated (arrows).

It was known from the literature that the enzyme responsible for itaconic acid production, cisaconitate decarboxylase, is induced by itaconic acid production conditions. Analyses of the data quickly revealed a transcript that appeared with high frequency (79 ESTs) in the onset phase that we identified as the cis-aconitate decarboxylase based on $100 \%$ identity to a gene that had recently been entered into GenBank. This transcript did not appear in the other two stages, indicating that it is turned on strongly at the onset of itaconic acid production and then quickly degraded, though the enzyme obviously persists throughout the production phase. The immediate identification of the cad gene eliminated the need for an activity we had planned for this year, which was a general search of the EST data for all decarboxylase genes. 
Another gene that was strongly transcribed in the onset phase was identified as having homology to a "putative mitochondrial transport protein" (YFR045W) in S. cerevisiae. We located these two genes on the Broad Institute's A. terreus genome browser, which showed that they were in a cluster immediately adjacent to the lovastatin biosynthesis cluster (see Figure 5.2). A transcription factor is located upstream of the YFR045W homolog and the cad gene, while a major facilitator superfamily (MFS) transporter is located immediately downstream of the cad gene. These four genes quickly entered our list of gene candidates for deletion to determine their effect on itaconic acid production. The transcription factor is especially exciting since this could control the putative "itaconic acid production cluster."

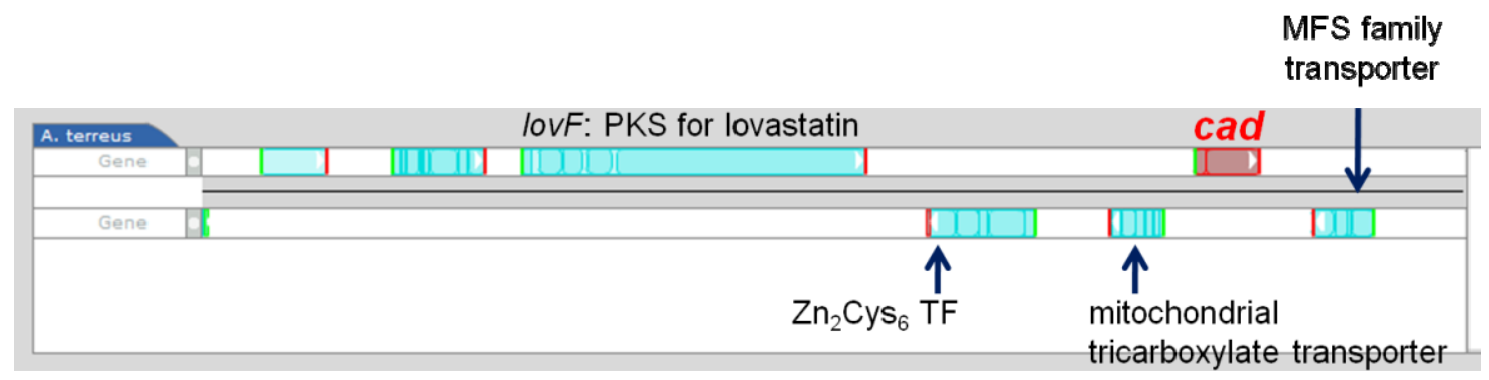

Figure 5.2. Snapshot of the Aspergillus terreus Chromosome Region Containing the Lovastatin and Itaconic Acid Gene Clusters

At the close of the last fiscal year continuing through April of 2009, we had been unable to reestablish the A. terreus transformation procedure that was lost upon the move from the main PNNL campus to Bioproducts, Sciences, and Engineering Laboratory (BSEL). At the Fungal Genetics Conference in Marc, Dr. Deng had discussions with other investigators who had previously transformed A. terreus. This led to some fresh approaches that ultimately proved successful in her hands. With the transformation system working again, we have proceeded to knock out four additional genes (through Aug 2009). The genes knocked out are as follows: phyA (phytase, deleted last year), creA (a transcription factor involved in carbon catabolite repression of many genes, including cellulases), cad, the mitochondrial transporter gene, and the transcription factor. Initial testing of these knockout mutants on itaconic acid production media in shake flasks will be done in the remainder of the fiscal year.

\subsection{Plans for FY2010}

- Continue to evaluate the EST data to generate leads for analysis by deletion and/or over-expression. Focus on transcription factors and kinases that regulate many genes or a pathway.

- Generate additional knockouts in A. terreus based on the evaluation of the EST data.

- Continue evaluation of current and new knockouts for itaconic acid production vs. wild type A. terreus in shake flasks and fermentors when appropriate.

- Express the A. terreus cis-aconitate decarboxylase gene in A. niger and evaluate the performance of this strain in shake flasks under citric acid production conditions. 


\subsection{Major Subtask A.4b Consolidated Bioprocesses}

\subsection{Background}

This task is focused on the understanding and development of single vessel bioprocesses for the conversion of complex biomass to fuels, organic acids, and enzymes. Task A.4b is concerned with developing, implementing, and optimizing fermentation processes and analytical techniques to examine the fungi developed in the other tasks with regard to morphology, productivity, and utilization of complex biomass in submerged fermentations. Specifically, this effort will investigate the conversion of complex biomass to products in fermentations using Aspergillus spp.

\subsubsection{Specific Objectives}

- Develop and implement techniques for studying fungal bioprocesses for the conversion of simple and lignocellulosic feedstocks to fuels, chemicals, and enzymes.

- Develop A. terreus and itaconic acid production as a model complex biomass to organic acid process.

- Investigate Trichoderma reesei as a model enzyme over-production organism using complex biomass.

Simplified biomass to products approaches have been called "simultaneous saccharification and fermentation" (SSF), "consolidated bioprocessing," and "direct microbial conversion." All of these terms describe a single vessel fermentation in which an organism grows on the complex biomass, produces the enzymes to hydrolyze the biomass to sugars, and uses the sugars to make products. The concept is appealing in that it requires fewer handling steps and less capital equipment, therefore making it potentially more economical. It is a simple concept but difficult to execute. It requires organisms capable of producing the correct suite of enzymes to degrade a particular lignocellulosic feedstock at sufficient quantities to perform the saccharification in a timely manner and preferably simultaneously (or sequentially) convert all of the hexose and pentose sugars to fuels, chemicals, or other products. The fungal kingdom is an ideal realm from which to recruit such organisms.

Given the challenges facing the implementation of simplified bioprocesses, it is important when examining particular aspects of a bioprocess that the entire process be considered as the framework for study. The overall bioprocess variables are included in the following steps: complex biomass pretreatment, fungal organism preparation, fungal bioprocessing, and product recovery. In this program, we are focused on fungal bioprocessing, but the other key variables are still integral to the thought progression in studying the complete biomass to products process.

\subsection{Accomplishments and Results}

We have performed replicate fermentations with A. terreus using glucose or xylose as the substrates to produce itaconic acid, and the results verify that fermentations with both carbon sources reach relatively high titers and are reproducible, although the rate is lower with xylose versus glucose. Itaconic acid was produced using enzymatically hydrolyzed ground corn (i.e., starch to glucose). Baseline runs with wet distillers grains (WDG) as the sole carbon source were performed. This material has little 
residual starch, just cellulose, arabinoxylan, and protein. As expected, no itaconic acid was detected, but the baseline case was important to establish. Detecting small amounts of sugars (glucose, xylose, and arabinose) that indicated that the structural polysaccharides were being degraded suggests that the fungus can use the biomass, but not produce sufficient sugar to support itaconic acid production. These runs were not supplemented with free sugars nor were any pre-treatments performed. We learned the challenges to be expected when handling high concentrations of particulate biomass. With the recovery of the transformation method for A. terreus, we were able to generate a creA deletion strain, which will be evaluated next FY.

Baseline runs of Trichoderma reesei QM6a (wild type) and RutC30 (over-production mutant) using glucose or cellulose with a small amount of glucose as carbon sources were performed. Key indicator biomass hydrolyzing enzyme activities were assayed to examine the variations between the strains. An example run is shown in Figure 6.1. A recent paper comparing the two strains of T. reesei indicates the multiple genetic differences between the strains. The numerous changes in T. reesei RutC30 are not surprising since this strain was derived in the traditional manner using multiple rounds of mutagenesis. As a start towards developing a genetically well defined enzyme production strain, we have knocked out one of the key genes, creA, previously identified as being critical to over-production of glycoside hydrolases in RutC30.

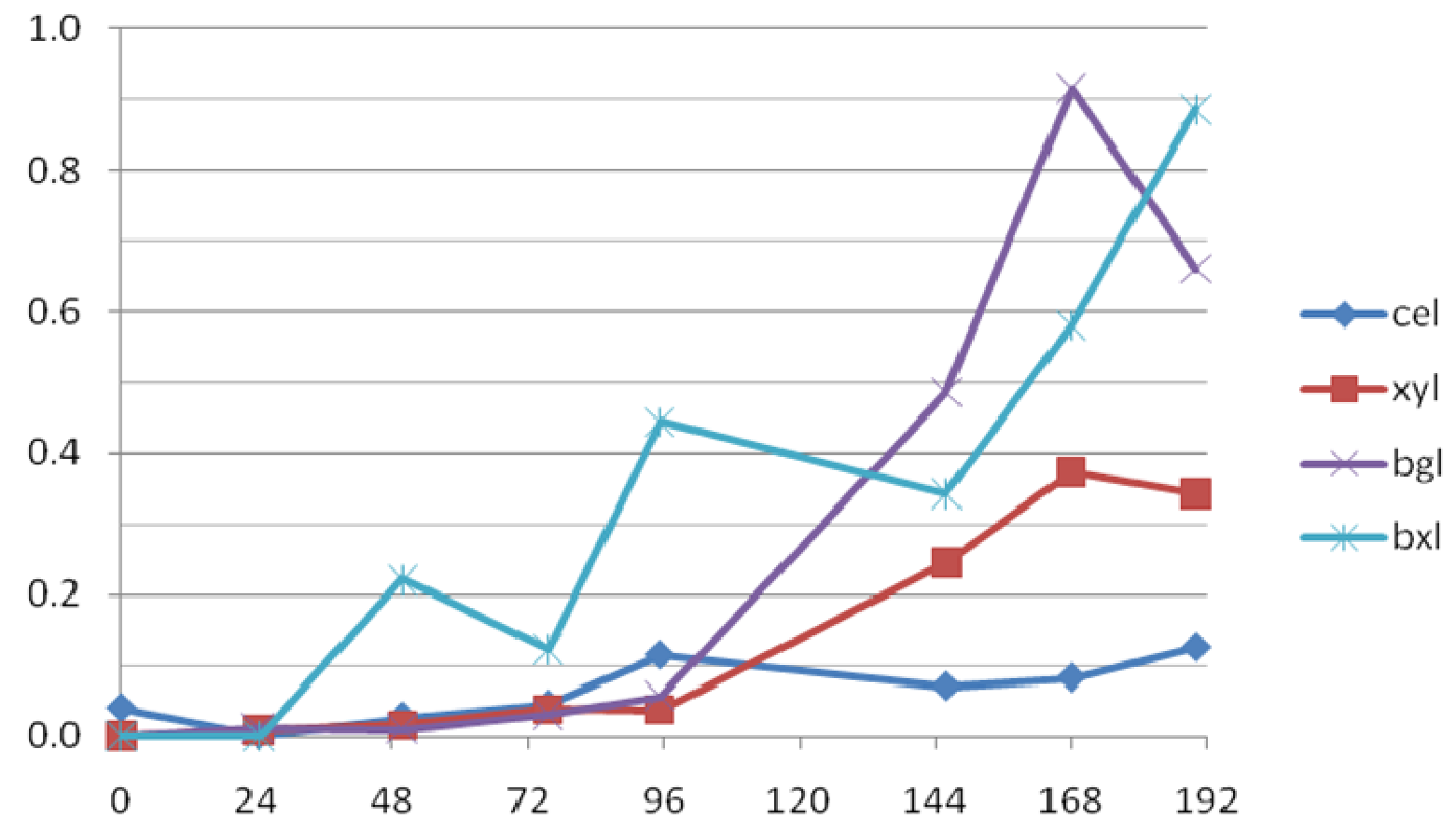

Figure 6.1. Enzyme activities in Trichoderma reesei QM6a Grown on Cellulose

Trichoderma reesei was grown in $10 \mathrm{~L}$ of chemically defined medium containing $2 \%$ cellulose and $1 \%$ glucose at $\mathrm{pH} 5.5,30^{\circ} \mathrm{C}$. Aliquots of the cleared media were assayed for cellulase (cel, endoglucanase), xylanase (xyl), $\beta$-glucosidase (bgl), and $\beta$-xylosidase (bxl). The $x$-axis shows time in hours after inoculation of the media with spores of $T$. reesei $\left(5 \times 10^{5}\right.$ per $\left.\mathrm{mL}\right)$ while the $y$-axis shows absorbance units (relative enzyme activity). The dissolved oxygen (DO) concentration declined rapidly 
and then rose as glucose was depleted. DO began to decline again at 48 hours, and enzyme activities were observed to rise at this time point or later as the fungus was challenged with growing on cellulose.

\subsection{Plans for FY2010}

- Examine the creA deletion strain of A. terreus on complex biomass, with or without pre-treatment, in shake flasks and fermentors. Analyses will include itaconic acid production and enzyme activities.

- Examine the creA deletion strain of T. reesei on complex biomass, with or without pre-treatment, in shake flasks and fermentors. Analyses will focus on enzyme activities. The wild-type strain QM6a will serve as the control. 


\subsection{Major Subtask A.5 Alternative Fungal Ethanologen Characterization and Metabolic Model Analysis}

\subsection{Background}

Like yeast, filamentous fungi possess the ability to produce ethanol when grown in low oxygen/ anaerobic culture conditions. However, in contrast to yeast, filamentous fungi are able to degrade lignocellulosic biomass, including cellulose and hemicellulose, as well as efficiently use xylose and other pentose sugars. Thus, filamentous fungi represent a direct path from biomass to ethanol, minimizing expensive pretreatment processes.

Despite their positive characteristics and perhaps due to their inherent biological complexity compared with yeast or bacteria, filamentous fungi have only been explored as ethanol production organisms in a limited way. This subtask focuses on the characterization and optimization of filamentous fungal ethanol production from both simple sugars and directly from lignocellulosic biomass. The primary objectives of this research are to gain a fundamental understanding of filamentous fungal ethanol production processes and to discover and evaluate the potential for fungal ethanol production. While the development of an industrial strain is not the objective of this subtask, it is expected that the ethanologen discovery and improvement efforts of this research will lead to 1) a strain that clearly demonstrates that there is industrial potential for filamentous fungal ethanol production and 2) tools that industry can apply to the development of efficacious industrial filamentous fungal ethanol processes.

For FY09, we planned to:

- Validate select metabolic models and apply models to Aspergillus oryzae ethanol fermentations and begin Constraint-Based Reconstruction and Analysis (COBRA) analysis of A. oryzae.

- Develop a high-throughput screening method to rapidly identify highly productive filamentous fungal ethanologens with the deliverable being a test or tests for screening fungi for ethanol production adaptable to 96-well format or a similar medium throughput format.

- Identify individual genes that improve ethanol production in filamentous fungi using genome-wide gene knock-out and overexpression methods and apply them to the model strain.

- Order materials for genetic analysis of candidate ethanol production genes.

Our accomplishments and results for FY09 and our plans for FY10 are reported in the sections that follow.

\subsection{Accomplishments and Results}

\subsubsection{Metabolic Modeling}

In FY09, we developed capabilities to perform flux balance analysis (FBA) (Rocha et al. 2008) to computationally simulate the fluxes of substrates and metabolites through all known chemical reaction and transport pathways that comprise the metabolic network of $A$. oryzae. FBA was successfully applied to a genome-scale stoichiometric network model for $A$. orzyae to predict expected changes in ethanol 
output as a function of decreasing levels of available oxygen. The WV1314 model used in this work had been published in early 2009 by our collaborators at Chalmers University, but in a proprietary format compatible only with their unpublished, in-house software (Vongsangnak et al. 2008). With their assistance, we converted this model to a System Biology Markup Language (SBML) format (Finney and Hucka 2003) that is compatible with open-source FBA software. Our creation of a valid SBML version of the WV1314 A. oryzae model should enable us to perform genome-wide simulations of gene deletions to support the genetic engineering of an effective filamentous fungal ethanologen in FY10. Moreover, our conversion of the model to an open-source format will enable others to more easily replicate our results and facilitate collaborative efforts to improve the ethanol production capabilities of $A$. oryzae.

The FBA simulations described above were performed with the open-source COBRA Toolbox (Becker et al. 2007) and the SBML Toolbox (Keating et al. 2006) suites of MATLAB functions. The software models the stoichiometry of all known metabolic transport and reaction pathways within a cellular system or subsystem as a system of linear equations. The units of the fluxes through the pathways are given as millimoles per gram of cellular biomass (dry weight)/per hour. The metabolism of the cell in FBA is assumed to be in a steady state such that the mass fluxes are balanced and sum to zero. One reaction pathway is then assigned to be the objective function of the cell. In FBA simulations of cellular metabolism, the objective function is typically assumed to be the maximization of cellular growth, or, more explicitly, the maximal production of the molecules required to make new cells (Becker et al. 2007).

In performing a particular simulation of metabolism using FBA, one or more transport or reaction fluxes are constrained with upper and lower bounds. The fluxes may also be constrained to be reversible or irreversible, or, in other words, bidirectional on unidirectional within a given metabolic pathway. A linear programming solver is then used to predict the optimal combination of specific fluxes through all pathways that, together, maximize the flux objective function pathway. In this way, FBA methods draw heavily from the field of operations research where problems such as the optimization of airline schedules, delivery routes, or factory outputs are commonplace.

To validate our SBML-formatted version of the WV1314 model for A. oryzae, we used the COBRA Toolbox to constrain the glucose uptake flux to 1.2 and the ATP maintenance flux to 1.9. Ammonia, phosphate, and sulfate uptake fluxes were left unconstrained, as were all intracellular and export fluxes. The objective function was defined as maximal growth of cell biomass. Under these conditions, the COBRA Toolbox predicted an optimized growth rate of $0.0993 \mathrm{mmol} / \mathrm{g}$ dry weight/hour. A visiting graduate student from the Nielsen group (our collaborators at Chalmers) performed an identical simulation using the proprietary BioOpt software and file format in which the WV1314 model had been originally produced; this resulted in a predicted growth rate of $0.0980 \mathrm{mmol} / \mathrm{g} \mathrm{DW} /$ hour. The close similarity of these values indicated that our conversion of the WV1314 metabolic network model to valid SBML had been successful. The work of converting the model to a form of SBML compatible with the COBRA Toolbox was challenging and time-consuming,partly because the network contains 729 enzymes, 1314 enzyme-encoding genes, 1073 metabolites, and 1846 biochemical reactions. Moreover, the COBRA Toolbox software was found to contain undocumented requirements for naming metabolites that lie outside the SBML specification (Finney et al. 2003). This made troubleshooting the conversion process difficult and delayed our progress until the problem was discovered.

Using the constraints described in the previous paragraph, we examined the relationship between ethanol output and oxygen uptake in A. oryzae. Fermentative ethanol production in fungi is well-known 
to require microaerobic, but not completely anaerobic, conditions. To our knowledge, however, the exact oxygen uptake fluxes required for optimal ethanol production by A. oryzae have not been defined. We therefore used FBA (using parameters described in the preceding paragraph) to simulate how gradually constraining its oxygen uptake flux may change its predicted ethanol output flux. We also tracked the changes in predicted growth rate for A. oryzae when oxygen uptake flux is constrained over identical intervals. Our results indicated that optimal ethanol output occurs within a range of oxygen uptake flux of about 0.1 to $0.01 \mathrm{mmol} / \mathrm{g} \mathrm{DW} /$ hour (Figure 7.1, left chart). Interestingly, the change in growth rate (Figure 7.1, right chart) appears to plateau across nearly the same range of oxygen uptake flux as that seen for optimal ethanol output flux. The results of the FBA simulation indicated that ethanol output from our fermentation experiments with $A$. oryzae might be easily improved by more closely controlling aeration levels in the fermentation vessels. Moreover, our reasonable results in simulating ethanol production in A. oryzae suggest that our FBA software and model are working in a logical manner and should serve us well in FY10 as we move on to performing genome-wide simulations of gene knock-out and overexpression within the COBRA Toolbox to support genetic engineering efforts in this and other tasks of our project.
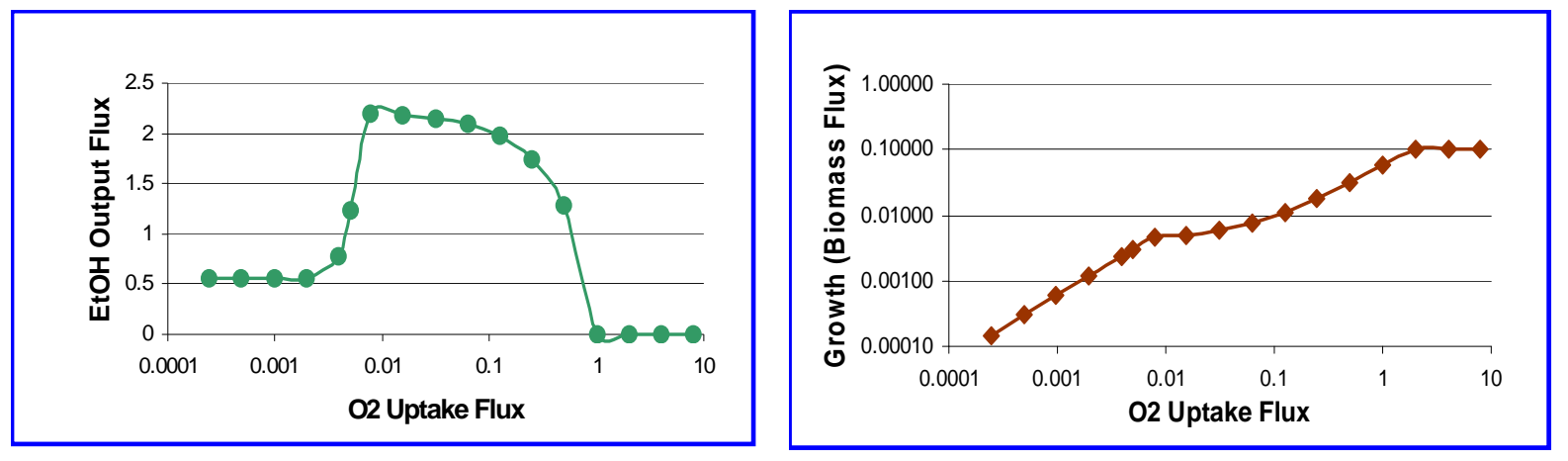

Figure 7.1. (Left chart) Ethanol Output Flux Changes Predicted from FBA of A. Oryzae Cellular Metabolism as a Function of Oxygen Uptake Flux. (Right chart) Biomass growth rate changes predicted by FBA of $A$. oryzae cellular metabolism as a function of oxygen uptake flux. Growth is defined as the rate of intracellular accumulation of biomass molecules. The units on both axes of both charts are given as millimoles per gram of cell dry weight per hour.

\subsubsection{Fermentation}

\subsubsection{Strain Development}

The effort towards Aspergillus oryzae transformation and strain development was continued. The first attempts at genetic modifications for improved ethanol production were completed and applied to fermentations. We verified the utility of our previously developed gene knockout system for A. oryzae by generating mutants of two genes, creA and alcR, that are potentially involved in conversion of xylose to ethanol. Homologous recombination was used to substitute the pyrG gene for the coding regions of the A. oryzae genes for 1) creA, mutation of which may prevent repression of a number of genes involved in xylose catabolism and 2) alcR, mutation of which prevents interconversion to acetaldehyde and ethanol by alcohol dehydrogenase. 
Although we successfully demonstrated our ability to produce knockout mutants in A. oryzae using the creA and alcR genes as model targets, based on the observation that neither of these genes resulted in significant improvement in conversion of simple sugars to ethanol (described below), plans for generation of a creA/alcR double mutant were abandoned.

To expand our mutant generation capabilities for A. oryzae strain improvements, a method was developed to allow knockouts of multiple genes in a single strain using a recyclable selection marker. This method involved construction of a pyrG selection cassette plasmid flanked by direct repeats. Unique sequences at the ends of the cassette allow construction of knockout constructs for any gene in the A. oryzae genome. Once a gene has been replaced by the pyrG selection cassette, the selection cassette can be removed with recombination between the flanking direct repeats and re-selection for pyrimidine auxotrophy.

Various approaches directed towards alleviating or bypassing the apparent redox imbalance in conversion of xylose to ethanol (as indicated by xylitol accumulation) were investigated for feasibility. Progress on these approaches has included:

- Identification of a xylose isomerase gene from the rumen fungus Orpinomyces that could be used to bypass the redox reaction steps in converting xylose to xylulose. To introduce a xylose isomerase gene into A. oryzae, a gene encoding the xylose isomerase from Orpinomyces was synthesized using the codon preference table for Aspergillus. The expression of this gene is driven by the constitutive A. nidulans gapdh promoter and will be introduced into the $A$. oryzae genome by random integration of a zeocin or pyrG selectable plasmid.

- Primers for producing single and double knockout mutants of the native xylose reductase and xylitol dehydrogenase genes were designed and ordered and will be used in conjunction with the recyclable selection marker system described above when it is completed.

- As an alternative approach to alleviate the apparent redox imbalance resulting from the different cofactor preferences of the native A. oryzae xylose reductase and/or xylitol dehydrogenase enzymes, a strategy to modify the $\mathrm{NAD}(\mathrm{P}) \mathrm{H}$ cofactor preferences of these enzymes has been developed based on molecular models of the $\mathrm{NAD}(\mathrm{P}) \mathrm{H}$ binding sites in several $\mathrm{NAD}(\mathrm{P}) \mathrm{H}$ requiring enzymes. The regions of the native $A$. oryzae xylose reductase and xylitol dehydrogenase enzymes involved in cofactor binding have been identified based on sequence similarity, and an approach to modify these sites has been designed.

In addition, other potentially problematic side reactions (e.g., ribitol and xylitol formation by nonspecific aldose reductases, acetate and lactate formation pathways) that are being identified using metabolic modeling. Strategies to block these side reactions by knockout mutagenesis are also being developed.

\subsubsection{High-Throughput Screening Method Development}

An effort to develop a high-throughput screening method to rapidly identify highly productive fungal ethanologens was initiated. Preliminary investigation of methods to identify individual variants with improved ethanol productivity from a large population was made. An in vitro method to detect ethanol production using ethanol oxidase was investigated and found to be useful for moderately high-throughput 96-well arrayed library assays. However, the alcohol oxidase enzyme was not sufficiently stable for use in very high-throughput plate assays. 
Microtiter plate-based assays allow screening of several thousand variants, but these variants must first be picked and arrayed into the 96 well format. In contrast, culture plate-based assays do not require picking and arraying and can therefore be adapted to screen hundreds of thousands of genetic variants, greatly increasing the chances of finding useful mutations. To develop a very high throughput culture plate bioassay to screen for improved ethanol production by filamentous fungi, five ethanol-responsive promoters from the E. coli genes dnaK, grpE, katG, pgaA, and uspA were fused with the reporter gene LacZ-alpha in a pBS KS (+) plasmid background, sequenced and transformed into E. coli (Figure 7.2).

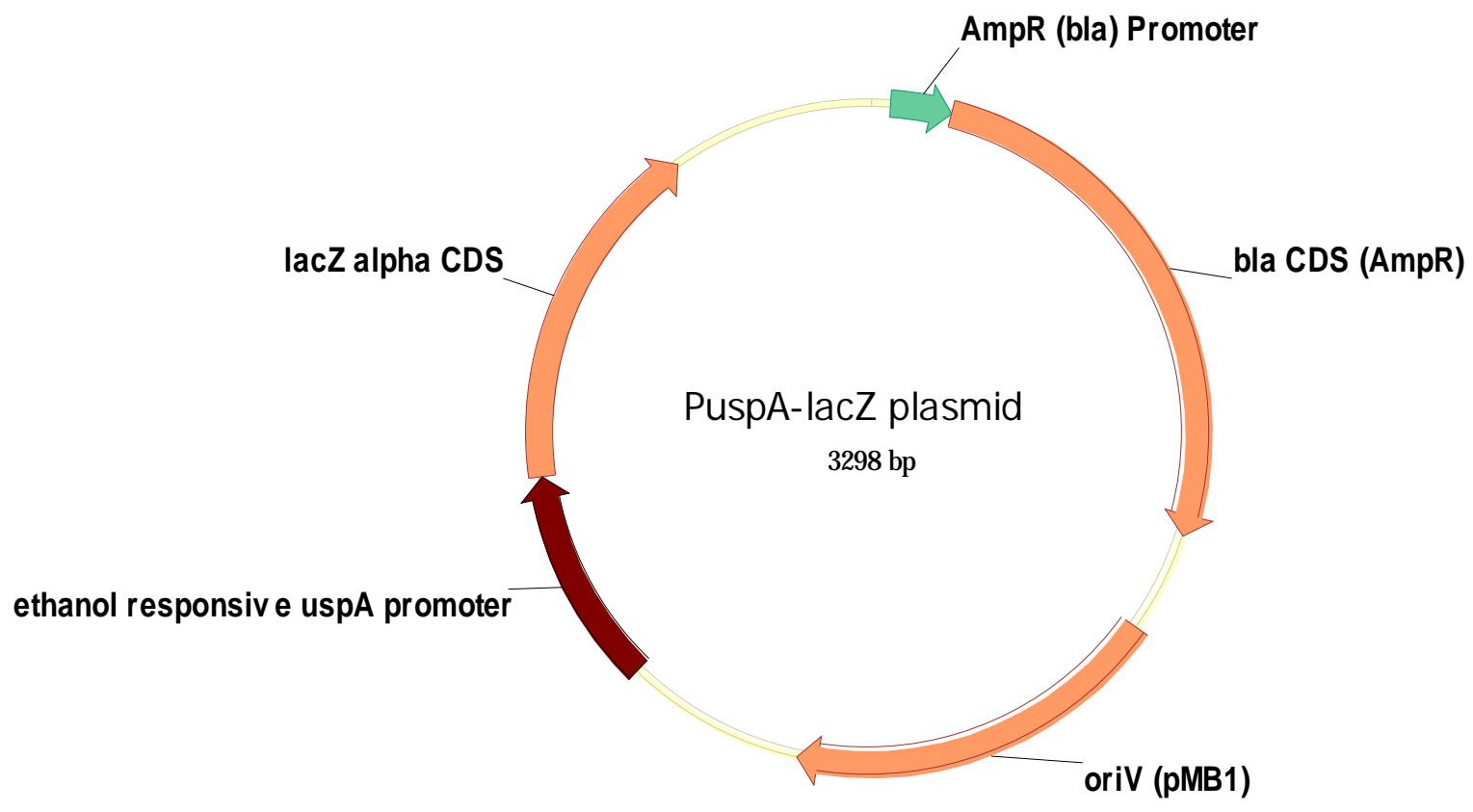

Figure 7.2. Ethanol Responsive Promoters from the E. coli Genes dnaK, grpE, katG, pgaA, and uspA Fused with Reporter Gene LacZ-Alpha in a pBS KS (+) Plasmid Background, Sequenced and Transformed into E. Coli

The resulting E. coli strains were tested for lacZ expression in response to ethanol under bioassay plate conditions. All were responsive to ethanol at $2 \%$ to some degree, but the response was most evident with the grpE-lacZ and uspA-lacZ. However, these promoters also showed a fairly high level of background expression at stationary phase in the absence of ethanol. We then tested the ethanol gradient responsiveness of this bacterial bioassay. The expected result was the development of larger zones of lacZ expression around higher concentrations of ethanol. At lower concentrations of ethanol $(<3 \%)$, this appeared to be true, but at ethanol concentrations above 3\%, there was no evidence of expression with any of these promoters. Control experiments with the constitutive lacZ promoter driving expression of lacZ demonstrated expression at ethanol concentrations up to $\sim 5 \%$, indicating that lacZ is active at higher ethanol concentrations. Three of the promoter constructs, (dnaK-lacZ, katG-lacZ, and uspA-lacZ) showed expression of lacZ at stationary phase in the absence of ethanol, but this stationary phase expression was completely repressed at $3 \%$ ethanol.

A further finding was that growth of the E. coli host strain was uniform up to $3 \%$ ethanol, but was completely inhibited at $6 \%$ ethanol. This led to the conclusion that this system may still be viable as a bioassay for ethanol, although not in the way that was originally envisioned. The bioassay as currently 
envisioned will use 1) activation of lacZ expression in exponentially growing cells up to $2 \%$ ethanol, 2) repression of lacZ repression of lacZ expression at stationary phase for ethanol concentrations up to $5 \%$, and 3) growth repression of the E. coli host above 5\%. The uspA-lacZ construct was judged to be the most efficacious for this purpose, and further tests are being performed with this construct.

In the event that the bioassay continues to prove useful, a strategy for replacing the lacZ reporter in the uspA-lacZ construct with the fluorescent egfp reporter was developed, and the primers to accomplish this were designed. This substitution will increase the speed and sensitivity of this assay and eliminate the need for the expensive lacZ.

Although the plate-based bioassay system still appears to have potential, concerns about the dynamic range of this assay and variability in response prompted us to continue development of a moderate throughput assay for ethanol production using an alcohol oxidase-based detection system. Results indicate that this system can easily be adapted to the 96 well format.

To generate the mutant population of $A$. oryzae that can be screened for mutations affecting ethanol production using the above methods, an Agrobacterium-based mutagenesis system is being developed. A T-DNA vector for fungal transformation was developed in-house from the plant transformation vector pBIN101. This vector is being further modified to use the pyrG selection system required for use in A. oryzae. We are currently developing a generally useful T-DNA vector for concomitant generation of an insertional knockout mutant library and an expressional trapping library. This approach uses a T-DNA region that contains the $A$. fumigatus pyrG gene to allow T-DNA integration events to be selected and also contains an outwardly directed $A$. nidulans gapd promoter adjacent to the right T-DNA border. Using this system, T-DNA insertions within coding sequences, or those disrupting native promoters, will yield loss of function mutants while insertions that place the T-DNA-derived gapdh promoter upstream of a coding sequence will result in constitutive overexpression of that gene. This will allow us to capture both null and over-expression phenotypes in a single library. Established protocols for Agrobacterium transformations were obtained from the literature and have been demonstrated to be functional in our laboratory.

\subsubsection{Fermentation Results}

Fermentation work initiated in FY08 continued in FY09 in support of the ethanologen development effort. Fermentations were conducted at $0.1,0.5$, and 20-liter working volumes to establish ethanol production baseline values for glucose, xylose, and glucose/xylose mix media and to discover experimental conditions that would decrease variability in the fermentation data so that valid evaluations of strain modifications would be possible. It was discovered that increasing the level of inoculation decreased data variability considerably. Increasing vent size from 1/16 in. ID to 3/16 in. ID on 250-mL flasks was found to increase ethanol production levels. These experimental conditions were applied to fermentations to establish new baselines for ethanol production and to compare the A. oryzae NRRL 697 parental strain to our newly generated creA and alcR mutants. Experiments showed that the two mutants produce slightly less ethanol than the parent strain. On 12\% glucose medium, the alcR mutant and creA mutants produced $1.6 \%$ and $7.6 \%$ less ethanol, respectively, than the parent strain (Figure 7.3). 


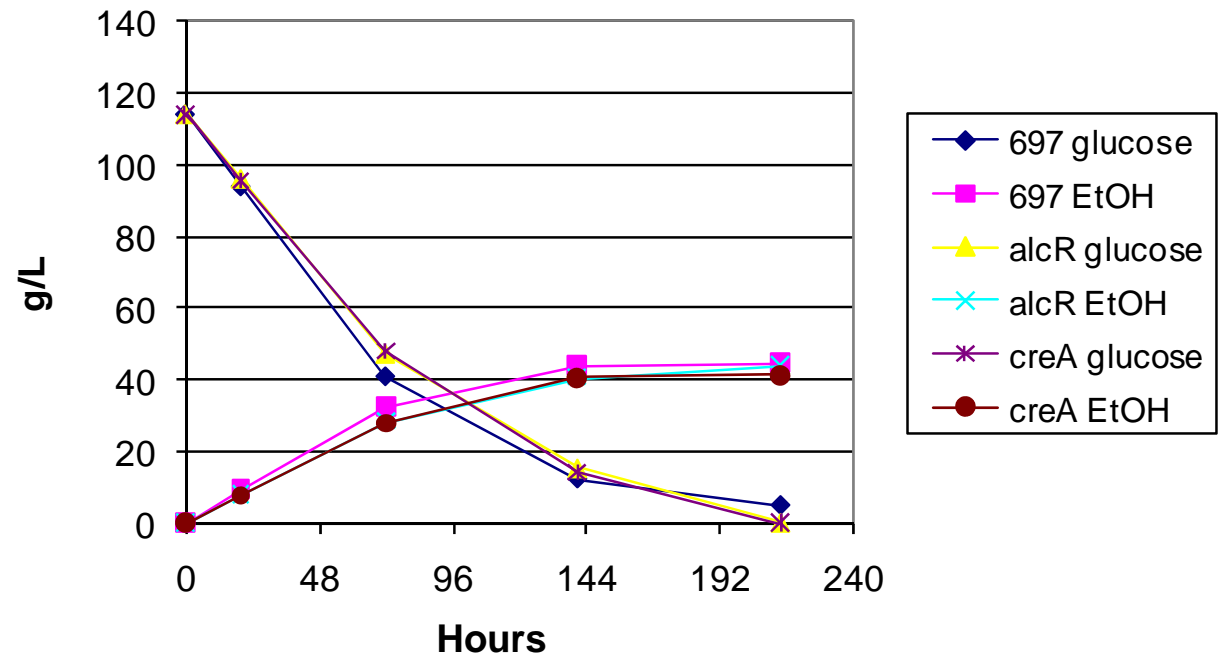

Figure 7.3. Exp 40, A. oryzae NRRL 697, alcR and creA Mutants Ethanol Production on 12\% Glucose Minimal Medium Enriched with $0.5 \%$ Yeast Extract (averages for nine replicates)

On $12 \%$ xylose medium, the alcR and creA mutants produced $3.2 \%$ and $10.1 \%$ less ethanol, respectively, than the parent strain (Figure 7.4).

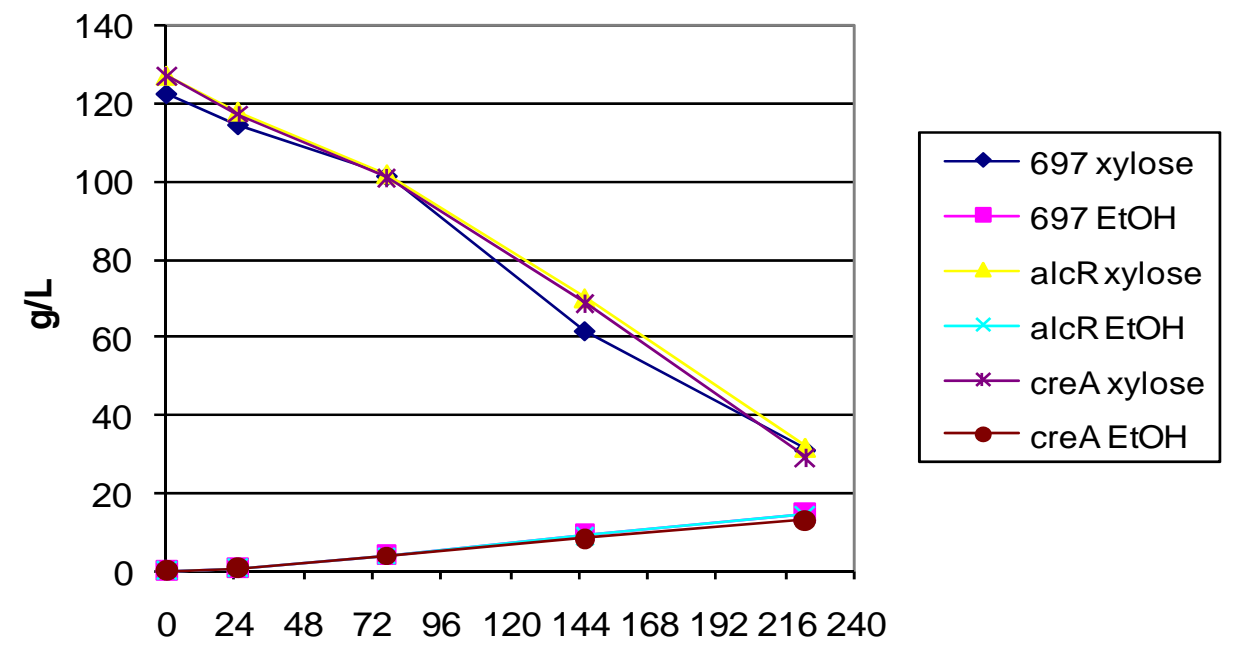

Hours

Figure 7.4. Exp 42, A. oryzae NRRL 697, alcR and creA Mutants Comparison for Ethanol Production on $12 \%$ Xylose Minimal Medium Enriched with $0.5 \%$ Yeast Extract (averages for nine replicates)

Neither of these strain modifications enhanced ethanol production. To provide scale-up data, $20-\mathrm{L}$ working volume fermentations in 30-L fermentors were completed to establish baseline values for ethanol titers and production rates on glucose, xylose, or glucose/xylose media using the A. oryzae model strain. Ethanol titer of $3.9 \%$ was achieved in 4 days from $12 \%$ glucose minimal medium enriched with 
$0.5 \%$ yeast extract when using an initial spore titer of $5 \times 10^{5}$ spores $/ \mathrm{mL}$. Applying what was learned in the flask experiments about inoculation levels to the fermentor, we conducted an experiment using the much higher spore titer of $2 \times 10^{7}$ spores $/ \mathrm{mL}$ and achieved a similar ethanol titer of $3.85 \%$ in only 3 days (Figure 7.5).

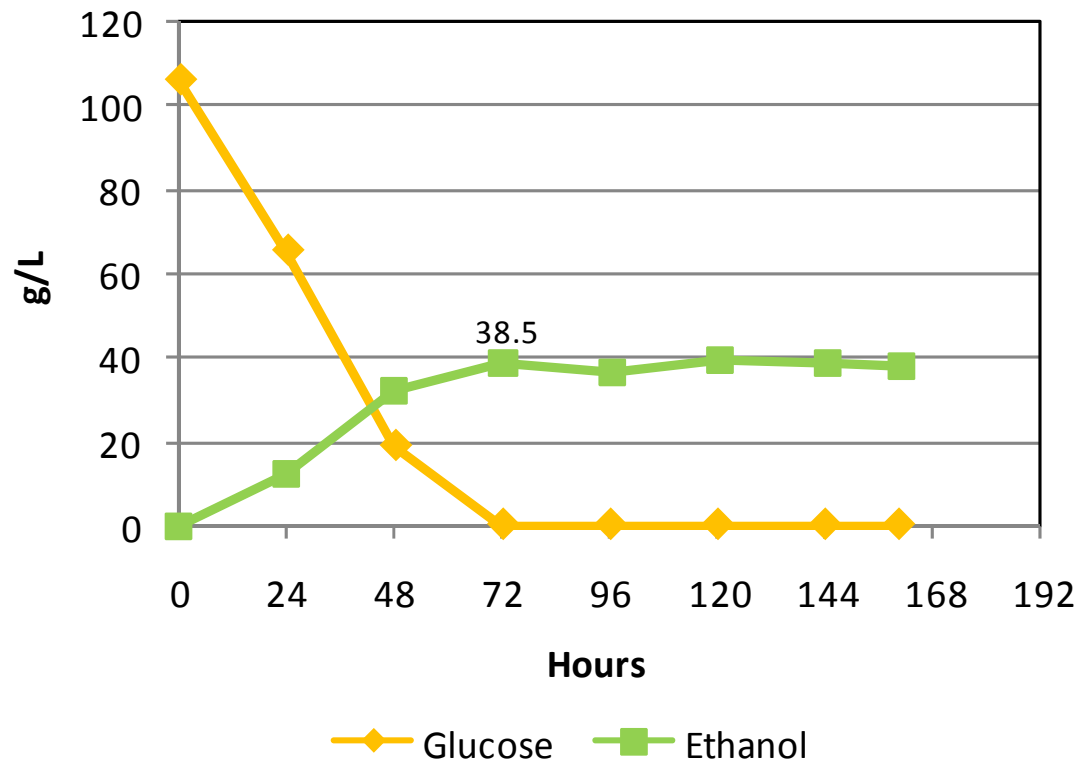

Figure 7.5. Exp 51, Aspergillus oryzae NRRL 697 Model Strain Ethanol Production on 12\% Glucose Minimal Medium Enriched with 0.5\% Yeast Extract, 20-Liter Working Volume, and $2 \times 10^{7}$ Spores $/ \mathrm{mL}$

When xylose was used as the carbon source in the fermentor, an ethanol titer of $5.9 \mathrm{~g} / \mathrm{L}$ was achieved in 9 days from an initial spore titer of $5 \times 10^{5}$ spores $/ \mathrm{mL}$. When the initial spore titer was increased to $2 \times 10^{7}$ spores $/ \mathrm{mL}$, an ethanol titer of $9.96 \mathrm{~g} / \mathrm{L}$ was reached in 8 days (Figure 7.6). Xylitol reached $39.6 \mathrm{~g} / \mathrm{L}$ by Day 7 (Figure 7.6) and gradually declined to $0.91 \mathrm{~g} / \mathrm{L}$ by Day 24 (not shown). 


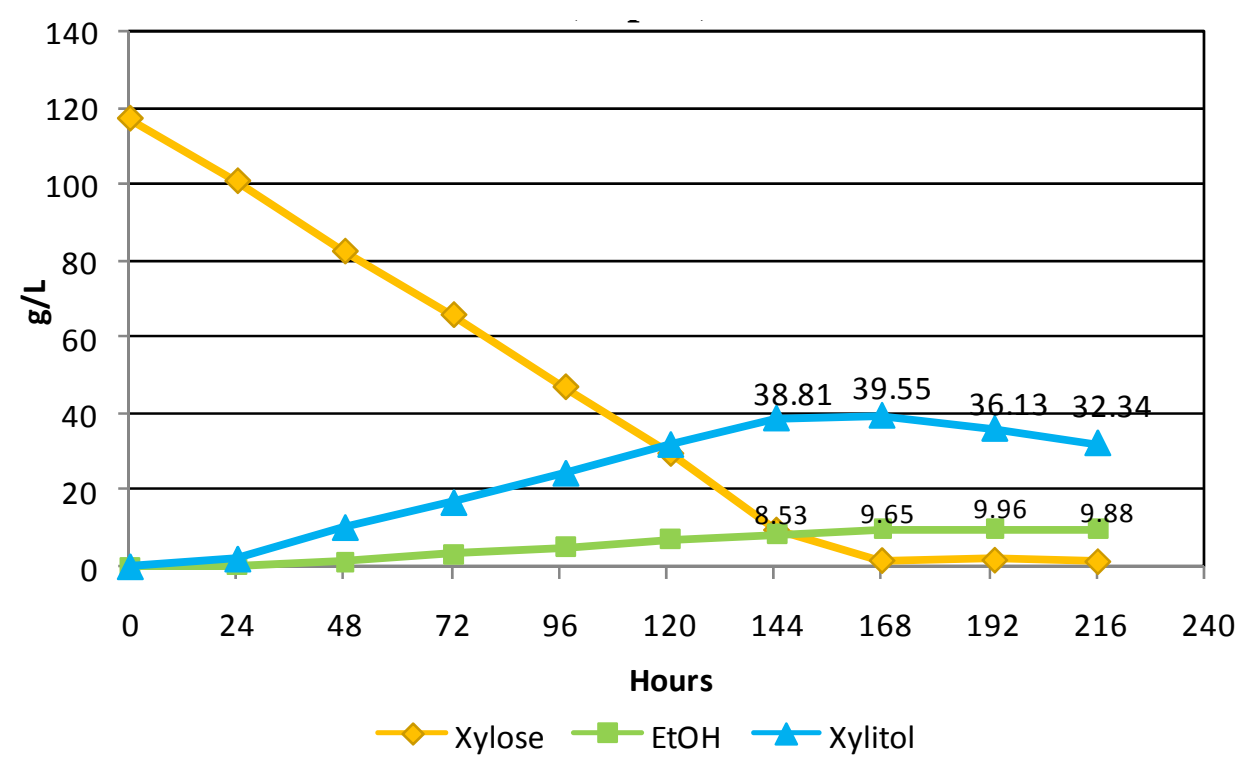

Figure 7.6. Exp 49, A. oryzae NRRL 697 Model Strain on Ethanol Production on 12\% Glucose Minimal Medium Enriched with $0.5 \%$ Yeast Extract, 20-Liter Working Volume, and $2 \times 10^{7}$ Spores $/ \mathrm{mL}$

Avoiding the formation of significant amounts of xylitol or quickly converting what is formed to ethanol is key to developing an effective $A$. oryzae based ethanologen for the conversion of xylose. To provide additional background information for our strain modification effort, a flask experiment using five replicate $250-\mathrm{mL}$ flasks containing $100 \mathrm{~mL}$ of working volume was conducted. The medium was $40 \mathrm{~g} / \mathrm{L}$ xylitol minimal medium enriched with $0.5 \%$ yeast extract. With xylitol as the primary carbon source, the $40 \mathrm{~g} / \mathrm{L}$ xylitol was converted by Day 12 (Figure 7.7). Only at or below detection limit concentrations of acetic acid and ethanol were detected by high-performance liquid chromatography (HPLC) analysis. Nuclear magnetic resonance (NMR) analysis indicated that formate, pyruvate, and succinate were also present, but further analysis is required to quantify these co-products. 


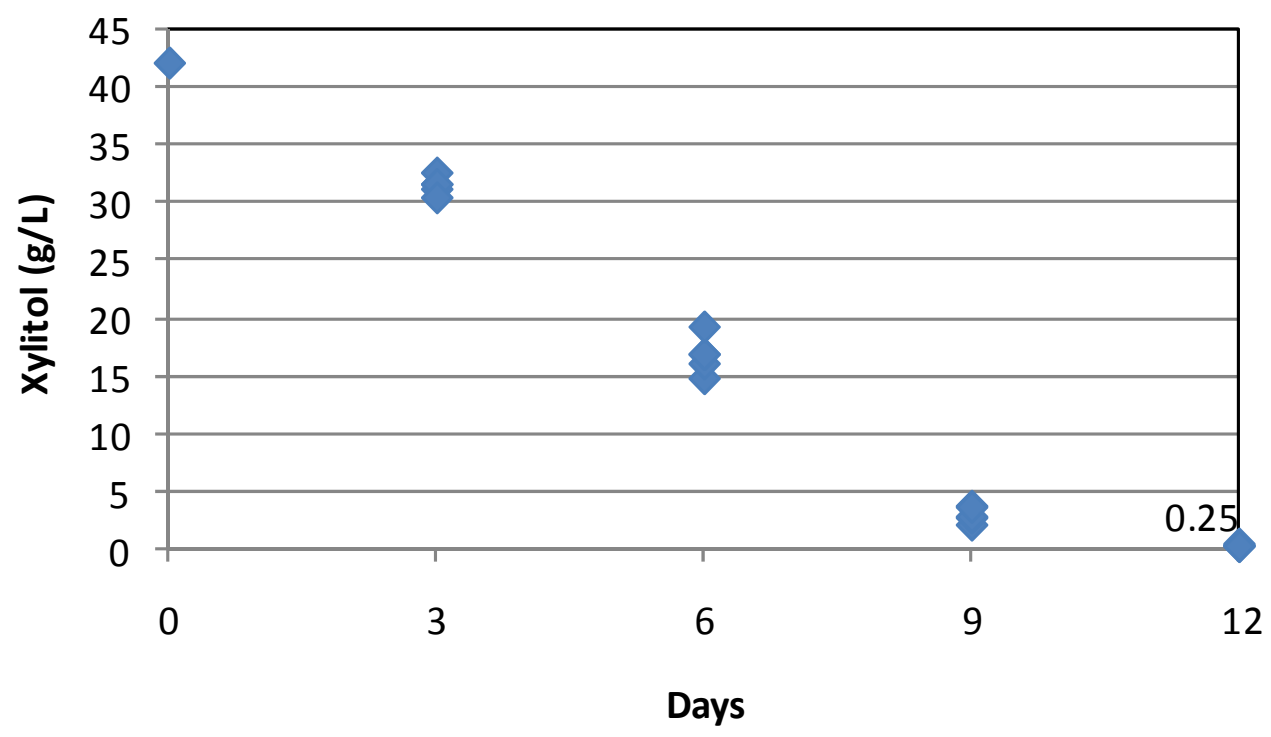

Figure 7.7. Exp 46, Xylitol Remaining from A. oryzae NRRL 697 Model Strain on 4\% Xylitol Minimal Medium Enriched with $0.5 \%$ Yeast Extract, $250-\mathrm{mL}$ flasks, $100 \mathrm{~mL}$ of working volume, and $2 \times 10^{7}$ spores $/ \mathrm{mL}$

A readily available and inexpensive material from an ethanol production process showed positive results when used as media enrichment to enhance ethanol yields for glucose and xylose conversions. Thin stillage from two distinctly different commercial operations both provided nutrients that enhanced the conversion of glucose and xylose (Figure 7.8). For glucose conversion, $0.5 \%$ yeast extract as a nutrient enrichment outperformed the $10 \%$ thin stillage enrichments slightly.

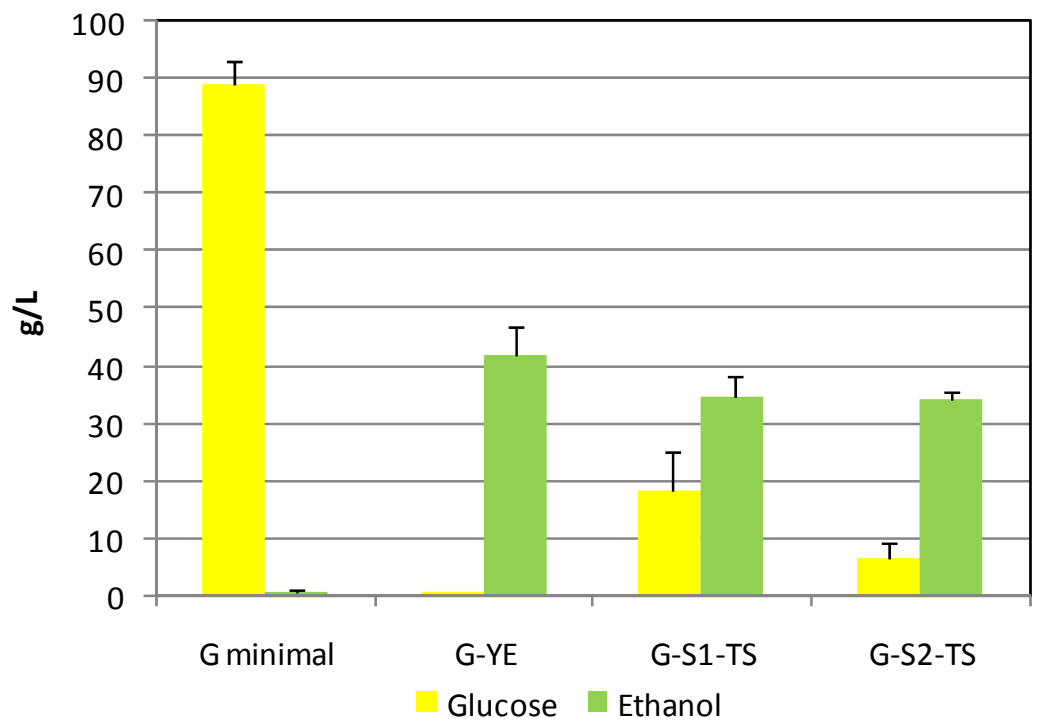

Figure 7.8. Exp 44, A. oryzae NRRL 697 Model Strain Ethanol Production on 12\% Glucose Minimal Medium Enriched with $0.5 \%$ Yeast Extract, or $10 \%$ Source 1 Thin Stillage or $10 \%$ Source 2 Thin Stillage, $250-\mathrm{mL}$ flasks, $100 \mathrm{~mL}$ of working volume, and $2 \times 10^{7}$ spores $/ \mathrm{mL}$ 
However, the positive effect of thin stillage enrichment on xylose conversion was more pronounced, with $10 \%$ thin stillage providing better xylose conversion results than $0.5 \%$ yeast extract (Figure 7.9 ). More ethanol was produced, less xylose was consumed, and less xylitol was produced. An invention report was submitted for review.

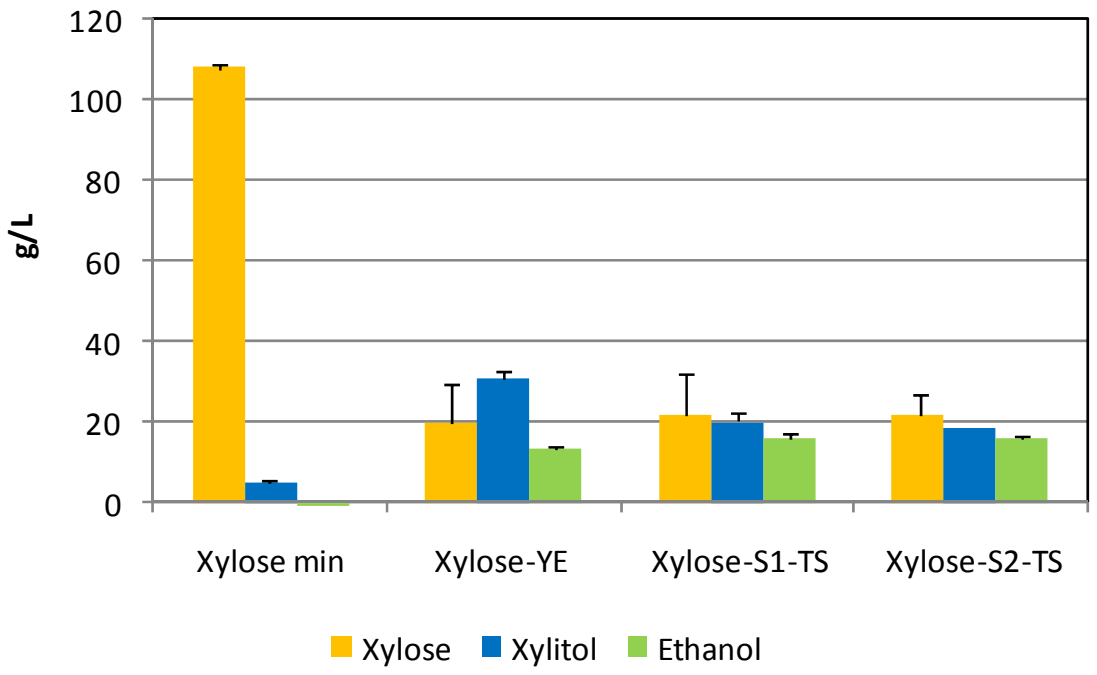

Figure 7.9. Exp 44, A. oryzae NRRL 697 Model Strain Ethanol Production on 12\% Xylose Minimal Medium Enriched with $0.5 \%$ Yeast Extract, or 10\% Source 1(S1) Thin Stillage or 10\% Source 2 (S2) Thin Stillage, 250-mL flasks, $100 \mathrm{~mL}$ of Working Volume, and $2 \times 10^{7}$ spores $/ \mathrm{mL}$

A method using rice and autoclavable plant tissue culture bags to easily and inexpensively produce large numbers of A. oryzae conidia for inoculation of the fermentors was developed. Using this method, one bag produces enough conidia to inoculate a fermentor at a small fraction of the labor and material costs associated with the previous plate-based production method.

\subsection{Plans for FY2010}

- Refine high-throughput screening method and create ethanol screening protocol. Continue to identify individual genes for ethanol production improvement and combine them to create a novel production strain and then establish baseline production levels on glucose, xylose, and complex biomass.

- Identify individual genes that improve ethanol tolerance in filamentous fungi using genome-wide gene knock-out and overexpression methods or other screening methods and apply to the model strain.

- Improve ethanol tolerance in the novel production strain by single or multiple gene modifications and/or applying screening methods. 


\subsection{Major Subtask A.6 Alternative Renewable Fuels from Fungi}

\subsection{Background}

The purpose of this subtask is to explore fungi as sources of alternative renewable fuels. We are interested in advanced biofuel molecules, i.e., those molecules that are infrastructure compatible. Beginning in FY10, we will identify promising fungi, enzymes, or pathways and perform proof-ofprinciple experiments to research possible routes to advanced biofuels.

\subsection{Accomplishments and Results}

In FY09, we performed a broad assessment of potential fungal routes to alternative renewable fuels. In regard to advanced biofuels, the primary compounds of interest are hydrocarbon or hydrocarbon-like compounds. Potential biofuel molecules would have the following desirable properties: low oxygen content, low water solubility, and high degree of saturation - in short, they would be infrastructure compatible fuels. Fungi can produce hydrocarbon or hydrocarbon-like compounds from a variety of pathways (Table 8.1). These include 1) fatty acid synthesis leading to triglycerides, 2) the isoprenoid pathway leading to compounds that are multiples of five carbon units from $\mathrm{C}_{10}$ to $\mathrm{C}_{40}, 3$ ) polyketide synthases that produce an amazing array of compounds of varying degrees of cyclization and functionalization, and 4) hydrocarbon compounds from $\mathrm{C}_{4}$ to $\mathrm{C}_{36}$ that may be produced by various mechanisms (Ladygina et al. 2006).

Table 8.1. Classes of Hydrocarbon and Hydrocarbon-Like Molecules Produced by Fungi

\begin{tabular}{lll}
\hline Compound & No. of Carbons & Key Enzyme(s) \\
\hline Fatty acids, triglycerides & $\mathrm{C}_{12}-\mathrm{C}_{22}$ & fatty acid synthases \\
Fatty alcohols & $\mathrm{C}_{12}-\mathrm{C}_{22}$ & acyl-reductases \\
Polyketides & $\mathrm{C}_{(2 \mathrm{n})+1} ; \mathrm{C}_{9}-\mathrm{C}_{65}$ & polyketide synthases, oxidases, modifying enzymes \\
Terpenes (isoprenoids) & $\mathrm{C}_{5 \mathrm{n}} ; \mathrm{C}_{10}-\mathrm{C}_{40}$ & terpene synthases, modifying enzymes \\
Alkanes, cycloalkanes & $\mathrm{C}_{4}-\mathrm{C}_{36}$ & acyl-reductases, thioesterases, decarbonylase, others? \\
\hline
\end{tabular}

It has been known for years that certain fungal species, including both yeasts and filamentous fungi, can produce and accumulate large amounts of lipids when grown on various carbon sources, including diverse sugars (Suzuki and Hasegawa 1974; Ratledge 2002; Fakas et al. 2009). These oil-producing (oleaginous) fungi accumulate triglycerides of varying fatty acid composition and/or carotenoids, which are 40-carbon compounds produced via the isoprenoid pathway. Some example genera of oleaginous or carotenogenic yeasts are Lipomyces, Debaryomyces, Rhodotorula, Candida, Yarrowia and Hansenula; and filamentous fungi Cunninghamella, Mortierella, Mucor, Blakeslea, and Phycomyces (all zygomycetes).

The oleaginous fungi are not the species of primary interest in this task, at least in regard to the triglycerides that they produce. However, these species might serve as platform organisms to overproduce hydrocarbons if the pathways to the hydrocarbons are identified and engineered into the oleaginous species. This assumes that these oleaginous strains can be genetically manipulated; this is 
certainly the case for many of the yeasts and at least one of the filamentous fungi named above (Ando et al. 2009). Using these oleaginous fungi as platforms would be potentially beneficial for two reasons. First, many fungal-derived hydrocarbons are generated by a few additional steps after fatty acid synthesis; thus, it follows that fatty acid anabolism will be crucial to generating large quantities of the hydrocarbons. Second, these oleaginous fungi already have mechanisms for accumulating and tolerating high concentrations of lipophilic compounds, so they might be well-equipped to accumulate high concentrations of hydrocarbons. This is important since high concentrations of hydrocarbons may be toxic to the native fungal producers of the hydrocarbons.

Even more intriguing, given our interest in alternative biofuels, are the examples of fungi producing one or more alkanes. These may arise from the fatty acid decarbonylation pathway, via the isoprenoid pathway, or some other undetermined route of biosynthesis. The decarbonylation route involves multiple enzymes, including acyl-coenzyme A (acyl-CoA) reductases, thioesterases and decarbonylase (SchneiderBelhaddad and Kolattukudy 2000). The result of this is the production of a hydrocarbon that is one carbon shorter than the starting fatty acid. Hormoconis resinae (aka Cladosporium resinae) is an example of a fungus capable of producing alkanes from $\mathrm{C}_{7}$ to $\mathrm{C}_{36}$ while growing heterotrophically on glucose or glutamic acid (Walker and Cooney 1973). This fungus is now the subject of a genome sequencing project in a collaboration involving PNNL, the DOE Office of Science (DOE-SC) funded Joint BioEnergy Institute (JBEI) and JGI. Quite recently, the fungus Gliocladium roseum was isolated and its suite of hydrocarbons characterized (Strobel et al. 2008). Volatile compounds are produced by a variety of fungi, including species of the cosmopolitan fungal genera Penicillium and Aspergillus. They produce a range of volatiles, including hydrocarbons, short chain alcohols, ketones, ethers, esters, and terpenes (Sunesson et al. 1995). All of these fungi accumulate rather low levels of the desirable hydrocarbons, and the biochemistry and genetics underlying the production of these compounds remains relatively poorly understood.

Polyketides are a large family of molecules generally produced by condensation of successive malonyl-CoA units. The large enzymes responsible for the production of polyketides are called polyketide synthases (PKSs). PKSs consist of multiple catalytic domains carrying out acyl transfer, ketoreductase, dehydratase, thioesterase, and other functions. Fungal polyketide synthases are referred to as iterative type I PKSs since they have the multiple catalytic domains on a single polypeptide chain, and the growing polyketide molecule may be passed through the catalytic domains more than once (Cox and Simpson 2009). The other interesting feature of polyketide synthesis in fungi is that PKSs and the associated modifying enzymes exist in gene clusters. This is the norm in the bacterial domain, but is largely restricted to secondary metabolite clusters, such as polyketides, isoprenoids, and non-ribosomal peptides, in fungi. The polyketide synthases and their associated modifying enzymes are basically one of nature's combinatorial chemistry toolboxes. Polyketides have a wide range of sizes from $\mathrm{C}_{9}$ to $\mathrm{C}_{65}$ and beyond. They also have a wide range of types and numbers of functional groups, including keto and hydroxyl groups, double and triple bonds, cycloalkane, cyclic ether, and aromatic groups. Some of these groups are introduced by accessory enzymes associated with the PKS gene clusters, such as cytochrome P450s. Since the goal from a biofuels perspective would be to generate molecules with relatively low levels of oxygen, we would like to identify PKSs that generate highly reduced polyketides. Since many polyketides are aromatic, they may also be potential fuel modifiers, e.g., octane boosters. In addition, the partially oxygenated polyketides could be alternative fuel oxygenates.

Isoprenoids are synthesized in fungi via the mevalonate pathway, which involves the condensation of activated $\mathrm{C}_{5}$ units (isopentenyl pyrophosphate and dimethylallyl pyrophosphate) derived from mevalonate 
to form a diverse family of higher molecular weight compounds (Scott et al. 2004, pp. 163-198). These include $\mathrm{C}_{10}$ (monoterpenes), $\mathrm{C}_{15}$ (sesquiterpenes), $\mathrm{C}_{20}$ (diterpenes), $\mathrm{C}_{30}$ (squalenes), and $\mathrm{C}_{40}$ (carotenoids) compounds. The family of isoprenoid compounds that include linear and cyclized molecules are formed by specific terpene synthases (Keeling and Bohlmann 2006). Subsequently, some of these molecules are further modified by accessory enzymes (Hamberger and Bohlmann 2006). The family of $\mathrm{C}_{10}$ and $\mathrm{C}_{15}$ compounds would be of greatest interest since they are in the size range of molecules found in diesel, Jet-A, or JP-8 fuels. Larger isoprenoids could potentially be catalytically cracked to smaller molecules in the gasoline to diesel/jet fuel range.

The diversity of hydrocarbon and hydrocarbon-like compounds produced by fungi holds great promise for identifying advanced biofuels. Some of the research challenges awaiting us are to identify the top candidate biofuel molecules and the pathways leading to the production of those molecules and to either manipulate fungal culture conditions or genetically manipulate the production organism to increase the production of the alternative biofuel molecule(s) into the economically relevant range.

\subsection{Plans for FY10}

In FY10, we will begin experimental work in three areas: terpene production, polyketide clusters as sources of biomolecules or modifying enzymes, and the genomics of hydrocarbon-producing fungi. Based on results of this fiscal year's experiments and analyses, we expect to develop a sharper focus on particular systems for more intensive study in out-years.

The hydrocarbon-producing fungi are ripe targets for further study. Specifically, genomics, transcriptomics, and proteomics studies would facilitate the discovery of enzymes and pathways. Genetic manipulation of fungi via knockout or over-expression of candidate genes identified via the genomic studies would be a natural follow-up. If molecular biological tools to manipulate the native host could be developed, then gene knockouts could proceed in this organism. Initially, we would plan on overexpressing acyl reductase and decarbonylase genes in one of our platform organisms, e.g., A. niger or A. terreus. These experiments in a non-hydrocarbon producing strain would help to confirm the pathways and/or create hydrocarbon over-producing strains. These studies would await the completion of the $H$. resinae genome and transcriptome sequencing. Therefore, the immediate goal for FY10 is to culture $H$. resinae for preparation of DNA for genome sequencing and RNA from a variety of conditions for transcriptome (expressed sequence tag; EST) sequencing. Further research on this organism or the genes is anticipated to begin at the end of FY10 or beginning of FY11 as the genome resources become available.

Accessory enzymes that reduce and dehydrate the growing polyketides could be useful for producing modified polyketides or modifying other potential fuel molecules of interest, starting with feedstock molecules that are not derived from PKSs; i.e., enzymatic deoxygenation of polyols. Efforts in the general area of studying PKSs and the associated modifying enzymes will build on an existing collaboration with Clay Wang of the University of California-Los Angeles, who is experienced in the analysis of PKS clusters and the products they produce (Chiang et al. 2008). The goal of this project will be to develop enzymes that can enhance the energy content or otherwise favorably alter organic compounds that are used as advanced biofuels. PKS gene clusters are often "silent" or expressed at very low levels in culture. Strains will be constructed that induce the expression of these PKS and modifying enzyme genes so that we can screen for novel polyketides and enzyme activities. A portion of the project 
will be dedicated to finding appropriate organic compounds that are both relevant to biofuel production and amenable to screening. Examples are the thermochemical biomass pretreatment by-products levulinic acid, furfural and hydroxymethylfurfural, or their reduced alcohol counterparts. These compounds or their derivatives are potential biofuels and also known inhibitors of fermentation processes, so the identification of enzymes to modify them would have two potential benefits/applications. In outyears, we will build upon the diversity of organic compound modifying enzymes present in fungi by creating pooled expression libraries of these genes containing random mutations. The libraries will then be screened for changes in substrate specificity. Ultimately, enzymes with activity on compounds from advanced biofuel production can be discovered by inducing the expression of these genes and then modifying them to be active on target substrates.

Beginning in FY10, we will genetically manipulate one of our model organisms, Aspergillus niger, to produce a monoterpene $\left(\mathrm{C}_{10}\right)$ by incorporating a terpene synthase gene alone or in combination with a geranyl diphosphate synthase gene to increase the concentration of substrate (geranyl diphosphate) for the terpene synthase. Active expression of the enzymes will be assessed by specific enzyme assays. Production of the desirable terpenes will be determined by gas chromatographic analysis. 


\subsection{References}

Ando A, Y Sumida, H Negoro, DA Suroto, J Ogawa, E Sakuradani, and S Shimizu. 2009.

"Establishment of Agrobacterium tumefaciens-Mediated Transformation of an Oleaginous Fungus, Mortierella alpina 1S-4, and Its Application for Eicosapentaenoic Acid Producer Breeding." Applied and Environmental Microbiology 75(17):5529-5535.

Becker SA, AM Feist, ML Mo, G Hannum, BO Palsson, and MJ Herrgard. 2007. "Quantitative prediction of cellular metabolism with constraint-based models: the COBRA Toolbox." Nat. Protocols 2(3):727-738.

Bergmeyer HU, M Grassl, and HE Walter. 1985. "Biochemical reagents for general use: Enzymes." In: (3rd ed.), HU Bergmeyer, Editor, Methods of Enzymatic Analysis, Vol. 2, Verlag Chemie, Weinheim.

Chiang YM, E Szewczyk, T Nayak, AD Davidson, JF Sanchez, HC Lo, WY Ho, H Simityan, E Kuo, A Praseuth, K Watanabe, BR Oakley, and CCC Wang. 2008. "Molecular genetic mining of the Aspergillus secondary metabolome: discovery of the emericellamide biosynthetic pathway." Chemistry \& Biology 15(6):527-532.

Colot HV, G Park, GE Turner, C Ringelberg, CM Crew, L Litvinkova, RL Weiss, KA Borkovich, and JC Dunlap. 2006. "A high-throughput gene knockout procedure for Neurospora reveals functions for multiple transcription factors." In: Proceedings of the National Academy of Sciences of the United States of America 103(27):10352-10357.

Conrads TP, GA Anderson, TD Veenstra, L Pasa-Tolić, and RD Smith. 2000. "Utility of Accurate Mass Tags for Proteome-Wide Protein Identification." Analytical Chemistry 72(14):3349-3354.

Cox RJ and TJ Simpson. 2009. "Fungal Type I Polyketide Synthases. Complex Enzymes in Microbial Natural Product Biosynthesis, Part B: Polyketides.” Aminocoumarins and Carbohydrates 459:49-78.

Daly DS, KK Anderson, EA Panisko, SO Purvne, R Fang, MM Monroe, and SE Baker. 2008. "MixedEffects Statistical Model for Comparative LC-MS Proteomic Studies." Journal of Proteome Research 7:1209-1217.

Fakas S, S Papanikolaou, A Batsos, M Galiotou-Panayotou, A Mallouchos, and G Aggelis. 2009. "Evaluating renewable carbon sources as substrates for single cell oil production by Cunninghamella echinulata and Mortierella isabellina.” Biomass \& Bioenergy 33(4):573-580.

Finney A and M Hucka. 2003. "Systems biology markup language: Level 2 and beyond." Biochem. Soc. Trans. 31(6):1472-1473.

Gao J, GJ Opiteck, MS Friedrichs, AR Dongre, and SA Hefta. 2003. "Changes in the Protein Expression of Yeast as a Function of Carbon Source." Journal of Proteome Research 2(6):643-649.

Gems D, IL Johnstone, and AJ Clutterbuck. 1991. "An Autonomously Replicating Plasmid Transforms Aspergillus-Nidulans at High-Frequency.” Gene 98(1):61-67. 
Gygi SP, B Rist, SA Gerber, F Turecek, MH Gelb, and R Aebersold. 1999. "Quantitative Analysis of Complex Protein Mixtures Using Isotope-Coded Affinity Tags.” Nature Biotechnology 17(10):994-999.

Hamberger B and J Bohlmann. 2006. "Cytochrome P450 mono-oxygenases in conifer genomes: discovery of members of the terpenoid oxygenase superfamily in spruce and pine." Biochemical Society Transactions 34:1209-1214.

Keeling CI and J Bohlmann. 2006. "Genes, enzymes and chemicals of terpenoid diversity in the constitutive and induced defence of conifers against insects and pathogens." New Phytologist 170(4):657675.

Keating SM, BJ Bornstein, A Finney, and M Hucka. 2006. "SBMLToolbox: an SBML toolbox for MATLAB users." Bioinformatics 22(10):1275-7.

Ladygina N, EG Dedyukhina, and MB Vainshtein. 2006. “A review on microbial synthesis of hydrocarbons." Process Biochemistry 41(5):1001-1014.

Magnuson JK and LL Lasure. 2004. Organic Acid Production by Filamentous Fungi. In: Advances in Fungal Biotechnology for Industry, Agriculture and Medicine, J. Tkacz (ed.), Kluwer Academic Publishers.

Meyer V, M Arentshorst, A El-Ghezal, AC Drews, R Kooistra, CAMJJ van den Hondel, and AFJ Ram. 2007. "Highly efficient gene targeting in the Aspergillus niger kusA mutant." Journal of Biotechnology 128(4):770-775.

Meyer V, M Arentshorst, CAMJJ Van den Hondel, and AFJ Ram. 2008. "The polarisome component SpaA localises to hyphal tips of Aspergillus niger and is important for polar growth." Fungal Genetics and Biology 45(2):152-164.

Moorthamer M and B Chaudhuri. 1999. "Identification of Ribosomal Protein L34 as a Novel Cdk5 Inhibitor." Biochemical and Biophysical Research Communications 255(3):631-638.

Nielsen JB, ML Nielsen, and UH Mortensen. 2008. "Transient disruption of non-homologous endjoining facilitates targeted genome manipulations in the filamentous fungus Aspergillus nidulans." Fungal Genetics and Biology 45(3):165-170.

Ninomiya Y, K Suzuki, C Ishii, and H Inoue. 2004. "Highly efficient gene replacements in Neurospora strains deficient for nonhomologous end-joining." In: Proceedings of the National Academy of Sciences of the United States of America 101(33):12248-12253.

Piddington CS, CS Houston, M Paloheimo, M Cantrell, A Miettinen-Oinonen, H Nevalainen, and J Rambosek. 1993. "The cloning and sequencing of the genes encoding phytase (phy) and pH 2.5optimum acid phosphatase (aph) from Aspergillus niger var. awamori." Gene 133: 55-62.

Ratledge C. 2002. "Regulation of lipid accumulation in oleaginous micro-organisms." Biochemical Society Transactions 30:1047-1050. 
Rocha I, J Forster, and J Nielsen. 2008. "Design and application of genome-scale reconstructed metabolic models." Methods Mol Biol. 416:409-31.

Schneider-Belhaddad F and P Kolattukudy. 2000. "Solubilization, partial purification, and characterization of a fatty aldehyde decarbonylase from a higher plant, Pisum sativum." Archives of Biochemistry and Biophysics 377(2):341-349.

Scott DB, GB Jameson, and EJ Parker. 2004. Isoprenoids: Gene Clusters and Chemical Puzzles. Advances in Fungal Biotechnology for Industry, Agriculture, and Medicine. JS Tkacz and L Lange. Kluwer Academic/Plenum Publishers, New York.

Strobel GA, B Knighton, K Kluck, YH Ren, T Livinghouse, M Griffin, D Spakowicz, and J Sears. 2008. "The production of myco-diesel hydrocarbons and their derivatives by the endophytic fungus Gliocladium roseum (NRRL 50072).” Microbiology-Sgm 154:3319-3328.

Sunesson A-L, WHJ Vaes, C-A Nilsson, G Blomquist, B Andersson, and R Carlson. 1995. "Identification of Volatile Metabolites from Five Fungal Species Cultivated on Two Media." Applied and Environmental Microbiology 61(8):2911-2918.

Suzuki T and K Hasegawa. 1974. "Variations in Lipid Compositions and in Lipid Molecular Species of Lipomyces-Starkeyi Cultivated in Glucose Sufficient and Glucose Deficient Media." Agricultural and Biological Chemistry 38(AUG):1485-1492.

Vongsangnak W, P Olsen, K Hansen, S Krogsgaard, and J Nielsen. 2008. "Improved annotation through genome-scale metabolic modeling of Aspergillus oryzae.” BMC Genomics 9:245.

Walker JD and JJ Cooney. 1973. "Aliphatic Hydrocarbons of Cladosporium resinae Cultured on Glucose, Glutamic Acid and Hydrocarbons.” Applied Microbiology 26(5):705-708.

Wilkins MR, Pasquali C, Appel RD, Ou K, Golaz O, Sanchez JC, Yan JX, Gooley AA, Hughes G, Humphery-Smith I, Williams KL, Hochstrasser DF. 1996. "From Proteins to Proteomes: Large Scale Protein Identification by Two-Dimensional Electrophoresis and Amino Acid Analysis." Bio-Technology 14(1):61-65. 


\subsection{Publications}

D Martinez, J Challacombe, I Morgenstern, D Hibbett, M Schmoll, CP KubicekP, P Ferreira, FJ RuizDuenas, AT Martinez, P Kersten, KE Hammel, A Vanden Wymelenberg, J Gaskell, E Lindquist, G Sabat, SS Bondurant, LF Larrondo, P Canessa, R Vicuna, J Yadav, H Doddapaneni, V Subramanian, AG Pisabarro, JL Lavín, JA Oguiza, E Master, B Henrissat, PM Coutinho, P Harris, JK Magnuson, SE Baker, K Bruno, W Kenealy, PJ Hoegger, U Kües, P Ramaiya, S Lucas, A Salamov, H Shapiro, H Tu, CL Chee, M Misra, G Xie, S Teter, D Yaver, T James, M Mokrejs, M Pospisek, IV Grigoriev, T Brettin,D Rokhsar, R Berka, and D Cullen. 2009. "Genome, transcriptome, and secretome analysis of wood decay fungus Postia placenta supports unique mechanisms of lignocellulose conversion." 2009. In: Proc Natl Acad Sci U S A. Feb10;106(6):1954-9. Epub 2009 Feb 4. PubMed PMID: 19193860; PubMed Central PMCID: PMC2644145.

Diego Martinez JC, I Morgenstern, D Hibbett, M Schmoll, CP Kubicek, P Ferreira, FJ Ruiz-Duenas, AT Martinez, P Kersten, KE Hammel, AV Wymelenberg, J Gaskell, E Lindquist, G Sabat, SS BonDurant, LF Larrondo, P Canessa, R Vicuna, J Yadav, H Doddapaneni, V Subramanian, AG Pisabarro, JL Lavín, JA Oguiza, E Master, B Henrissat, PM Coutinho, P Harris, JK Magnuson, SE Baker, K Bruno, W Kenealy, PJ Hoegger, U Kües, P Ramaiya, S Lucas, A Salamov, H Shapiro, H Tu, CL Chee, M Misra, G Xie, S Teter, D Yaver, T James, M Mokrejs, M Pospisek, IV Grigoriev, T Brettin, D Rokhsar, R Berka, and D Cullen. 2009. "Genome, transcriptome, and secretome analysis of wood decay fungus Postia placenta supports unique mechanisms of lignocellulose conversion." In: Proceedings of the National Academy of Sciences 106(6):1954-1959.

Jovanovic I, JK Magnuson, F Collart, B Robbertse, WS Adney, ME Himmel, and SE Baker. 2009. "Fungal glycoside hydrolases for saccharification of lignocellulose: outlook for new discoveries fueled by genomics and functional studies." Cellulose 16(4):687-697.

Le Crom S, W Schackwitz, L Pennacchio, JK Magnuson, DE Culley, JR Collett, J Martin, IS Druzhinina, H Mathis, F Monot, B Seiboth, B Cherry, M Rey, R Berka, CP Kubicek, SE Baker, and A Margeot. 2009. "Tracking the roots of cellulase hyperproduction by the fungus Trichoderma reesei using massively parallel DNA sequencing Proc Natl Acad Sci U S A.” Published online before print September 2, 2009, doi:10.1073/pnas.0905848106.

Martinez D, RM Berka, B Henrissat, M Saloheimo, M Arvas, SE Baker, J Chapman, O Chertkov, PM Coutinho, D Cullen, EGJ Danchin, IV Grigoriev, P Harris, M Jackson, CP Kubicek, CS Han, I Ho, LF Larrondo, AL de Leon, JK Magnuson, S Merino, M Misra, B Nelson, N Putnam, B Robbertse, AA Salamov, M Schmoll, A Terry, N Thayer, A Westerholm-Parvinen, CL Schoch, J Yao, R Barbote, MA Nelson, C Detter, D Bruce, CR Kuske, G Xie, P Richardson, DS Rokhsar, SM Lucas, EM Rubin, N Dunn-Coleman, M Ward, and TS Brettin. 2008. "Genome sequencing and analysis of the biomassdegrading fungus Trichoderma reesei (syn. Hypocrea jecorina).” Nature Biotechnology 26(5):553-560.

Panisko EA, I Grigoriev, DS Daly, B-J Webb-Robertson, and SE Baker. 2009. "Genomes to Proteomes." In: Automation in Genomics and Proteomics: An Engineering Case-Based Approach. G Alterovitz, M Ramoni, and RM Benson (eds.). Wiley, West Sussex. 
Panisko EA, I Grigoriev, DS Daly, B-J Webb-Robertson, and SE Baker. 2009 "Genomes to Proteomes." In Automation in Genomics and Proteomics: An Engineering Case-Based Approach. G Alterovitz, M Ramoni, and RM Benson (eds.). Wiley, West Sussex.

Shary S, AN Kapich, EA Panisko, JK Magnuson, D Cullen, and KE Hammel. 2008. "Differential Expression in Phanerochaete chrysosporium of Membrane-Associated Proteins Relevant to Lignin Degradation." Appl. Environ. Microbiol. 74:7252-7257.

Thykaer J, MR Andersen, and SE Baker. 2009. "Essential pathway identification: from in silico analysis to potential antifungal targets in Aspergillus fumigatus." Med Mycol., 47 Suppl 1:S80-7. Epub 2009 Feb 27. PubMed PMID: 19253142.

Tsang A, G Butler, J Powlowski, EA Panisko, and SE Baker. 2009 "Analytical and Computational Approaches to Define the Aspergillus niger Secretome." Fungal Genetics and Biology. 46 S1, 1563-160.

Wright JC, D Sugden, S Francis-McIntyre, I Riba-Garcia, SJ Gaskell, IV Grigoriev, SE Baker, RJ Beynon, and SJ Hubbard. 2009. "Exploiting proteomic data for genome annotation and gene model validation in Aspergillus niger." BMC Genomics. Feb 4;10:61. PubMed PMID: 19193216; PubMed Central PMCID: PMC2644712.

Zhou K, EA Panisko, JK Magnuson, SE Baker, and I Grigoriev. 2009. "Proteomics for Validation of Automated Gene Model Predictions.” Methods Mol. Biol. 492:447-452. 
Appendix A

\section{Complete Analysis Report}


Appendix A: Complete Analysis Report

\begin{tabular}{|c|c|c|c|c|c|c|c|c|c|c|c|}
\hline JGI ID & $\begin{array}{l}\text { No Mn } \\
\text { pH } 4.5 \\
\end{array}$ & $\begin{array}{c}\text { No } \mathrm{Mn} p \mathrm{H} \\
5.0 \\
\end{array}$ & $\begin{array}{l}\text { No Mn } \\
\text { pH } 5.5 \\
\end{array}$ & $\begin{array}{c}\mathrm{Mn} \mathrm{pH} \\
4.5 \\
\end{array}$ & $\begin{array}{c}\mathrm{Mn} \mathrm{pH} \\
5.0 \\
\end{array}$ & $\begin{array}{c}\mathrm{Mn} \mathrm{pH} \\
5.5 \\
\end{array}$ & $\begin{array}{l}\text { Blast } \\
\text { Score }\end{array}$ & $\begin{array}{c}\text { Blast } \\
\text { eValue }\end{array}$ & Blast Hit Name & Hit Description & Species \\
\hline 206688 & 28 & 135 & 405 & 25 & 91 & 379 & 1929 & 0 & RL3_ASPFU & $60 \mathrm{~S}$ ribomal protein $\mathrm{L} 3$ & A. fumigatus \\
\hline 209168 & 187 & 305 & 386 & 181 & 169 & 418 & 3784 & 0 & CHL1_ASPNC & ATP-dependent RNA helicase chll & A. niger \\
\hline 55586 & 16 & 35 & 262 & 7 & 16 & 274 & 1643 & 0 & ALF_ASPOR & Fructe-bisphphate aldolase & A. oryzae \\
\hline 212044 & 7 & 6 & 195 & 10 & 6 & 236 & 1305 & $1 \mathrm{E}-143$ & ADT_NEUCR & ADP,ATP carrier protein & N. crassa \\
\hline 199998 & 1 & 19 & 190 & & 12 & 195 & 510 & $3 \mathrm{E}-51$ & COX4_NEUCR & Cytochrome c oxidase polypeptide 4 , mitochondrial & N. crassa \\
\hline 52600 & 19 & 206 & 141 & 19 & 117 & 155 & 1292 & $1 \mathrm{E}-141$ & DCE1_ARATH & Glutamate decarboxylase 1 & A. thaliana \\
\hline 180126 & 1 & 22 & 133 & & 10 & 158 & 802 & $1 \mathrm{E}-84$ & HEX1_EMENI & Woronin body major protein & E. nidulans \\
\hline 54616 & & 26 & 132 & 2 & 12 & 143 & 880 & $8 \mathrm{E}-94$ & ILV6_YEAST & Acetolactate synthase small subunit, mitochondrial & S. cerevisiae \\
\hline 208547 & & 4 & 128 & & 3 & 160 & 2788 & 0 & ACL1_NEUCR & Probable ATP-citrate synthase subunit 1 & N. crassa \\
\hline 53301 & 1 & 11 & 128 & 3 & 8 & 136 & & & -No-Hit- & No Matching Hit found & \\
\hline 200483 & & 14 & 127 & 4 & 6 & 174 & 1928 & 0 & ACT_BOTFU & Actin & B. fuckeliana \\
\hline 54217 & 2 & 4 & 123 & 1 & 2 & 129 & & & -No-Hit- & No Matching Hit found & \\
\hline 53274 & & & 109 & & & 108 & & & -No-Hit- & No Matching Hit found & \\
\hline 210029 & 1 & 5 & 100 & & 2 & 123 & 738 & $3 \mathrm{E}-77$ & EF1G2_YEAST & Elongation factor 1-gamma 2 & S. cerevisiae \\
\hline 204461 & 10 & 16 & 98 & 7 & 10 & 119 & 1079 & $1 \mathrm{E}-117$ & RL2_ASHGO & $60 \mathrm{~S}$ ribomal protein $\mathrm{L} 2$ & A. gossypii \\
\hline 199133 & 2 & & 78 & 2 & & 97 & 1925 & 0 & 6PGD1_YEAST & 6-phphogluconate dehydrogenase, decarboxylating 1 & S. cerevisiae \\
\hline 199043 & & 3 & 66 & & 6 & 73 & 1425 & $1 \mathrm{E}-157$ & ACL2_SCHPO & Probable ATP-citrate synthase subunit 2 & S. pombe \\
\hline 214270 & 1 & 4 & 63 & 1 & 2 & 64 & 1402 & $1 \mathrm{E}-154$ & AATM_MOUSE & Aspartate aminotransferase, mitochondrial & M. musculus \\
\hline 206816 & & 3 & 60 & & 2 & 82 & 3609 & 0 & EF2_NEUCR & Elongation factor 2 & N. crassa \\
\hline 209716 & & & 60 & & & 74 & 820 & $2 \mathrm{E}-87$ & SODC_ASPNC & Superoxide dismutase $[\mathrm{Cu}-\mathrm{Zn}]$ & A. niger \\
\hline 208343 & 1 & 4 & 55 & & 3 & 60 & 1857 & 0 & SAHH_YEAST & Adenylhomocysteinase & S. cerevisiae \\
\hline 56247 & & & 53 & & & 52 & 856 & $2 \mathrm{E}-90$ & SPO14_YEAST & Phpholipase D1 & S. cerevisiae \\
\hline 51717 & & 7 & 51 & 2 & 1 & 74 & 859 & $2 \mathrm{E}-91$ & MPCP_YEAST & Mitochondrial phphate carrier protein & S. cerevisiae \\
\hline 55611 & & 1 & 51 & & & 60 & 944 & $1 \mathrm{E}-101$ & IF2A_SCHPO & Eukaryotic translation initiation factor 2 subunit alpha & S. pombe \\
\hline 197949 & 11 & 38 & 49 & 15 & 31 & 59 & 567 & $4 \mathrm{E}-58$ & RL21A_SCHPO & $60 \mathrm{~S}$ ribomal protein $\mathrm{L} 21-\mathrm{A}$ & S. pombe \\
\hline 210867 & 14 & 70 & 49 & 13 & 49 & 50 & 374 & $2 \mathrm{E}-35$ & RL13_CANAL & $60 \mathrm{~S}$ ribomal protein $\mathrm{L} 13$ & C. albicans \\
\hline 52362 & & 3 & 47 & & 1 & 61 & 924 & $5 \mathrm{E}-99$ & RS0_NEUCR & 40S ribomal protein $\mathrm{S} 0$ & N. crassa \\
\hline 54488 & & 31 & 47 & & 17 & 48 & & & -No-Hit- & No Matching Hit found & \\
\hline 213187 & & & 46 & & & 72 & 4902 & 0 & CLH_SCHPO & Probable clathrin heavy chain & S. pombe \\
\hline 56462 & & 3 & 46 & & 3 & 65 & 1940 & 0 & GLYC_NEUCR & Serine hydroxymethyltransferase, cytolic & N. crassa \\
\hline 209386 & 2 & 10 & 44 & & 6 & 49 & 647 & $2 \mathrm{E}-67$ & RS11_YEAST & $40 \mathrm{~S}$ ribomal protein $\mathrm{S} 11$ & S. cerevisiae \\
\hline
\end{tabular}




\begin{tabular}{|c|c|c|c|c|c|c|c|c|c|c|c|}
\hline JGI ID & $\begin{array}{l}\text { No Mn } \\
\text { pH } 4.5\end{array}$ & $\begin{array}{c}\text { No } \mathrm{Mn} \mathrm{pH} \\
5.0\end{array}$ & $\begin{array}{l}\text { No Mn } \\
\text { pH } 5.5\end{array}$ & $\begin{array}{c}\mathrm{Mn} \mathrm{pH} \\
4.5\end{array}$ & $\begin{array}{l}\mathrm{Mn} \mathrm{pH} \\
5.0\end{array}$ & $\begin{array}{c}\mathrm{Mn} \mathrm{pH} \\
5.5\end{array}$ & $\begin{array}{l}\text { Blast } \\
\text { Score }\end{array}$ & $\begin{array}{l}\text { Blast } \\
\text { eValue }\end{array}$ & Blast Hit Name & Hit Description & Species \\
\hline 55040 & & 7 & 42 & & 2 & 35 & 619 & $8 \mathrm{E}-64$ & SODM_ARATH & Superoxide dismutase $[\mathrm{Mn}]$, mitochondrial & A. thaliana \\
\hline 214348 & & & 39 & & 1 & 41 & 3295 & 0 & ACSA_EMENI & Acetyl-coenzyme A synthetase & E. nidulans \\
\hline 210514 & 1 & 4 & 38 & & 2 & 54 & 1071 & $1 \mathrm{E}-116$ & IF3EI_DANRE & Eukaryotic translation initiation factor 3 subunit & D. rerio \\
\hline 196714 & 3 & 29 & 38 & 3 & 7 & 38 & 948 & $1 \mathrm{E}-102$ & RL15_ASPNG & 60 S ribomal protein L15 & A. niger \\
\hline 212096 & & 2 & 38 & & 1 & 32 & 2280 & 0 & EF1A_ASPOR & Elongation factor 1-alpha & A. oryzae \\
\hline 52269 & & & 37 & & & 46 & 1661 & 0 & EIF3X_SCHPO & Probable eukaryotic translation initiation factor subunit & S. pombe \\
\hline 208387 & & 12 & 37 & & 11 & 33 & 229 & $7 \mathrm{E}-18$ & YLA3_SCHPO & Uncharacterized HTH La-type RNA-binding protein & S. pombe \\
\hline 214397 & & 4 & 35 & & 2 & 51 & 273 & $3 \mathrm{E}-23$ & AAT_AQUAE & Aspartate aminotransferase & A. aeolicus \\
\hline 118704 & & & 35 & & & 40 & 430 & $1 \mathrm{E}-40$ & YHKC_SCHPO & Uncharacterized aminotransferase C660.12c & S. pombe \\
\hline 139271 & & & 34 & & & 40 & 2182 & 0 & GFA1_YEAST & Glucamine--fructe-6-phphate aminotransferase & S. cerevisiae \\
\hline 36287 & & 1 & 34 & & 1 & 32 & 605 & $2 \mathrm{E}-62$ & IF5A_CANAL & Eukaryotic translation initiation factor $5 \mathrm{~A}$ & C. albicans \\
\hline 56891 & 1 & & 33 & & & 40 & 1863 & 0 & SYEC_SCHPO & Probable glutamyl-tRNA synthetase, cytoplasmic & S. pombe \\
\hline 55618 & & & 33 & & & 39 & 1303 & $1 \mathrm{E}-143$ & FPPS_GIBFU & Farnesyl pyrophphate synthetase & G. fujikuroi \\
\hline 51912 & & 1 & 32 & & & 50 & 1400 & $1 \mathrm{E}-154$ & ARLZ_SCHPO & Probable argininuccinate lyase & S. pombe \\
\hline 207206 & & 5 & 32 & & & 37 & 829 & $8 \mathrm{E}-88$ & KTR1_YEAST & Alpha-1,2 mannyltransferase KTR1 & S. cerevisiae \\
\hline 202152 & 7 & 27 & 32 & 7 & 6 & 33 & 491 & $4 \mathrm{E}-49$ & RL19B_SCHPO & 60 S ribomal protein L19-B & S. pombe \\
\hline 198713 & & & 31 & & & 41 & 1670 & 0 & SSD1_YEAST & Protein SSD1 & S. cerevisiae \\
\hline 53525 & & 10 & 31 & & 3 & 34 & 534 & $2 \mathrm{E}-54$ & RL32_NEUCR & 60 S ribomal protein L32 & N. crassa \\
\hline 52554 & & & 30 & & & 48 & 3422 & 0 & SYLC_NEUCR & Leucyl-tRNA synthetase, cytoplasmic & N. crassa \\
\hline 55644 & & 6 & 30 & & 2 & 41 & 807 & $9 \mathrm{E}-86$ & RS9_PODAN & 40 S ribomal protein $\mathrm{S} 9$ & P. anserina \\
\hline 206105 & & & 30 & & & 38 & 1699 & 0 & EIF3A_SCHPO & Probable eukaryotic translation initiation factor subunit & S. pombe \\
\hline 36448 & & & 30 & & & 26 & 127 & $1 \mathrm{E}-6$ & BTK_HUMAN & Tyrine-protein kinase BTK & H. sapiens \\
\hline 202416 & & 1 & 29 & & 1 & 50 & 880 & $6 \mathrm{E}-94$ & RS3_SCHPO & $40 \mathrm{~S}$ ribomal protein $\mathrm{S} 3$ & S. pombe \\
\hline 56195 & & & 29 & & 1 & 45 & 1971 & 0 & COPG_SCHPO & Probable coatomer subunit gamma & S. pombe \\
\hline 202202 & & & 28 & & & 38 & 2098 & 0 & FIMB_YEAST & Fimbrin & S. cerevisiae \\
\hline 173627 & & 64 & 28 & & 36 & 31 & 715 & $8 \mathrm{E}-75$ & UREG_ANADF & Urease accessory protein ureG & $\begin{array}{l}\text { Anaeromyxobacter } \\
\text { sp. }\end{array}$ \\
\hline 56836 & & 1 & 28 & & & 30 & 999 & $1 \mathrm{E}-108$ & RHOA_EMENI & GTP-binding protein rhoA & E. nidulans \\
\hline 199485 & & 14 & 28 & & 8 & 30 & 257 & $2 \mathrm{E}-22$ & ATPK_SCHPO & ATP synthase subunit $\mathrm{f}$, mitochondrial & S. pombe \\
\hline 56548 & & & 28 & & & 26 & 1361 & $1 \mathrm{E}-149$ & ERG6_NEUCR & Sterol 24-C-methyltransferase & N. crassa \\
\hline 124929 & & & 28 & & & 25 & 309 & $1 \mathrm{E}-27$ & MPPD1_MOUSE & Metallophphoesterase domain-containing protein 1 & M. musculus \\
\hline 208481 & & & 27 & & & 45 & 1906 & 0 & SYMC_YEAST & Methionyl-tRNA synthetase, cytoplasmic & S. cerevisiae \\
\hline 205706 & & & 27 & & & 38 & 1378 & $1 \mathrm{E}-151$ & SPM1_SCHPO & Mitogen-activated protein kinase spm1 & S. pombe \\
\hline 198674 & & 1 & 27 & & & 29 & 882 & $2 \mathrm{E}-94$ & RL10A_NEUCR & $60 \mathrm{~S}$ ribomal protein $\mathrm{L} 10 \mathrm{a}$ & N. crassa \\
\hline 52756 & & & 27 & & & 28 & 2338 & 0 & COPB_SCHPO & Coatomer subunit beta & S. pombe \\
\hline
\end{tabular}




\begin{tabular}{|c|c|c|c|c|c|c|c|c|c|c|c|}
\hline JGI ID & $\begin{array}{l}\text { No Mn } \\
\text { pH } 4.5\end{array}$ & $\begin{array}{l}\text { No } \mathrm{Mn} p \mathrm{H} \\
5.0 \\
\end{array}$ & $\begin{array}{l}\text { No Mn } \\
\text { pH } 5.5\end{array}$ & $\begin{array}{c}\mathrm{Mn} \mathrm{pH} \\
4.5 \\
\end{array}$ & $\begin{array}{c}\mathrm{Mn} \mathrm{pH} \\
5.0 \\
\end{array}$ & $\begin{array}{c}\mathrm{Mn} \mathrm{pH} \\
5.5 \\
\end{array}$ & $\begin{array}{l}\text { Blast } \\
\text { Score } \\
\end{array}$ & $\begin{array}{c}\text { Blast } \\
\text { eValue }\end{array}$ & Blast Hit Name & Hit Description & Species \\
\hline 199495 & & 1 & 26 & & & 49 & 1072 & $1 \mathrm{E}-116$ & RS4A_SCHPO & $40 \mathrm{~S}$ ribomal protein $\mathrm{S} 4-\mathrm{A}$ & S. pombe \\
\hline 52961 & & & 26 & & & 25 & 266 & $2 \mathrm{E}-22$ & PCBP3_HUMAN & Poly(rC)-binding protein 3 & H. sapiens \\
\hline 198893 & & & 26 & & & 21 & 308 & $6 \mathrm{E}-27$ & PBP1_YEAST & PAB1-binding protein 1 & S. cerevisiae \\
\hline 56136 & & & 24 & & & 27 & 1331 & $1 \mathrm{E}-146$ & AMPM1_SCHPO & Probable methionine aminopeptidase 1 & S. pombe \\
\hline 199481 & & & 24 & & & 18 & 566 & $1 \mathrm{E}-57$ & NDUS4_NEUCR & $\begin{array}{l}\text { NADH-ubiquinone oxidoreductase subunit, } \\
\text { mitochondrial }\end{array}$ & N. crassa \\
\hline 208201 & & & 23 & & & 39 & 899 & $2 \mathrm{E}-96$ & ARF_AJECA & ADP-ribylation factor & A. capsulata \\
\hline 55252 & & & 23 & & & 37 & 968 & $1 \mathrm{E}-104$ & RS5_NEUCR & 40 S ribomal protein S5 & N. crassa \\
\hline 202811 & & & 23 & & & 34 & 2553 & 0 & HSP90_PODAN & Heat shock protein 90 homolog & P. anserina \\
\hline 49311 & & 25 & 23 & & 23 & 26 & & & -No-Hit- & No Matching Hit found & \\
\hline 174332 & & & 23 & & & 16 & 132 & $7 \mathrm{E}-7$ & ZN341_HUMAN & Zinc finger protein 341 & H. sapiens \\
\hline 182560 & & & 22 & & & 38 & 647 & $3 \mathrm{E}-66$ & IMB5_SCHPO & Importin subunit beta- 5 & S. pombe \\
\hline 197593 & & & 22 & & & 33 & & & -No-Hit- & No Matching Hit found & \\
\hline 210935 & & & 22 & & & 28 & 1672 & 0 & EIF3C_SCHPO & $\begin{array}{l}\text { Probable eukaryotic translation initiation factor } 3 \\
\text { subunit }\end{array}$ & S. pombe \\
\hline 207376 & & & 22 & & & 24 & 1109 & $1 \mathrm{E}-120$ & EIF3I_SCHPO & Eukaryotic translation initiation factor $339 \mathrm{kDa}$ subunit & S. pombe \\
\hline 199503 & 14 & 20 & 22 & 16 & 13 & 24 & 478 & $6 \mathrm{E}-48$ & RL37_EMENI & 60 S ribomal protein $\mathrm{L} 37$ & E. nidulans \\
\hline 196275 & & & 22 & & & 18 & 1562 & $1 \mathrm{E}-173$ & GBLP_NEUCR & Guanine nucleotide-binding protein subunit beta-like & N. crassa \\
\hline 203758 & & & 21 & & & 35 & 2009 & 0 & DHE4_PENCH & NADP-specific glutamate dehydrogenase & P. chrysogenum \\
\hline 51711 & & & 21 & & & 27 & 1257 & $1 \mathrm{E}-137$ & PURA_SCHPO & Adenyluccinate synthetase & S. pombe \\
\hline 52676 & & & 21 & & & 25 & 1265 & $1 \mathrm{E}-138$ & RL5_NEUCR & $60 \mathrm{~S}$ ribomal protein $\mathrm{L} 5$ & N. crassa \\
\hline 196044 & & 1 & 21 & & & 22 & 820 & $3 \mathrm{E}-87$ & RL17_ASPFU & 60 S ribomal protein $\mathrm{L} 17$ & A. fumigatus \\
\hline 53563 & & & 20 & & & 29 & 1206 & $1 \mathrm{E}-131$ & ENOF1_HUMAN & Mitochondrial enolase superfamily member 1 & H. sapiens \\
\hline 56775 & & 4 & 20 & & & 19 & 1784 & 0 & ARP3_NEUCR & Actin-related protein 3 & N. crassa \\
\hline 210558 & & & 20 & & & 19 & 2143 & 0 & ILVB_YEAST & Acetolactate synthase catalytic subunit, mitochondrial & S. cerevisiae \\
\hline 183753 & & & 20 & & & 15 & 728 & $3 \mathrm{E}-76$ & GCY_YEAST & Protein GCY & S. cerevisiae \\
\hline 206681 & & & 20 & & & 14 & 1568 & $1 \mathrm{E}-173$ & CREA_ASPNG & DNA-binding protein creA & A. niger \\
\hline 55422 & & 1 & 19 & & & 31 & 3872 & 0 & SEC23_ASPNC & Protein transport protein sec 23 & A. niger \\
\hline 201401 & & & 19 & & & 29 & 872 & $4 \mathrm{E}-93$ & RL7_NEUCR & $60 \mathrm{~S}$ ribomal protein $\mathrm{L} 7$ & N. crassa \\
\hline 206038 & & & 19 & & & 24 & 633 & $2 \mathrm{E}-65$ & ALTA7_ALTAL & Minor allergen Alt a 7 & A. alternata \\
\hline 201439 & & 1 & 19 & & & 20 & 788 & $6 \mathrm{E}-83$ & YOI1_SCHPO & Uncharacterized $\mathrm{J}$ domain-containing protein & S. pombe \\
\hline 212837 & & 10 & 18 & & 6 & 29 & 1795 & 0 & UGPA1_SCHPO & Probable UTP--gluce-1-phphate uridylyltransferase & S. pombe \\
\hline 214104 & & 1 & 18 & & & 25 & 1094 & $1 \mathrm{E}-118$ & KHSE_YEAST & Homerine kinase & S. cerevisiae \\
\hline 214112 & & & 18 & & & 16 & 1827 & 0 & CBF5_ASPFU & Centromere/microtubule-binding protein cbf5 & A. fumigatus \\
\hline 192720 & & & 17 & & & 32 & 925 & $8 \mathrm{E}-99$ & YCFD_SCHPO & UPF0364 protein C1393.13 & S. pombe \\
\hline
\end{tabular}




\begin{tabular}{|c|c|c|c|c|c|c|c|c|c|c|c|}
\hline JGI ID & $\begin{array}{l}\text { No Mn } \\
\text { pH } 4.5\end{array}$ & $\begin{array}{l}\text { No } \mathrm{Mn} \mathrm{pH} \\
5.0 \\
\end{array}$ & $\begin{array}{l}\text { No Mn } \\
\text { pH } 5.5 \\
\end{array}$ & $\begin{array}{c}\mathrm{Mn} \mathrm{pH} \\
4.5 \\
\end{array}$ & $\begin{array}{c}\mathrm{Mn} \mathrm{pH} \\
5.0 \\
\end{array}$ & $\begin{array}{c}\mathrm{Mn} \mathrm{pH} \\
5.5 \\
\end{array}$ & $\begin{array}{l}\text { Blast } \\
\text { Score }\end{array}$ & $\begin{array}{l}\text { Blast } \\
\text { eValue }\end{array}$ & Blast Hit Name & Hit Description & Species \\
\hline 205400 & & & 17 & & & 27 & 1972 & 0 & IMB1_SCHPO & Importin subunit beta-1 & S. pombe \\
\hline 189367 & & & 17 & & & 20 & 1385 & $1 \mathrm{E}-152$ & LAC2_BOTFU & Laccase-2 & B. fuckeliana \\
\hline 130307 & & & 17 & & & 20 & 669 & $6 \mathrm{E}-69$ & BRX1_YEAST & Ribome biogenesis protein $\mathrm{BRX} 1$ & S. cerevisiae \\
\hline 52803 & 2 & 6 & 17 & 5 & 2 & 15 & 863 & 7E-92 & ODC2_YEAST & Mitochondrial 2-oxodicarboxylate carrier 2 & S. cerevisiae \\
\hline 196131 & & & 17 & & & 13 & 168 & $1 \mathrm{E}-11$ & ATPN_YEAST & ATP synthase subunit g, mitochondrial & S. cerevisiae \\
\hline 209058 & & & 16 & & & 34 & 2806 & 0 & MET3_ASPNG & Sulfate adenylyltransferase & A. niger \\
\hline 52388 & & & 16 & & & 29 & 2201 & 0 & VPS1_SCHPO & Vacuolar protein sorting-associated protein 1 & S. pombe \\
\hline 206944 & & 16 & 16 & & 7 & 23 & 341 & $6 \mathrm{E}-32$ & UBIQ_CANAL & Ubiquitin & C. albicans \\
\hline 46314 & & & 16 & & & 21 & 3723 & 0 & YD22_SCHPO & Uncharacterized protein $\mathrm{C} 56 \mathrm{~F} 8.02$ & S. pombe \\
\hline 51703 & & & 16 & & & 19 & 401 & $6 \mathrm{E}-38$ & PP2C4_SCHPO & Protein phphatase $2 \mathrm{C}$ homolog 4 & S. pombe \\
\hline 183233 & & & 16 & & & 17 & 1459 & $1 \mathrm{E}-160$ & THRC_SCHPO & Threonine synthase & S. pombe \\
\hline 128861 & & & 16 & & & 15 & 1023 & $1 \mathrm{E}-109$ & ACD11_CHICK & Acyl-CoA dehydrogenase family member 11 & G. gallus \\
\hline 197796 & 1 & & 15 & 1 & & 24 & & & -No-Hit- & No Matching Hit found & \\
\hline 208263 & & & 15 & & & 22 & 2195 & 0 & TBB_ASPOR & Tubulin beta chain & A. oryzae \\
\hline 128750 & & & 15 & & & 21 & 861 & $1 \mathrm{E}-90$ & YCKC_SCHPO & PX domain-containing protein $\mathrm{C} 1450.12$ & S. pombe \\
\hline 52878 & & & 15 & & & 19 & 197 & $2 \mathrm{E}-14$ & NAB2_YEAST & Nuclear polyadenylated RNA-binding protein NAB2 & S. cerevisiae \\
\hline 49729 & & & 15 & & & 19 & 659 & $5 \mathrm{E}-68$ & SCJ1_YEAST & DnaJ-related protein SCJ1 & S. cerevisiae \\
\hline 208051 & & & 15 & & & 18 & 1289 & $1 \mathrm{E}-141$ & IDH2_SCHPO & $\begin{array}{l}\text { Isocitrate dehydrogenase [NAD] subunit } 2 \text {, } \\
\text { mitochondrial }\end{array}$ & S. pombe \\
\hline 174236 & & 1 & 15 & & & 18 & & & -No-Hit- & No Matching Hit found & \\
\hline 214233 & & & 15 & & & 17 & 5122 & 0 & AGLU_ASPNG & Alpha-glucidase & A. niger \\
\hline 213140 & & & 15 & & & 17 & 1001 & $1 \mathrm{E}-107$ & SAC1_YEAST & Phphoinitide phphatase SAC1 & S. cerevisiae \\
\hline 199078 & & & 15 & & & 15 & 285 & $1 \mathrm{E}-24$ & MTAD_METS3 & 5-methylthioadenine/S-adenylhomocysteine deaminase & M. smithii \\
\hline 187248 & 1 & & 15 & & & 15 & 1731 & 0 & 2AAA_SCHPO & Protein phphatase PP2A regulatory subunit A & S. pombe \\
\hline 181698 & & & 14 & & & 26 & 1673 & 0 & YNR7_SCHPO & Uncharacterized protein $\mathrm{C} 11 \mathrm{G} 11.07$ & S. pombe \\
\hline 56871 & & & 14 & & & 17 & 1037 & $1 \mathrm{E}-112$ & YHM2_YEAST & Mitochondrial DNA replication protein YHM2 & S. cerevisiae \\
\hline 52880 & & & 14 & & & 17 & 1714 & 0 & UBR1_SCHPO & E3 ubiquitin-protein ligase ubr1 & S. pombe \\
\hline 51819 & & & 14 & & & 16 & 1999 & 0 & SYTC_SCHPO & Threonyl-tRNA synthetase, cytoplasmic & S. pombe \\
\hline 42169 & & & 14 & & & 14 & 561 & $5 \mathrm{E}-57$ & LAMB_EMENI & Lactam utilization protein lamB & E. nidulans \\
\hline 178461 & 1 & 12 & 14 & & 8 & 11 & 770 & $1 \mathrm{E}-80$ & YAC2_SCHPO & Uncharacterized protein $\mathrm{C} 16 \mathrm{C} 9.02 \mathrm{c}$ & S. pombe \\
\hline 52441 & & & 14 & & & 8 & 1749 & 0 & TCPD_SCHPO & T-complex protein 1 subunit delta & S. pombe \\
\hline 57091 & & & 14 & & & 6 & 1863 & 0 & ASNS_SCHPO & $\begin{array}{l}\text { Probable asparagine synthetase [glutamine- } \\
\text { hydrolyzing] }\end{array}$ & S. pombe \\
\hline 52642 & & & 13 & & & 24 & 3374 & 0 & SYIC_SCHPO & Isoleucyl-tRNA synthetase, cytoplasmic & S. pombe \\
\hline 56469 & & & 13 & & & 22 & 3386 & 0 & COPA_SCHPO & Putative coatomer subunit alpha & S. pombe \\
\hline
\end{tabular}




\begin{tabular}{|c|c|c|c|c|c|c|c|c|c|c|c|}
\hline JGI ID & $\begin{array}{l}\text { No Mn } \\
\text { pH } 4.5\end{array}$ & $\begin{array}{l}\text { No } \mathrm{Mn} \mathrm{pH} \\
5.0\end{array}$ & $\begin{array}{l}\text { No Mn } \\
\text { pH } 5.5\end{array}$ & $\begin{array}{c}\mathrm{Mn} \mathrm{pH} \\
4.5 \\
\end{array}$ & $\begin{array}{c}\mathrm{Mn} \mathrm{pH} \\
5.0\end{array}$ & $\begin{array}{c}\mathrm{Mn} \mathrm{pH} \\
5.5 \\
\end{array}$ & $\begin{array}{l}\text { Blast } \\
\text { Score }\end{array}$ & $\begin{array}{l}\text { Blast } \\
\text { eValue }\end{array}$ & Blast Hit Name & Hit Description & Species \\
\hline 56715 & & & 13 & & & 21 & 7228 & 0 & ACAC_SCHPO & Acetyl-CoA carboxylase & S. pombe \\
\hline 198959 & & & 13 & & & 17 & 599 & $1 \mathrm{E}-61$ & RL9B_YEAST & 60S ribomal protein L9-B & S. cerevisiae \\
\hline 202504 & & 3 & 13 & & 4 & 16 & 721 & $4 \mathrm{E}-76$ & RS19_EMENI & $40 \mathrm{~S}$ ribomal protein $\mathrm{S} 19$ & E. nidulans \\
\hline 52474 & & & 13 & & & 13 & 1079 & $1 \mathrm{E}-116$ & NRD1_SCHPO & Negative regulator of differentiation 1 & S. pombe \\
\hline 197079 & & & 13 & & & 13 & & & -No-Hit- & No Matching Hit found & \\
\hline 56312 & & & 13 & & & 12 & 178 & $2 \mathrm{E}-12$ & WWOX_CHICK & WW domain-containing oxidoreductase & G. gallus \\
\hline 47873 & & & 13 & & & 12 & 1903 & 0 & SYKC_SCHPO & Lysyl-tRNA synthetase, cytoplasmic & S. pombe \\
\hline 171507 & & 3 & 13 & & & 11 & 1019 & $1 \mathrm{E}-110$ & HIS8_SCHPO & Histidinol-phphate aminotransferase & S. pombe \\
\hline 45992 & & & 13 & & & 10 & 3830 & 0 & CHSC_ASPFU & Chitin synthase $\mathrm{C}$ & A. fumigatus \\
\hline 119441 & & & 13 & & & 8 & & & -No-Hit- & No Matching Hit found & \\
\hline 53726 & & & 13 & & & 7 & 181 & $2 \mathrm{E}-12$ & SFL1_YEAST & Flocculation suppression protein & S. cerevisiae \\
\hline 210782 & & & 12 & & & 23 & 174 & $3 \mathrm{E}-12$ & YA02_SCHPO & Uncharacterized protein $\mathrm{C} 5 \mathrm{H} 10.02 \mathrm{c}$ & S. pombe \\
\hline 57363 & & & 12 & & & 18 & 917 & $3 \mathrm{E}-97$ & PSME4_HUMAN & Proteasome activator complex subunit 4 & H. sapiens \\
\hline 209010 & & & 12 & & & 15 & 921 & 2E-98 & DHAS_SCHPO & Probable aspartate-semialdehyde dehydrogenase & S. pombe \\
\hline 205810 & & & 12 & & & 15 & 2060 & 0 & CALX_ASPFU & Calnexin homolog & A. fumigatus \\
\hline 56120 & & & 12 & & 1 & 14 & & & -No-Hit- & No Matching Hit found & \\
\hline 56390 & & & 12 & & & 13 & 1085 & $1 \mathrm{E}-117$ & AATC_SCHPO & Aspartate aminotransferase, cytoplasmic & S. pombe \\
\hline 211700 & & & 12 & & & 12 & 1862 & 0 & GLYM_NEUCR & $\begin{array}{l}\text { Putative serine hydroxymethyltransferase, } \\
\text { mitochondrial }\end{array}$ & N. crassa \\
\hline 47102 & & & 12 & & & 10 & 1554 & $1 \mathrm{E}-171$ & 2A5D_HUMAN & $\begin{array}{l}\text { Serine/threonine-protein phphatase subunit delta } \\
\text { isoform }\end{array}$ & H. sapiens \\
\hline 55693 & & & 12 & & & 6 & 433 & $9 \mathrm{E}-43$ & HNT1_YEAST & Hit family protein 1 & S. cerevisiae \\
\hline 207105 & & & 11 & & & 17 & 1313 & $1 \mathrm{E}-143$ & YB2G_SCHPO & Uncharacterized protein $\mathrm{C} 31 \mathrm{~F} 10.16$ & S. pombe \\
\hline 200845 & & & 11 & & & 15 & 516 & $5 \mathrm{E}-51$ & SPO14_YEAST & Phpholipase D1 & S. cerevisiae \\
\hline 57431 & & & 11 & & & 14 & 1696 & 0 & PYRG_NEUCR & CTP synthase & N. crassa \\
\hline 206881 & & 1 & 11 & & 3 & 14 & 843 & 7E-90 & RS7_NEUCR & $40 \mathrm{~S}$ ribomal protein $\mathrm{S} 7$ & N. crassa \\
\hline 206203 & & & 11 & & & 14 & 398 & $7 \mathrm{E}-38$ & DHSO_BACHD & Sorbitol dehydrogenase & B. halodurans \\
\hline 183952 & & & 11 & & & 11 & 590 & $3 \mathrm{E}-60$ & CPSF5_XENLA & $\begin{array}{l}\text { Cleavage and polyadenylation specificity factor subunit } \\
5\end{array}$ & X. laevis \\
\hline 182955 & & & 11 & & & 11 & & & -No-Hit- & No Matching Hit found & \\
\hline 56526 & & & 11 & & & 10 & 943 & $1 \mathrm{E}-101$ & AFG1_YEAST & Protein AFG1 & S. cerevisiae \\
\hline 46615 & & 3 & 11 & & & 9 & 1470 & $1 \mathrm{E}-161$ & YCW2_YEAST & WD repeat-containing protein YCR072C & S. cerevisiae \\
\hline 201877 & & & 11 & & & 9 & 2522 & 0 & HXKG_ASPNG & Glucokinase & A. niger \\
\hline 42881 & & & 11 & & & 7 & 555 & $5 \mathrm{E}-56$ & URH1_YEAST & Uridine nucleidase & S. cerevisiae \\
\hline 52248 & & & 10 & & & 27 & 1467 & $1 \mathrm{E}-161$ & GAD8_SCHPO & Serine/threonine-protein kinase gad8 & S. pombe \\
\hline 214022 & & & 10 & & & 19 & 780 & $3 \mathrm{E}-82$ & ADK1_ARATH & Adenine kinase 1 & A. thaliana \\
\hline
\end{tabular}




\begin{tabular}{|c|c|c|c|c|c|c|c|c|c|c|c|}
\hline JGI ID & $\begin{array}{l}\text { No Mn } \\
\text { pH } 4.5\end{array}$ & $\begin{array}{l}\text { No Mn } \mathrm{pH} \\
5.0\end{array}$ & $\begin{array}{l}\text { No Mn } \\
\text { pH } 5.5\end{array}$ & $\begin{array}{c}\mathrm{Mn} \mathrm{pH} \\
4.5\end{array}$ & $\begin{array}{c}\mathrm{Mn} \mathrm{pH} \\
5.0\end{array}$ & $\begin{array}{c}\mathrm{Mn} \mathrm{pH} \\
5.5\end{array}$ & $\begin{array}{l}\text { Blast } \\
\text { Score }\end{array}$ & $\begin{array}{c}\text { Blast } \\
\text { eValue }\end{array}$ & Blast Hit Name & Hit Description & Species \\
\hline 172591 & & & 10 & & & 18 & 1137 & $1 \mathrm{E}-123$ & DCUP_YEAST & Uroporphyrinogen decarboxylase & S. cerevisiae \\
\hline 55918 & & & 10 & & & 17 & 1802 & 0 & PP2A1_EMENI & $\begin{array}{l}\text { Serine/threonine-protein phphatase PP2A catalytic } \\
\text { subunit }\end{array}$ & E. nidulans \\
\hline 54362 & & & 10 & & & 16 & 1163 & $1 \mathrm{E}-126$ & SYWC_YEAST & Tryptophanyl-tRNA synthetase, cytoplasmic & S. cerevisiae \\
\hline 130008 & & & 10 & & & 15 & 1640 & 0 & AAP1_YEAST & Alanine/arginine aminopeptidase & S. cerevisiae \\
\hline 46410 & & & 10 & & & 14 & 1076 & $1 \mathrm{E}-116$ & NOC2_YEAST & Nucleolar complex protein 2 & S. cerevisiae \\
\hline 53120 & & & 10 & & & 13 & 1949 & 0 & PMT2_YEAST & Dolichyl-phphate-manne--protein mannyltransferase 2 & S. cerevisiae \\
\hline 38927 & & & 10 & & & 11 & 150 & $3 \mathrm{E}-09$ & YA03_SCHPO & Uncharacterized protein $\mathrm{C} 5 \mathrm{H} 10.03$ & S. pombe \\
\hline 212077 & & & 10 & & & 11 & 923 & $3 \mathrm{E}-98$ & AP3B1_CANFA & AP-3 complex subunit beta- 1 & C. familiaris \\
\hline 173656 & & & 10 & & & 11 & 1979 & 0 & LIDS_GAEGR & Linoleate diol synthase & G. graminis \\
\hline 120745 & & & 10 & & & 10 & 540 & $4 \mathrm{E}-54$ & MCS4_SCHPO & Response regulator mcs 4 & S. pombe \\
\hline 53063 & & & 10 & & & 8 & 144 & 4E-09 & YNV8_SCHPO & Uncharacterized protein $\mathrm{C} 3 \mathrm{H} 7.08 \mathrm{c}$ & S. pombe \\
\hline 47529 & & & 10 & & & 8 & 1062 & $1 \mathrm{E}-114$ & SPT20_HUMAN & Spermatogenesis-associated protein 20 & H. sapiens \\
\hline 119127 & & & 10 & & & 8 & 168 & $1 \mathrm{E}-10$ & GP1_CHLRE & Vegetative cell wall protein gp1 & C. reinhardtii \\
\hline 180613 & & & 10 & & & 6 & 3008 & 0 & SEC7_YEAST & Protein transport protein SEC7 & S. cerevisiae \\
\hline 210951 & & & 10 & & & 4 & 2647 & 0 & GCSP_SCHPO & Putative glycine dehydrogenase, mitochondrial & S. pombe \\
\hline 50058 & & & 10 & & & 2 & 406 & $1 \mathrm{E}-38$ & TGTL_SCHPO & Queuine tRNA-ribyltransferase-like protein & S. pombe \\
\hline 35679 & & & 9 & & & 16 & 324 & $6 \mathrm{E}-29$ & NIRA_EMENI & Nitrogen assimilation transcription factor nirA & E. nidulans \\
\hline 205183 & 1 & & 9 & & & 15 & 3688 & 0 & CDC48_EMENI & Cell division control protein 48 & E. nidulans \\
\hline 136122 & & & 9 & & & 15 & 196 & $1 \mathrm{E}-14$ & CBP3_YEAST & Protein $\mathrm{CBP} 3$, mitochondrial & S. cerevisiae \\
\hline 47739 & & & 9 & & & 14 & 286 & $5 \mathrm{E}-25$ & MOB2_YEAST & CBK1 kinase activator protein MOB2 & S. cerevisiae \\
\hline 181434 & & & 9 & & & 13 & 2608 & 0 & PP2B_ASPFU & Serine/threonine-protein phphatase 2B catalytic subunit & A. fumigatus \\
\hline 55770 & & & 9 & & & 12 & 119 & $1 \mathrm{E}-5$ & ZN362_HUMAN & Zinc finger protein 362 & H. sapiens \\
\hline 213652 & & 1 & 9 & & & 12 & 705 & $4 \mathrm{E}-73$ & PK1_DICDI & Forkhead-associated domain-containing protein kinase & D. discoideum \\
\hline 198862 & & & 9 & & & 12 & 245 & $2 \mathrm{E}-20$ & YE1I_SCHPO & Uncharacterized protein C1B3.18c & S. pombe \\
\hline 54201 & & & 9 & & & 11 & 982 & $1 \mathrm{E}-105$ & RPN6_SCHPO & Probable $26 \mathrm{~S}$ proteasome regulatory subunit rpn6 & S. pombe \\
\hline 53576 & & & 9 & & 1 & 10 & 231 & $2 \mathrm{E}-19$ & RLA2_ASPFU & $60 \mathrm{~S}$ acidic ribomal protein $\mathrm{P} 2$ & A. fumigatus \\
\hline 40848 & & & 9 & & & 10 & 232 & $1 \mathrm{E}-18$ & AIFM2_HUMAN & Apoptis-inducing factor 2 & H. sapiens \\
\hline 212992 & & & 9 & & & 10 & 3429 & 0 & ODO1_YEAST & $\begin{array}{l}\text { 2-oxoglutarate dehydrogenase E1 component, } \\
\text { mitochondrial }\end{array}$ & S. cerevisiae \\
\hline 209956 & & & 9 & & & 10 & 1402 & $1 \mathrm{E}-154$ & GSK3_SCHPO & Protein kinase gsk3 & S. pombe \\
\hline 190965 & & & 9 & & & 10 & 271 & $4 \mathrm{E}-23$ & YJIA_ECOLI & Uncharacterized GTP-binding protein yjiA & E. coli \\
\hline 49747 & & 7 & 9 & & 4 & 9 & 2056 & 0 & STUA_EMENI & Cell pattern formation-associated protein stuA & E. nidulans \\
\hline 209660 & & & 9 & & & 7 & 130 & $2 \mathrm{E}-6$ & EP300_HUMAN & Histone acetyltransferase $\mathrm{p} 300$ & H. sapiens \\
\hline 55430 & & & 9 & & & 6 & & & -No-Hit- & No Matching Hit found & \\
\hline
\end{tabular}




\begin{tabular}{|c|c|c|c|c|c|c|c|c|c|c|c|}
\hline JGI ID & $\begin{array}{l}\text { No Mn } \\
\text { pH } 4.5\end{array}$ & $\begin{array}{l}\text { No } \mathrm{Mn} \mathrm{pH} \\
5.0 \\
\end{array}$ & $\begin{array}{l}\text { No Mn } \\
\text { pH } 5.5\end{array}$ & $\begin{array}{c}\mathrm{Mn} \mathrm{pH} \\
4.5 \\
\end{array}$ & $\begin{array}{c}\mathrm{Mn} \mathrm{pH} \\
5.0 \\
\end{array}$ & $\begin{array}{c}\mathrm{Mn} \mathrm{pH} \\
5.5 \\
\end{array}$ & $\begin{array}{l}\text { Blast } \\
\text { Score }\end{array}$ & $\begin{array}{l}\text { Blast } \\
\text { eValue }\end{array}$ & Blast Hit Name & Hit Description & Species \\
\hline 36954 & & 2 & 9 & & & 6 & 196 & $2 \mathrm{E}-14$ & YL8J_SCHPO & Zinc finger protein $\mathrm{C} 25 \mathrm{~B} 8.19 \mathrm{c}$ & S. pombe \\
\hline 48253 & & & 9 & & & 2 & & & -No-Hit- & No Matching Hit found & \\
\hline 38101 & & & 9 & & & 1 & 2538 & 0 & TAO3_YEAST & Cell morphogenesis protein PAG1 & S. cerevisiae \\
\hline 56295 & & & 8 & & & 22 & 1826 & 0 & CSE1_YEAST & Importin alpha re-exporter & S. cerevisiae \\
\hline 55563 & & & 8 & & & 12 & 1313 & $1 \mathrm{E}-144$ & URIC_ASPFL & Uricase & A. flavus \\
\hline 212876 & 1 & 3 & 8 & & 1 & 12 & 819 & $6 \mathrm{E}-87$ & RS2_YEAST & $40 \mathrm{~S}$ ribomal protein $\mathrm{S} 2$ & S. cerevisiae \\
\hline 56606 & & & 8 & & & 11 & 271 & $6 \mathrm{E}-24$ & RM51_YEAST & $54 \mathrm{~S}$ ribomal protein $\mathrm{L} 51$, mitochondrial & S. cerevisiae \\
\hline 53687 & & & 8 & & & 10 & 406 & $4 \mathrm{E}-39$ & YLIJ_ECOLI & Uncharacterized GST-like protein yliJ & E. coli \\
\hline 56196 & & & 8 & & & 8 & 1298 & $1 \mathrm{E}-142$ & SYDC_YEAST & Aspartyl-tRNA synthetase, cytoplasmic & S. cerevisiae \\
\hline 43791 & & & 8 & & & 6 & 365 & $3 \mathrm{E}-34$ & YE16_SCHPO & Uncharacterized methyltransferase C1B3.06c & S. pombe \\
\hline 35307 & & & 8 & & & 4 & 1457 & $1 \mathrm{E}-160$ & ARGD_NEUCR & Acetylornithine aminotransferase, mitochondrial & N. crassa \\
\hline 210170 & & & 8 & & & 1 & 1945 & 0 & RGA1_SCHPO & Rho-type GTPase-activating protein 1 & S. pombe \\
\hline 200308 & & & 7 & & & 17 & 3300 & 0 & EF3_CANAL & Elongation factor 3 & C. albicans \\
\hline 197883 & & 1 & 7 & & & 14 & 2038 & 0 & PMA2_SCHPO & Plasma membrane ATPase 2 & S. pombe \\
\hline 47358 & & & 7 & & & 13 & 8477 & 0 & UTP10_ASPNC & U3 small nucleolar RNA-associated protein 10 & A. niger \\
\hline 207465 & & & 7 & & & 12 & 971 & $1 \mathrm{E}-103$ & YN8E_SCHPO & Pumilio domain-containing protein P35G2.14 & S. pombe \\
\hline 181371 & & & 7 & & & 12 & 2651 & 0 & HSP70_EMENI & Heat shock $70 \mathrm{kDa}$ protein & E. nidulans \\
\hline 56424 & & & 7 & & & 10 & 840 & $2 \mathrm{E}-89$ & DPM1_HUMAN & Dolichol-phphate mannyltransferase & H. sapiens \\
\hline 46621 & & & 7 & & & 10 & 3547 & 0 & GDE_YEAST & Glycogen debranching enzyme & S. cerevisiae \\
\hline 55637 & & & 7 & & & 7 & 2464 & 0 & DHSA_SCHPO & $\begin{array}{l}\text { Probable succinate dehydrogenase subunit, } \\
\text { mitochondrial }\end{array}$ & S. pombe \\
\hline 55469 & & & 7 & & & 7 & 565 & $1 \mathrm{E}-56$ & VPS52_SCHPO & Vacuolar protein sorting-associated protein 52 & S. pombe \\
\hline 52997 & & & 7 & & 1 & 7 & 1134 & $1 \mathrm{E}-122$ & YDE1_SCHPO & $\begin{array}{l}\text { Probable ubiquitin fusion degradation protein } \\
\text { C12B10.01c }\end{array}$ & S. pombe \\
\hline 40551 & & & 7 & & & 7 & 839 & $5 \mathrm{E}-89$ & TOXG_COCCA & Alanine racemase TOXG & C. carbonum \\
\hline 202289 & & & 7 & & & 7 & 136 & $1 \mathrm{E}-7$ & YII1_SCHPO & Uncharacterized protein $\mathrm{C} 139.01 \mathrm{c}$ & S. pombe \\
\hline 137752 & 3 & 3 & 7 & & 1 & 7 & 640 & $2 \mathrm{E}-66$ & RL20_YEAST & $60 \mathrm{~S}$ ribomal protein $\mathrm{L} 20$ & S. cerevisiae \\
\hline 57072 & & & 7 & & & 6 & 1776 & 0 & IF2G_YEAST & Eukaryotic translation initiation factor 2 subunit gamma & S. cerevisiae \\
\hline 206125 & & & 7 & & & 6 & 1083 & $1 \mathrm{E}-117$ & MAS5_SCHPO & Mitochondrial protein import protein mas 5 & S. pombe \\
\hline 209509 & 3 & 7 & 7 & 2 & 4 & 5 & 463 & $1 \mathrm{E}-44$ & YDSB_SCHPO & $\begin{array}{l}\text { Uncharacterized WD repeat-containing protein } \\
\text { C4F8.11 }\end{array}$ & S. pombe \\
\hline 209509 & 3 & 7 & 7 & 2 & 4 & 5 & 463 & $1 \mathrm{E}-44$ & YDSB_SCHPO & $\begin{array}{l}\text { Uncharacterized WD repeat-containing protein } \\
\text { C4F8.11 }\end{array}$ & S. pombe \\
\hline 38370 & & & 7 & & & 4 & 1430 & $1 \mathrm{E}-157$ & AACS_CHICK & Acetoacetyl-CoA synthetase & G. gallus \\
\hline 132771 & & & 7 & & & 4 & 885 & $3 \mathrm{E}-94$ & PMM_SCHPO & Phphomannomutase & S. pombe \\
\hline 206602 & & & 7 & & & 3 & 316 & $2 \mathrm{E}-28$ & TPIS2_RHILO & Triephphate isomerase 2 & R. loti \\
\hline
\end{tabular}




\begin{tabular}{|c|c|c|c|c|c|c|c|c|c|c|c|}
\hline JGI ID & $\begin{array}{l}\text { No Mn } \\
\text { pH } 4.5\end{array}$ & $\begin{array}{l}\text { No } \mathrm{Mn} p \mathrm{H} \\
5.0 \\
\end{array}$ & $\begin{array}{l}\text { No Mn } \\
\text { pH } 5.5\end{array}$ & $\begin{array}{c}\mathrm{Mn} \mathrm{pH} \\
4.5 \\
\end{array}$ & $\begin{array}{c}\mathrm{Mn} \mathrm{pH} \\
5.0 \\
\end{array}$ & $\begin{array}{c}\mathrm{Mn} \mathrm{pH} \\
5.5 \\
\end{array}$ & $\begin{array}{l}\text { Blast } \\
\text { Score }\end{array}$ & $\begin{array}{c}\text { Blast } \\
\text { eValue }\end{array}$ & Blast Hit Name & Hit Description & Species \\
\hline 52614 & & & 7 & & & 2 & 337 & $1 \mathrm{E}-30$ & DHC24_HUMAN & 24-dehydrocholesterol reductase & H. sapiens \\
\hline 207217 & & & 6 & & & 15 & 3070 & 0 & GYS_NEUCR & Glycogen [starch] synthase & N. crassa \\
\hline 207705 & & & 6 & & & 12 & 847 & $6 \mathrm{E}-90$ & RPN9_SCHPO & Probable $26 \mathrm{~S}$ proteasome regulatory subunit rpn 9 & S. pombe \\
\hline 52666 & & & 6 & & & 10 & 461 & $2 \mathrm{E}-44$ & NU184_SCHPO & Nucleoporin nup184 & S. pombe \\
\hline 57311 & & & 6 & & & 9 & 1463 & $1 \mathrm{E}-161$ & SERA_YEAST & D-3-phphoglycerate dehydrogenase 1 & S. cerevisiae \\
\hline 55785 & & & 6 & & & 9 & 399 & $6 \mathrm{E}-38$ & RM03_YEAST & $54 \mathrm{~S}$ ribomal protein $\mathrm{L} 3$, mitochondrial & S. cerevisiae \\
\hline 54566 & & & 6 & & & 9 & 1219 & $1 \mathrm{E}-133$ & SYYM_NEUCR & Tyryl-tRNA synthetase, mitochondrial & N. crassa \\
\hline 53690 & & & 6 & & & 9 & 448 & $4 \mathrm{E}-44$ & ARPC3_SCHPO & Actin-related protein $2 / 3$ complex subunit 3 & S. pombe \\
\hline 56145 & & & 6 & & & 8 & 2401 & 0 & TPSB_ASPNG & Alpha,alpha-trehale-phphate synthase [UDP-forming] 2 & A. niger \\
\hline 55738 & & & 6 & & & 8 & 10186 & 0 & PYR1_EMENI & Protein pyrABCN & E. nidulans \\
\hline 54083 & & & 6 & & & 8 & & & -No-Hit- & No Matching Hit found & \\
\hline 52883 & & & 6 & & & 8 & 914 & $8 \mathrm{E}-98$ & PSB5_YEAST & Proteasome component PRE2 & S. cerevisiae \\
\hline 48257 & & & 6 & & & 8 & 896 & $1 \mathrm{E}-95$ & TFTE_BURCE & Maleylacetate reductase & B. серасіа \\
\hline 42464 & & & 6 & & & 7 & 654 & $4 \mathrm{E}-68$ & SSP1_NEUCR & Peptidyl-prolyl cis-trans isomerase ssp-1 & N. crassa \\
\hline 209255 & & & 6 & & & 7 & 1095 & $1 \mathrm{E}-119$ & YHM1_YEAST & Putative mitochondrial carrier protein YHM1/SHM1 & S. cerevisiae \\
\hline 208393 & & & 6 & & & 7 & & & -No-Hit- & No Matching Hit found & \\
\hline 45754 & & & 6 & & & 6 & 1642 & 0 & SYQ_SCHPO & Probable glutaminyl-tRNA synthetase & S. pombe \\
\hline 207660 & & & 6 & & & 6 & 9361 & 0 & FKS1_ASPNG & 1,3-beta-glucan synthase component FKS1 & A. niger \\
\hline 171927 & & & 6 & & & 6 & 1500 & $1 \mathrm{E}-165$ & FET3_CANAL & Iron transport multicopper oxidase FET3 & C. albicans \\
\hline 56635 & & & 6 & & & 5 & 1565 & $1 \mathrm{E}-173$ & RIR2_NEUCR & Ribonucleide-diphphate reductase small chain & N. crassa \\
\hline 45634 & & & 6 & & & 2 & 384 & $9 \mathrm{E}-36$ & $\underset{\mathrm{N}}{\mathrm{ANKH}{ }_{-} \text {HUMA }}$ & Ankyrin repeat and $\mathrm{KH}$ domain-containing protein 1 & H. sapiens \\
\hline 172390 & & 1 & 5 & & 2 & 13 & 1019 & $1 \mathrm{E}-110$ & SODB_ASPNG & Superoxide dismutase [Mn], mitochondrial & A. niger \\
\hline 56049 & & & 5 & & & 9 & 995 & $1 \mathrm{E}-107$ & PSD12_BOVIN & $26 \mathrm{~S}$ proteasome non-ATPase regulatory subunit 12 & B. taurus \\
\hline 211731 & & & 5 & & & 9 & 882 & 7E-94 & YFH6_YEAST & Uncharacterized peptidase YFR006W & S. cerevisiae \\
\hline 209198 & & & 5 & & & 9 & 2110 & 0 & DHH1_ASPNC & ATP-dependent RNA helicase dhh1 & A. niger \\
\hline 207219 & & & 5 & & & 9 & 1639 & 0 & NMT1_ASPPA & Protein NMT1 homolog & A. parasiticus \\
\hline 55011 & & & 5 & & & 7 & 2496 & 0 & NDUV1_ASPNG & $\begin{array}{l}\text { NADH-ubiquinone oxidoreductase subunit, } \\
\text { mitochondrial }\end{array}$ & A. niger \\
\hline 53232 & & 1 & 5 & & & 7 & 1446 & $1 \mathrm{E}-159$ & DLDH_SCHPO & Dihydrolipoyl dehydrogenase, mitochondrial & S. pombe \\
\hline 41311 & & & 5 & & & 7 & 1912 & 0 & MU138_SCHPO & Putative zinc protease mug 138 & S. pombe \\
\hline 55365 & & & 5 & & & 6 & & & -No-Hit- & No Matching Hit found & \\
\hline 55055 & & 1 & 5 & & & 6 & 2194 & 0 & SIP5_ASPOR & Protein sip5 & A. oryzae \\
\hline 213185 & & & 5 & & & 6 & 5645 & 0 & PYC_ASPNG & Pyruvate carboxylase & A. niger \\
\hline 207003 & & & 5 & & & 6 & 1698 & 0 & LYS1_EMENI & $\begin{array}{l}\text { Saccharopine dehydrogenase [NAD+, L-lysine- } \\
\text { forming] }\end{array}$ & E. nidulans \\
\hline
\end{tabular}




\begin{tabular}{|c|c|c|c|c|c|c|c|c|c|c|c|}
\hline JGI ID & $\begin{array}{l}\text { No Mn } \\
\text { pH 4.5 }\end{array}$ & $\begin{array}{c}\text { No Mn } \mathrm{pH} \\
5.0 \\
\end{array}$ & $\begin{array}{l}\text { No Mn } \\
\text { pH 5.5 }\end{array}$ & $\begin{array}{c}\mathrm{Mn} \mathrm{pH} \\
4.5 \\
\end{array}$ & $\begin{array}{c}\mathrm{Mn} \mathrm{pH} \\
5.0 \\
\end{array}$ & $\begin{array}{c}\mathrm{Mn} \mathrm{pH} \\
5.5 \\
\end{array}$ & $\begin{array}{l}\text { Blast } \\
\text { Score } \\
\end{array}$ & $\begin{array}{l}\text { Blast } \\
\text { eValue }\end{array}$ & Blast Hit Name & Hit Description & Species \\
\hline 207470 & & & 5 & & & 5 & 1481 & $1 \mathrm{E}-163$ & SYNC_YEAST & Asparaginyl-tRNA synthetase, cytoplasmic & S. cerevisiae \\
\hline 57102 & & 5 & 5 & 1 & 4 & 4 & 3420 & 0 & RIR1_NEUCR & Ribonucleide-diphphate reductase large chain & N. crassa \\
\hline 56817 & & & 5 & & & 4 & 1063 & $1 \mathrm{E}-115$ & ANM1_SCHPO & Probable protein arginine $\mathrm{N}$-methyltransferase & S. pombe \\
\hline 38620 & & & 5 & & & 4 & 942 & $1 \mathrm{E}-100$ & YIJ1_YEAST & Uncharacterized protein YIL091C & S. cerevisiae \\
\hline 206025 & & & 5 & & & 4 & 905 & 9E-97 & ARPC2_SCHPO & Actin-related protein $2 / 3$ complex subunit 2 & S. pombe \\
\hline 193777 & & & 5 & & & 4 & 5615 & 0 & BRR2_SCHPO & Pre-mRNA-splicing factor brr2 & S. pombe \\
\hline 192903 & & & 5 & & & 4 & 971 & $1 \mathrm{E}-104$ & CSN6_EMENI & COP9 signalome complex subunit 6 & E. nidulans \\
\hline 198943 & & & 5 & & & 3 & 766 & $2 \mathrm{E}-80$ & PCY1_SCHPO & Probable choline-phphate cytidylyltransferase & S. pombe \\
\hline 52146 & & & 5 & & & 2 & 2678 & 0 & TRP_NEUCR & Tryptophan synthase & N. crassa \\
\hline 207204 & & & 5 & & & 2 & 457 & $2 \mathrm{E}-45$ & COX6_NEUCR & Cytochrome c oxidase polypeptide 6 , mitochondrial & N. crassa \\
\hline 53467 & & & 5 & & & 1 & & & -No-Hit- & No Matching Hit found & \\
\hline 57277 & & & 4 & & & 15 & 722 & $5 \mathrm{E}-76$ & YOP1_ASPFU & Protein yop 1 & A. fumigatus \\
\hline 51987 & & & 4 & & & 12 & 1726 & 0 & PP1_EMENI & Serine/threonine-protein phphatase PP1 & E. nidulans \\
\hline 194077 & & & 4 & & & 11 & 2783 & 0 & SYV_NEUCR & Valyl-tRNA synthetase, mitochondrial & N. crassa \\
\hline 56701 & & & 4 & & & 10 & 882 & $2 \mathrm{E}-94$ & RL10A_SCHPO & 60 S ribomal protein L10-A & S. pombe \\
\hline 212120 & & & 4 & & & 10 & 1244 & $1 \mathrm{E}-135$ & AGM1_CANAL & Phphoacetylglucamine mutase & C. albicans \\
\hline 47885 & & & 4 & & & 9 & 472 & $3 \mathrm{E}-47$ & YGL4_SCHPO & Uncharacterized protein $\mathrm{C} 216.04 \mathrm{c}$ & S. pombe \\
\hline 56093 & & & 4 & & & 8 & 2499 & 0 & CND1_SCHPO & Condensin complex subunit 1 & S. pombe \\
\hline 210433 & & & 4 & & & 8 & 2575 & 0 & G6PI_ASPOR & Gluce-6-phphate isomerase & A. oryzae \\
\hline 206692 & & & 4 & & & 8 & 1497 & $1 \mathrm{E}-165$ & PUR8_YEAST & Adenyluccinate lyase & S. cerevisiae \\
\hline 204050 & & & 4 & & & 8 & & & -No-Hit- & No Matching Hit found & \\
\hline 202461 & & 1 & 4 & & & 8 & 898 & $3 \mathrm{E}-96$ & RL16_NEUCR & $60 \mathrm{~S}$ ribomal protein L16 & N. crassa \\
\hline 194752 & & & 4 & & & 8 & & & -No-Hit- & No Matching Hit found & \\
\hline 212484 & & & 4 & & & 7 & 2098 & 0 & HAT2_ASPOR & Histone acetyltransferase type B subunit 2 & A. oryzae \\
\hline 54762 & & & 4 & & & 6 & 2137 & 0 & AMPD_SCHPO & AMP deaminase & S. pombe \\
\hline 35734 & & & 4 & & & 6 & 957 & $1 \mathrm{E}-102$ & LKH1_SCHPO & Dual specificity protein kinase lkh1 & S. pombe \\
\hline 209562 & & & 4 & & & 6 & 383 & $6 \mathrm{E}-37$ & RS20_SCHPO & $40 \mathrm{~S}$ ribomal protein $\mathrm{S} 20$ & S. pombe \\
\hline 198350 & & & 4 & & & 6 & 3179 & 0 & NCPR_ASPNG & NADPH--cytochrome P450 reductase & A. niger \\
\hline 189778 & & & 4 & & & 6 & 190 & $1 \mathrm{E}-14$ & YA044_YEAST & Uncharacterized bolA-like protein YAL044W-A & S. cerevisiae \\
\hline 138621 & & & 4 & & & 6 & 2402 & 0 & STT4_YEAST & Phphatidylinitol 4-kinase STT4 & S. cerevisiae \\
\hline 55909 & & & 4 & & & 5 & 1163 & $1 \mathrm{E}-126$ & SPN2_SCHPO & Septin homolog spn2 & S. pombe \\
\hline 44033 & & & 4 & & & 5 & 2354 & 0 & APE2_YEAST & Aminopeptidase 2, mitochondrial & S. cerevisiae \\
\hline 213093 & & & 4 & & & 5 & 1800 & 0 & RPN2_SCHPO & $26 \mathrm{~S}$ proteasome regulatory subunit rpn 2 & S. pombe \\
\hline 203669 & & & 4 & & & 5 & 2365 & 0 & METE_SCHPO & Probable homocysteine methyltransferase & S. pombe \\
\hline
\end{tabular}




\begin{tabular}{|c|c|c|c|c|c|c|c|c|c|c|c|}
\hline JGI ID & $\begin{array}{l}\text { No Mn } \\
\mathrm{pH} 4.5\end{array}$ & $\begin{array}{l}\text { No } \mathrm{Mn} p \mathrm{H} \\
5.0\end{array}$ & $\begin{array}{l}\text { No Mn } \\
\text { pH } 5.5\end{array}$ & $\begin{array}{c}\mathrm{Mn} \mathrm{pH} \\
4.5 \\
\end{array}$ & $\begin{array}{c}\mathrm{Mn} \mathrm{pH} \\
5.0 \\
\end{array}$ & $\begin{array}{c}\mathrm{Mn} \mathrm{pH} \\
5.5 \\
\end{array}$ & $\begin{array}{l}\text { Blast } \\
\text { Score } \\
\end{array}$ & $\begin{array}{c}\text { Blast } \\
\text { eValue }\end{array}$ & Blast Hit Name & Hit Description & Species \\
\hline 128777 & & & 4 & & & 5 & 6505 & 0 & DOP1_EMENI & Protein dopey & E. nidulans \\
\hline 55511 & & & 4 & & & 4 & 7908 & 0 & FAS2_PENPA & Fatty acid synthase subunit alpha & P. patulum \\
\hline 53927 & & & 4 & & & 4 & 867 & $3 \mathrm{E}-92$ & IPI1_ASPOR & Pre-rRNA-processing protein ipil & A. oryzae \\
\hline 213429 & & & 4 & & & 4 & 1258 & $1 \mathrm{E}-137$ & GSHR_NEUCR & Glutathione reductase & N. crassa \\
\hline 56454 & & & 4 & & & 3 & 1470 & $1 \mathrm{E}-162$ & SIK1_SCHPO & Ribome biynthesis protein sik1 & S. pombe \\
\hline 52653 & & & 4 & & & 3 & 1509 & $1 \mathrm{E}-166$ & PTPA2_ASPOR & Serine/threonine-protein phphatase $2 \mathrm{~A}$ activator 2 & A. oryzae \\
\hline 38457 & & & 4 & & & 3 & 621 & $1 \mathrm{E}-63$ & VATC_YEAST & V-type proton ATPase subunit C & S. cerevisiae \\
\hline 179814 & & & 4 & & & 3 & 558 & $3 \mathrm{E}-56$ & SERB_SCHPO & Probable phpherine phphatase & S. pombe \\
\hline 54781 & & & 4 & & & 2 & 289 & $4 \mathrm{E}-25$ & EIF3M_SCHPO & Eukaryotic translation initiation factor 3 subunit $\mathrm{M}$ & S. pombe \\
\hline 36569 & & & 4 & & & 2 & 1120 & $1 \mathrm{E}-121$ & VIP1_YEAST & $\begin{array}{l}\text { Initol hexakisphphate/diphphoinitol-pentakisphphate } \\
\text { kinase }\end{array}$ & S. cerevisiae \\
\hline 191251 & & & 4 & & & 2 & 1486 & $1 \mathrm{E}-164$ & ALO_NEUCR & Putative D-arabinono-1,4-lactone oxidase & N. crassa \\
\hline 183352 & & & 4 & & & 2 & 622 & $1 \mathrm{E}-63$ & NHG1_PSEPU & Salicylate hydroxylase & P. putida \\
\hline 52774 & & & 4 & & & 1 & 2550 & 0 & HTS1_COCCA & HC-toxin synthetase & C. carbonum \\
\hline 38814 & & & 4 & & & & 184 & $1 \mathrm{E}-12$ & SSR4_SCHPO & SWI/SNF and RSC complexes subunit ssr 4 & S. pombe \\
\hline 142854 & & & 4 & & & & 137 & 7E-08 & Y4213_ARATH & UPF0480 protein At4g32130 & A. thaliana \\
\hline 214140 & & & 3 & & & 13 & 3445 & 0 & MYO2_SACKL & Myin-2 & S. kluyveri \\
\hline 208510 & & & 3 & & & 8 & 3446 & 0 & XPO1_SCHPO & Exportin-1 & S. pombe \\
\hline 202623 & & & 3 & & & 7 & 939 & $1 \mathrm{E}-100$ & YDQD_SCHPO & Uncharacterized protein C5D6.13 & S. pombe \\
\hline 176760 & & & 3 & & & 7 & 5276 & 0 & NM111_ASPNC & Pro-apoptotic serine protease nma111 & A. niger \\
\hline 56425 & & & 3 & & & 6 & 1347 & $1 \mathrm{E}-147$ & VPS35_SCHPO & Vacuolar protein sorting-associated protein 35 & S. pombe \\
\hline 48994 & & & 3 & & & 6 & 2074 & 0 & NOT1_SCHPO & General negative regulator of transcription subunit 1 & S. pombe \\
\hline 36874 & & & 3 & 1 & & 6 & 1236 & $1 \mathrm{E}-135$ & KAPB_YEAST & cAMP-dependent protein kinase type 2 & S. cerevisiae \\
\hline 129080 & & & 3 & & & 6 & 3462 & 0 & SF3B1_MOUSE & Splicing factor $3 \mathrm{~B}$ subunit 1 & M. musculus \\
\hline 54890 & & & 3 & & & 5 & 2320 & 0 & CARA_ASPNC & $\begin{array}{l}\text { Carbamoyl-phphate synthase arginine-specific small } \\
\text { chain }\end{array}$ & A. niger \\
\hline 214511 & & & 3 & & & 5 & 1470 & $1 \mathrm{E}-162$ & CSK2A_NEUCR & Casein kinase II subunit alpha & N. crassa \\
\hline 213627 & & & 3 & & & 5 & 1986 & 0 & DNM1_YEAST & Dynamin-related protein DNM1 & S. cerevisiae \\
\hline 208165 & & & 3 & & & 5 & 1643 & 0 & LCB2_SCHPO & Serine palmitoyltransferase 2 & S. pombe \\
\hline 200934 & & & 3 & & & 5 & 2005 & 0 & IMA3_SCHPO & Probable importin c550.11 & S. pombe \\
\hline 184284 & & & 3 & & & 5 & & & -No-Hit- & No Matching Hit found & \\
\hline 56298 & & & 3 & & & 4 & 1811 & 0 & GCS1_SCHPO & Probable mannyl-oligaccharide glucidase & S. pombe \\
\hline 55402 & & & 3 & & & 4 & 883 & $2 \mathrm{E}-93$ & YDHE_SCHPO & Pumilio domain-containing protein C6G9.14 & S. pombe \\
\hline 40314 & & & 3 & & & 4 & 316 & $2 \mathrm{E}-28$ & YC4C_SCHPO & UPF0363 protein $\mathrm{C} 1672.12 \mathrm{c}$ & S. pombe \\
\hline 209784 & & 1 & 3 & & & 4 & 1175 & $1 \mathrm{E}-127$ & CMC1_MOUSE & Calcium-binding mitochondrial carrier protein Aralar1 & M. musculus \\
\hline
\end{tabular}




\begin{tabular}{|c|c|c|c|c|c|c|c|c|c|c|c|}
\hline JGI ID & $\begin{array}{l}\text { No Mn } \\
\text { pH } 4.5\end{array}$ & $\begin{array}{l}\text { No Mn } \mathrm{pH} \\
5.0\end{array}$ & $\begin{array}{l}\text { No Mn } \\
\text { pH } 5.5\end{array}$ & $\begin{array}{c}\mathrm{Mn} \mathrm{pH} \\
4.5\end{array}$ & $\begin{array}{c}\mathrm{Mn} \mathrm{pH} \\
5.0\end{array}$ & $\begin{array}{c}\mathrm{Mn} \mathrm{pH} \\
5.5\end{array}$ & $\begin{array}{l}\text { Blast } \\
\text { Score }\end{array}$ & $\begin{array}{c}\text { Blast } \\
\text { eValue }\end{array}$ & Blast Hit Name & Hit Description & Species \\
\hline 211677 & 2 & 5 & 3 & 3 & 1 & 3 & 519 & $1 \mathrm{E}-52$ & RL44_PICJA & $60 \mathrm{~S}$ ribomal protein $\mathrm{L} 44$ & P. jadinii \\
\hline 176640 & & & 3 & & & 3 & 148 & $1 \mathrm{E}-08$ & YN25_SCHPO & $\begin{array}{l}\text { Uncharacterized transcriptional regulatory protein } \\
\text { C530.05 }\end{array}$ & S. pombe \\
\hline 171085 & & & 3 & & & 3 & 369 & 4E-34 & ARP9 SCHPO & SWI/SNF and RSC complexes subunit arp9 & S. pombe \\
\hline 204582 & & & 3 & & & 2 & & & -No-Hit- & No Matching Hit found & \\
\hline 193773 & & & 3 & & & 2 & 2871 & 0 & U5S1_CHICK & $\begin{array}{l}116 \mathrm{kDa} \text { U5 small nuclear ribonucleoprotein } \\
\text { component }\end{array}$ & G. gallus \\
\hline 191914 & & & 3 & & & 2 & 334 & $2 \mathrm{E}-30$ & ACADL_MOUSE & $\begin{array}{l}\text { Long-chain specific acyl-CoA dehydrogenase, } \\
\text { mitochondrial }\end{array}$ & M. musculus \\
\hline 206102 & & 17 & 3 & & 10 & 1 & 474 & $6 \mathrm{E}-46$ & SNT2_SCHPO & Lid2 complex component snt2 & S. pombe \\
\hline 202783 & & & 3 & & & 1 & 874 & $2 \mathrm{E}-93$ & YPT1_NEUCR & GTP-binding protein ypt1 & N. crassa \\
\hline 56222 & & & 3 & & & & 524 & $6 \mathrm{E}-52$ & K0090_CHICK & Uncharacterized protein KIAA0090 homolog & G. gallus \\
\hline 55587 & & & 3 & & & & 149 & $2 \mathrm{E}-08$ & YGVA_SCHPO & CUE domain-containing protein C354.10 & S. pombe \\
\hline 52445 & & & 3 & & & & & & -No-Hit- & No Matching Hit found & \\
\hline 124156 & & & 3 & & & & 1578 & $1 \mathrm{E}-174$ & FDH_EMENI & Probable formate dehydrogenase & E. nidulans \\
\hline 47658 & & & 2 & & & 9 & 235 & $3 \mathrm{E}-18$ & NU120_SCHPO & Nucleoporin nup120 & S. pombe \\
\hline 52865 & & & 2 & & & 8 & & & -No-Hit- & No Matching Hit found & \\
\hline 197350 & & & 2 & & & 8 & 596 & $1 \mathrm{E}-61$ & RS16_ASHGO & 40S ribomal protein $\mathrm{S} 16$ & A. gossypii \\
\hline 205755 & & & 2 & & & 7 & 908 & $2 \mathrm{E}-97$ & ERV25_ASPFU & Endoplasmic reticulum vesicle protein 25 & A. fumigatus \\
\hline 55590 & & & 2 & & & 6 & 2626 & 0 & PGM_ASPFU & Phphoglucomutase & A. fumigatus \\
\hline 49499 & & & 2 & & & 6 & 170 & $3 \mathrm{E}-11$ & PAMO_THEFY & Phenylacetone monooxygenase & T. fusca \\
\hline 210814 & & & 2 & & & 6 & 741 & $5 \mathrm{E}-78$ & YPT2_SCHPO & GTP-binding protein ypt2 & S. pombe \\
\hline 207011 & & & 2 & & & 6 & 889 & $1 \mathrm{E}-94$ & KES1_YEAST & Protein KES1 & S. cerevisiae \\
\hline 200566 & & & 2 & & & 6 & 598 & $2 \mathrm{E}-61$ & NACA_ASPNC & Nascent polypeptide-associated complex subunit alpha & A. niger \\
\hline 52335 & & & 2 & & & 5 & 923 & 2E-98 & ANM3_SCHPO & Ribomal protein arginine $\mathrm{N}$-methytransferase rmt3 & S. pombe \\
\hline 209597 & & & 2 & & & 5 & 1417 & $1 \mathrm{E}-156$ & HHP1_SCHPO & Casein kinase I homolog hhp1 & S. pombe \\
\hline 207707 & & & 2 & & & 5 & 1428 & $1 \mathrm{E}-157$ & NDUA9_NEUCR & $\begin{array}{l}\text { NADH-ubiquinone oxidoreductase subunit, } \\
\text { mitochondrial }\end{array}$ & N. crassa \\
\hline 203924 & & & 2 & & & 5 & 2159 & 0 & SC61A_NEUCR & Protein transport protein SEC61 subunit alpha & N. crassa \\
\hline 52565 & & & 2 & & & 4 & 4180 & 0 & SEC24_ASPNC & Protein transport protein sec 24 & A. niger \\
\hline 35776 & & & 2 & & & 4 & 554 & $1 \mathrm{E}-55$ & YEY6_SCHPO & Putative methyltransferase $\mathrm{C} 2 \mathrm{C} 4.06 \mathrm{c}$ & S. pombe \\
\hline 44220 & & & 2 & & & 3 & 241 & 4E-19 & CL030_HUMAN & TPR repeat-containing protein $\mathrm{C} 12$ orf 30 & H. sapiens \\
\hline 213437 & & & 2 & & & 3 & 915 & $1 \mathrm{E}-97$ & BGLA_BACCI & Beta-glucidase & B. circulans \\
\hline 211010 & & & 2 & & & 3 & 649 & $9 \mathrm{E}-67$ & DSK1_SCHPO & Protein kinase dsk1 & S. pombe \\
\hline 210321 & & & 2 & & & 3 & 1678 & 0 & IMA1_SCHPO & Importin subunit alpha-1 & S. pombe \\
\hline 204865 & & 1 & 2 & & & 3 & 405 & 4E-39 & YHS2 YEAST & UPF0195 protein YHR122W & S. cerevisiae \\
\hline
\end{tabular}




\begin{tabular}{|c|c|c|c|c|c|c|c|c|c|c|c|}
\hline JGI ID & $\begin{array}{l}\text { No Mn } \\
\text { pH } 4.5\end{array}$ & $\begin{array}{l}\text { No Mn } \mathrm{pH} \\
5.0\end{array}$ & $\begin{array}{l}\text { No Mn } \\
\text { pH } 5.5\end{array}$ & $\begin{array}{c}\mathrm{Mn} \mathrm{pH} \\
4.5\end{array}$ & $\begin{array}{c}\mathrm{Mn} \mathrm{pH} \\
5.0\end{array}$ & $\begin{array}{c}\mathrm{Mn} \mathrm{pH} \\
5.5\end{array}$ & $\begin{array}{l}\text { Blast } \\
\text { Score }\end{array}$ & $\begin{array}{c}\text { Blast } \\
\text { eValue }\end{array}$ & Blast Hit Name & Hit Description & Species \\
\hline 199462 & & & 2 & & & 3 & 396 & $2 \mathrm{E}-38$ & RL261_ARATH & 60S ribomal protein L26-1 & A. thaliana \\
\hline 185810 & & 3 & 2 & & & 3 & & & -No-Hit- & No Matching Hit found & \\
\hline 185582 & & & 2 & & & 3 & 921 & 3E-98 & YC7C_SCHPO & Uncharacterized esterase/lipase C417.12 & S. pombe \\
\hline 136079 & & & 2 & & & 3 & 820 & $6 \mathrm{E}-87$ & YFG5_SCHPO & Uncharacterized mitochondrial carrier C19G12.05 & S. pombe \\
\hline & & & & & & & & & ELMO2_HUMA & & \\
\hline 54759 & & & 2 & & & 2 & 281 & $6 \mathrm{E}-24$ & $\mathrm{~N}$ & Engulfment and cell motility protein 2 & H. sapiens \\
\hline 54540 & & & 2 & & & 2 & 1268 & $1 \mathrm{E}-138$ & AROF_NEUCR & Phpho-2-dehydro-3-deoxyheptonate aldolase & N. crassa \\
\hline 51860 & & & 2 & & & 2 & 513 & $2 \mathrm{E}-51$ & YJZ4_YEAST & Putative aldolase class 2 protein YJR024C & S. cerevisiae \\
\hline 49007 & & & 2 & & & 2 & 200 & $6 \mathrm{E}-15$ & FOL1_PNECA & Folic acid synthesis protein foll & P. carinii \\
\hline 44948 & & & 2 & & & 2 & & & -No-Hit- & No Matching Hit found & \\
\hline 44363 & & & 2 & & & 2 & 444 & $2 \mathrm{E}-42$ & NU132_SCHPO & Nucleoporin nup132 & S. pombe \\
\hline 38174 & & & 2 & & & 2 & 1353 & $1 \mathrm{E}-148$ & RAV1_YEAST & $\begin{array}{l}\text { Regulator of V-ATPase in vacuolar membrane protein } \\
1\end{array}$ & S. cerevisiae \\
\hline 211691 & & & 2 & & & 2 & 3565 & 0 & GCN1_SCHPO & Translational activator gen1 & S. pombe \\
\hline 206151 & & & 2 & & & 2 & 922 & 4E-99 & SAR1_ASPNG & Small COPII coat GTPase SAR1 & A. niger \\
\hline 190197 & & & 2 & & & 2 & 247 & $5 \mathrm{E}-20$ & DPF6_CAEEL & Dipeptidyl peptidase family member 6 & C. elegans \\
\hline 180652 & & & 2 & & & 2 & & & -No-Hit- & No Matching Hit found & \\
\hline 174315 & & & 2 & & & 2 & 2869 & 0 & YM54_YEAST & Uncharacterized protein YMR196W & S. cerevisiae \\
\hline 137182 & & & 2 & & & 2 & 317 & $5 \mathrm{E}-29$ & RL14A_YEAST & 60 S ribomal protein L14-A & S. cerevisiae \\
\hline 54451 & & & 2 & & & 1 & 1075 & $1 \mathrm{E}-116$ & UAP1_CANAL & UDP-N-acetylglucamine pyrophphorylase & C. albicans \\
\hline 53297 & & & 2 & & & 1 & 1293 & $1 \mathrm{E}-141$ & SND1_SCHPO & Staphylococcal nuclease domain-containing protein 1 & S. pombe \\
\hline 52578 & & & 2 & & & 1 & 860 & $2 \mathrm{E}-91$ & YAUB_SCHPO & UPF0012 hydrolase C26A3.11 & S. pombe \\
\hline 51257 & & & 2 & & & 1 & 635 & $7 \mathrm{E}-65$ & NOP14_YARLI & Probable nucleolar complex protein 14 & Y. lipolytica \\
\hline 50504 & & & 2 & & & 1 & 697 & $1 \mathrm{E}-72$ & ALDX_SPOSA & Aldehyde reductase 1 & S. salmonicolor \\
\hline 46347 & & & 2 & & & 1 & & & -No-Hit- & No Matching Hit found & \\
\hline 36938 & & & 2 & & & 1 & & & -No-Hit- & No Matching Hit found & \\
\hline 196625 & & & 2 & & & 1 & 900 & $6 \mathrm{E}-96$ & YAI8_SCHPO & Uncharacterized protein C24B11.08c & S. pombe \\
\hline 196055 & & & 2 & & & 1 & & & -No-Hit- & No Matching Hit found & \\
\hline 193747 & & & 2 & & & 1 & 532 & $2 \mathrm{E}-53$ & RCL1_SCHPO & Probable RNA 3'-terminal phphate cyclase-like protein & S. pombe \\
\hline 181700 & & & 2 & & & 1 & 1098 & $1 \mathrm{E}-119$ & RPN11_SCHPO & $26 \mathrm{~S}$ proteasome regulatory subunit rpn 11 & S. pombe \\
\hline 143580 & & & 2 & & & 1 & 389 & $1 \mathrm{E}-37$ & RS10A_YEAST & 40S ribomal protein S10-A & S. cerevisiae \\
\hline 54281 & & & 2 & & & & 1928 & 0 & CYSD_EMENI & O-acetylhomerine (thiol)-lyase & E. nidulans \\
\hline 51606 & & & 2 & & & & 258 & $2 \mathrm{E}-21$ & RLM1_YEAST & Transcription factor RLM1 & S. cerevisiae \\
\hline 47046 & & & 2 & & & & 685 & $1 \mathrm{E}-71$ & ARF6_HUMAN & ADP-ribylation factor 6 & H. sapiens \\
\hline 40650 & & & 2 & & & & 123 & $1 \mathrm{E}-5$ & YL278_YEAST & Uncharacterized transcriptional regulatory protein & S. cerevisiae \\
\hline
\end{tabular}




\begin{tabular}{|c|c|c|c|c|c|c|c|c|c|c|c|}
\hline JGI ID & $\begin{array}{l}\text { No Mn } \\
\text { pH } 4.5\end{array}$ & $\begin{array}{l}\text { No } \mathrm{Mn} \mathrm{pH} \\
5.0\end{array}$ & $\begin{array}{l}\text { No Mn } \\
\text { pH } 5.5\end{array}$ & $\begin{array}{c}\mathrm{Mn} \mathrm{pH} \\
4.5\end{array}$ & $\begin{array}{c}\mathrm{Mn} \mathrm{pH} \\
5.0\end{array}$ & $\begin{array}{c}\mathrm{Mn} \mathrm{pH} \\
5.5\end{array}$ & $\begin{array}{l}\text { Blast } \\
\text { Score }\end{array}$ & $\begin{array}{c}\text { Blast } \\
\text { eValue }\end{array}$ & Blast Hit Name & Hit Description & Species \\
\hline 39468 & & & 2 & & & & 416 & $5 \mathrm{E}-40$ & CIA30_NEUCR & $\begin{array}{l}\text { Complex I intermediate-associated protein } 30 \text {, } \\
\text { mitochondrial }\end{array}$ & N. crassa \\
\hline 214686 & & & 2 & & & & 1082 & $1 \mathrm{E}-117$ & OXDC_BACSU & Oxalate decarboxylase oxdC & B. subtilis \\
\hline 207730 & & & 2 & & & & 920 & $1 \mathrm{E}-98$ & RL8_SCHPO & $60 \mathrm{~S}$ ribomal protein $\mathrm{L} 8$ & S. pombe \\
\hline 170595 & & & 2 & & & & 1207 & $1 \mathrm{E}-131$ & TAF5_SCHPO & Transcription initiation factor TFIID subunit 5 & S. pombe \\
\hline 37620 & & & 1 & & & 9 & 3574 & 0 & DHE2_NEUCR & NAD-specific glutamate dehydrogenase & N. crassa \\
\hline 181825 & & & 1 & & & 7 & 466 & $3 \mathrm{E}-45$ & NCBP1_YEAST & Nuclear cap-binding protein complex subunit 1 & S. cerevisiae \\
\hline 40935 & & & 1 & & & 6 & 373 & $5 \mathrm{E}-35$ & PIP_BACCO & Proline iminopeptidase & B. coagulans \\
\hline 211159 & & & 1 & & & 6 & 2265 & 0 & ATPB_NEUCR & ATP synthase subunit beta, mitochondrial & N. crassa \\
\hline 178053 & & & 1 & & & 6 & 444 & $6 \mathrm{E}-43$ & CP67_UROFA & Cytochrome P450 67 (Fragment) & U. fabae \\
\hline 56378 & & & 1 & & & 5 & & & -No-Hit- & No Matching Hit found & \\
\hline 52396 & & & 1 & & & 4 & 804 & $1 \mathrm{E}-84$ & YE04_SCHPO & Uncharacterized RNA-binding protein $\mathrm{C} 17 \mathrm{H} 9.04 \mathrm{c}$ & S. pombe \\
\hline 48594 & & & 1 & & & 3 & 3859 & 0 & SEPA_EMENI & Cytokinesis protein sepA & E. nidulans \\
\hline 44662 & & & 1 & & & 3 & 122 & $3 \mathrm{E}-6$ & FYV4_ASHGO & Protein FYV4, mitochondrial & A. gossypii \\
\hline 212902 & & & 1 & & & 3 & 522 & $4 \mathrm{E}-52$ & YHXB_SCHPO & Uncharacterized $\mathrm{J}$ domain-containing protein $\mathrm{C} 3 \mathrm{E} 7.11 \mathrm{c}$ & S. pombe \\
\hline 212470 & & & 1 & & & 3 & 2111 & 0 & UBP21_SCHPO & Ubiquitin carboxyl-terminal hydrolase 21 & S. pombe \\
\hline 208150 & & & 1 & & & 3 & 1260 & $1 \mathrm{E}-137$ & NDH1_SCHPO & $\begin{array}{l}\text { Probable NADH-ubiquinone oxidoreductase, } \\
\text { mitochondrial }\end{array}$ & S. pombe \\
\hline 206525 & & & 1 & & & 3 & 945 & $1 \mathrm{E}-101$ & SYYC_YEAST & Tyryl-tRNA synthetase, cytoplasmic & S. cerevisiae \\
\hline 197459 & & & 1 & & & 3 & 1023 & $1 \mathrm{E}-110$ & EIF3E_SCHPO & Eukaryotic translation initiation factor 3 subunit $\mathrm{E}$ & S. pombe \\
\hline 55763 & & & 1 & & & 2 & 1850 & 0 & MPI_ASPFU & Manne-6-phphate isomerase & A. fumigatus \\
\hline 55041 & & & 1 & & & 2 & 2363 & 0 & HSP75_CANAL & Heat shock protein SSB1 & C. albicans \\
\hline 52748 & & & 1 & & & 2 & 479 & $1 \mathrm{E}-47$ & RL6B_YEAST & $60 \mathrm{~S}$ ribomal protein $\mathrm{L} 6-\mathrm{B}$ & S. cerevisiae \\
\hline 52431 & & & 1 & & & 2 & 522 & $3 \mathrm{E}-52$ & IF2B_SCHPO & $\begin{array}{l}\text { Probable eukaryotic translation initiation factor } 2 \\
\text { subunit }\end{array}$ & S. pombe \\
\hline 52249 & & & 1 & & & 2 & 2297 & 0 & COPB2_HUMAN & Coatomer subunit beta' & H. sapiens \\
\hline 51182 & & & 1 & & & 2 & 3122 & 0 & TOM1_NEUCR & E3 ubiquitin-protein ligase TOM1-like protein & N. crassa \\
\hline 48846 & & & 1 & & & 2 & 660 & $1 \mathrm{E}-67$ & SCC3_SCHPO & Cohesin subunit psc3 & S. pombe \\
\hline 46294 & & & 1 & & & 2 & 1463 & $1 \mathrm{E}-161$ & PAP_SCHPO & Poly(A) polymerase pla1 & S. pombe \\
\hline 214434 & & & 1 & & & 2 & 183 & $2 \mathrm{E}-12$ & CTF1A_FUSSO & Cutinase transcription factor 1 alpha & F. solani \\
\hline 213708 & & & 1 & & & 2 & 359 & $4 \mathrm{E}-33$ & YLP3_PSEPU & Uncharacterized methyltransferase in lpd-3 5'region & P. putida \\
\hline 202801 & & & 1 & & & 2 & 2253 & 0 & CISY_ASPNG & Citrate synthase, mitochondrial & A. niger \\
\hline 200493 & & & 1 & & & 2 & 663 & $7 \mathrm{E}-69$ & HIS7_NEUCR & Imidazoleglycerol-phphate dehydratase & N. crassa \\
\hline 56096 & & 3 & 1 & & & & 1411 & $1 \mathrm{E}-154$ & PO152_SCHPO & Probable nucleoporin POM152-like & S. pombe \\
\hline 36909 & 1 & 17 & 1 & 3 & 8 & & 140 & $2 \mathrm{E}-7$ & MUC1_BOVIN & Mucin-1 & B. taurus \\
\hline 190014 & & 2 & 1 & & & & 1087 & $1 \mathrm{E}-117$ & WA_EMENI & Conidial yellow pigment biynthesis polyketide synthase & E. nidulans \\
\hline
\end{tabular}




\begin{tabular}{|c|c|c|c|c|c|c|c|c|c|c|c|}
\hline JGI ID & $\begin{array}{l}\text { No Mn } \\
\text { pH } 4.5\end{array}$ & $\begin{array}{l}\text { No } \mathrm{Mn} p \mathrm{H} \\
5.0 \\
\end{array}$ & $\begin{array}{l}\text { No Mn } \\
\text { pH } 5.5\end{array}$ & $\begin{array}{c}\mathrm{Mn} \mathrm{pH} \\
4.5 \\
\end{array}$ & $\begin{array}{c}\mathrm{Mn} \mathrm{pH} \\
5.0 \\
\end{array}$ & $\begin{array}{c}\mathrm{Mn} \mathrm{pH} \\
5.5 \\
\end{array}$ & $\begin{array}{l}\text { Blast } \\
\text { Score } \\
\end{array}$ & $\begin{array}{c}\text { Blast } \\
\text { eValue }\end{array}$ & Blast Hit Name & Hit Description & Species \\
\hline 119698 & & 2 & 1 & & & & 257 & $5 \mathrm{E}-21$ & ZDS1_SCHPO & Protein zds1 & S. pombe \\
\hline 39005 & & 1 & & & & 4 & & & -No-Hit- & No Matching Hit found & \\
\hline 56485 & 1 & & & & & 3 & 1656 & 0 & G3P_ASPNG & Glyceraldehyde-3-phphate dehydrogenase & A. niger \\
\hline 56124 & 5 & 28 & & & 18 & 1 & 169 & $1 \mathrm{E}-10$ & YE38_SCHPO & Uncharacterized protein $\mathrm{C} 20 \mathrm{G} 4.08$ & S. pombe \\
\hline 49737 & & 5 & & & 2 & 1 & & & -No-Hit- & No Matching Hit found & \\
\hline 170608 & & 3 & & & & 1 & & & -No-Hit- & No Matching Hit found & \\
\hline 56903 & 4 & & & 3 & & & 458 & $7 \mathrm{E}-45$ & IF4E2_MOUSE & Eukaryotic translation initiation factor 4E type 2 & M. musculus \\
\hline 55964 & & & & & 2 & & 1115 & $1 \mathrm{E}-121$ & HOT_BOVIN & Hydroxyacid-oxoacid transhydrogenase, mitochondrial & B. taurus \\
\hline 55859 & 2 & 21 & & 1 & 16 & & 2351 & 0 & HRP3_SCHPO & Chromodomain helicase hrp3 & S. pombe \\
\hline 54867 & 4 & 4 & & 3 & 1 & & & & -No-Hit- & No Matching Hit found & \\
\hline 53737 & 3 & 2 & & 2 & & & 759 & $2 \mathrm{E}-79$ & SCD2_SCHPO & Protein scd2/ral3 & S. pombe \\
\hline 53632 & & 22 & & & 16 & & 178 & $8 \mathrm{E}-12$ & NSR1_YEAST & Nuclear localization sequence-binding protein & S. cerevisiae \\
\hline 53539 & & 3 & & & & & 162 & $1 \mathrm{E}-10$ & YKH3_SCHPO & Uncharacterized protein PYUK $71.03 \mathrm{c}$ & S. pombe \\
\hline 52694 & & 9 & & & 6 & & 727 & $2 \mathrm{E}-75$ & RPH1_YEAST & $\begin{array}{l}\text { DNA damage-responsive transcriptional repressor } \\
\text { RPH1 }\end{array}$ & S. cerevisiae \\
\hline 49427 & & 2 & & & & & 190 & $2 \mathrm{E}-13$ & EME1_SCHPO & Crsover junction endonuclease eme 1 & S. pombe \\
\hline 41302 & & 3 & & & & & & & -No-Hit- & No Matching Hit found & \\
\hline 39038 & & 7 & & & 4 & & & & -No-Hit- & No Matching Hit found & \\
\hline 214402 & & 2 & & & & & 310 & $8 \mathrm{E}-28$ & XFIN_XENLA & Zinc finger protein Xfin & $X$. laevis \\
\hline 210265 & 14 & 6 & & 12 & 2 & & 900 & $1 \mathrm{E}-95$ & GEPH_DICDI & Gephyrin & D. discoideum \\
\hline 209514 & & 4 & & & 4 & & 115 & $4 \mathrm{E}-5$ & MYB_XENLA & Myb protein & $X$. laevis \\
\hline 208244 & 8 & 13 & & 12 & 8 & & 1421 & $1 \mathrm{E}-156$ & KIN1_SCHPO & Protein kinase kin 1 & S. pombe \\
\hline 202206 & & & & & 3 & & 1260 & $1 \mathrm{E}-137$ & PROA_SCHPO & Probable gamma-glutamyl phphate reductase & S. pombe \\
\hline 202087 & & 2 & & & & & 1370 & $1 \mathrm{E}-150$ & NDE1_ASPFU & Nuclear distribution protein nudE homolog 1 & A. fumigatus \\
\hline 190247 & & 4 & & & 1 & & & & -No-Hit- & No Matching Hit found & \\
\hline 181863 & & 2 & & & & & 5465 & 0 & SEC16_ASPNC & COPII coat assembly protein sec 16 & A. niger \\
\hline 177822 & & 20 & & & 8 & & 318 & $7 \mathrm{E}-29$ & YN82_SCHPO & UPF0424 protein P35G2.02 & S. pombe \\
\hline 174643 & & 1 & & & 2 & & 2774 & 0 & SCONB_EMENI & Sulfur metabolite repression control protein & E. nidulans \\
\hline
\end{tabular}






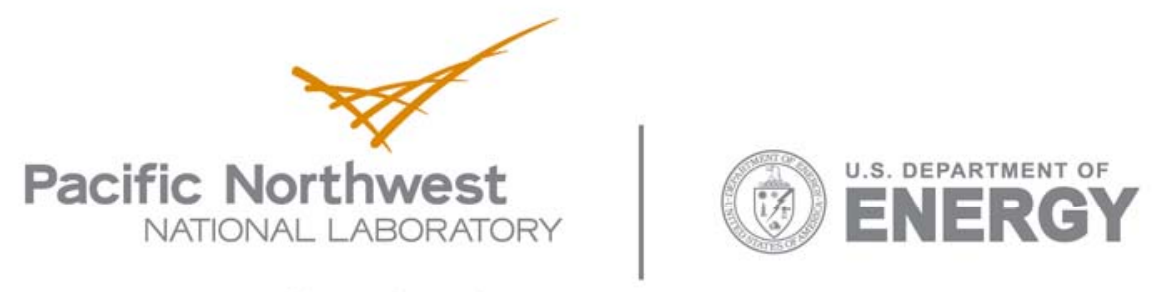

902 Battelle Boulevard

P.O. Box 999

Richland, WA 99352

1-888-375-PNNL (7665)

www.pnl.gov 